Andrews University

Digital Commons @ Andrews University

\title{
An Investigation of the Attitudes Held by General Education Teachers Toward Students with Disabilities in a Pilot Inclusive Education Program in Cameroon
}

Agnes Y. Mngo

Andrews University, yensi@andrews.edu

Follow this and additional works at: https://digitalcommons.andrews.edu/dissertations

Part of the Disability and Equity in Education Commons

\section{Recommended Citation}

Mngo, Agnes Y., "An Investigation of the Attitudes Held by General Education Teachers Toward Students with Disabilities in a Pilot Inclusive Education Program in Cameroon" (2017). Dissertations. 1627. https://digitalcommons.andrews.edu/dissertations/1627 https://dx.doi.org/10.32597/dissertations/1627

This Dissertation is brought to you for free and open access by the Graduate Research at Digital Commons @ Andrews University. It has been accepted for inclusion in Dissertations by an authorized administrator of Digital Commons@ Andrews University. For more information, please contact repository@andrews.edu. 


\begin{abstract}
AN INVESTIGATION OF THE ATTITUDES HELD BY GENERAL EDUCATION TEACHERS TOWARD STUDENTS WITH DISABILITIES IN A PILOT INCLUSIVE EDUCATION PROGRAM IN CAMEROON
\end{abstract}

Agnes Y. Mngo

Chair: Lee Davidson 


\title{
ABSTRACT OF GRADUATE STUDENT RESEARCH
}

Dissertation

\author{
Andrews University \\ School of Education
}

\section{Title: AN INVESTIGATION OF THE ATTITUDES HELD BY GENERAL EDUCATION TEACHERS TOWARD STUDENTS WITH DISABILITIES IN A PILOT INCLUSIVE EDUCATION PROGRAM IN CAMEROON}

Name of the researcher: Agnes Y. Mngo

Name and degree of faculty chair: Lee Davidson, Ed.D.

Date completed: March 2017

\section{Problem Statement}

The literature from Cameroon depicts that the implementation of inclusive education is not only in its embryonic stage but faces resistance from educators who are still not accepting of the presence of students with disabilities in general education classrooms. This resistance has been attributed to several factors ranging from attachment to customs and traditions that encourage the isolation of persons with disabilities, to the lack of resources and professionals needed for the successful implementation of inclusive education programs. These unfavorable attitudes have been a cause for concern among parents, educators, and especially government leaders who do not want to be left behind the international community in embracing inclusive education. Researchers have found 
that unsuccessful inclusive programs stem from teachers' perceptions of the concept of inclusion, their teaching ability, classroom management, and benefits/outcomes of inclusion. As a result, this study sought to examine if there is a relationship between teachers' characteristics (such as gender, age, the level of education, years of teaching experience, experience teaching in inclusive classrooms, training, and teachers' language of instruction), and their attitudes toward inclusive education.

\section{Method}

A quantitative non-experimental descriptive survey research design was used in this study. Participants included 346 full-time state licensed general education teachers from seven bilingual secondary schools participating in SEEPD pilot inclusive education program in the North West Region of Cameroon. A survey instrument "Opinions Relative to the Integration of Students with Disabilities" (ORI) was used to collect data in determining the attitudes of general education teachers toward inclusion. The Statistical Package for Social Sciences Software (SPSS) was used to analyze the data, organize the results, and provide descriptive statistics, multivariate and univariate analysis of variances (MANOVA, and ANOVA).

\section{Results}

Teachers' attitudes toward inclusive education in Cameroon were negative on how they perceived the concept of inclusion and perceptions of their ability to teach in inclusive classrooms. They had positive attitudes toward managing students with disabilities in inclusive classrooms, and about the outcomes/benefits of inclusion. Overall, most teachers in the pilot inclusive education program in the North West Region 
of Cameroon were not accepting of the presence of students with disabilities in general education classrooms. These negative attitudes were manifested in teachers' selfperceptions of their inability or lack of training in both special and inclusive education. There was no significant difference in attitudes on the basis of the language of instruction. However, differences were found regarding the other demographic variables such as age, gender, experience, and education. Male teachers were more favorable to inclusion than their female colleagues. Additionally, older, more experienced, more qualified, and more educated teachers, were more likely to be supportive of inclusive education than younger, less experienced, less qualified, and less educated ones.

\section{Conclusion}

This study was conducted in general education secondary schools actively engaged in a pilot effort to introduce inclusive classroom practices in seven selected bilingual secondary schools in the North West Region of Cameroon. It is not certain what the level of acceptance the practice of integrating students with disabilities into the general education classroom would be if the study were carried out in schools not actively involved in the inclusive education initiative. Nonetheless, what stands out about the findings of this study is that most teachers showed negative attitudes about the success or outcome of inclusive education and indicated that the training they received in special education and inclusive education was not enough to ensure a successful integration of students with disabilities into general education classrooms. These findings support not only the rationale but also the urgent need for investment by all Cameroonian education stakeholders, especially the leading sponsor of education, the government, in the training of special education professionals and paraprofessionals in the country. These 
revelations also constitute a call for needed action from instructional leaders and higher education leaders who can make a difference by promoting professional development through seminars and workshops as well as creating targeted special education programs in the various institutions of higher learning in the country. 
Andrews University

School of Education

\title{
AN INVESTIGATION OF THE ATTITUDES HELD BY GENERAL EDUCATION TEACHERS TOWARD STUDENTS WITH DISABILITIES IN A PILOT INCLUSIVE EDUCATION PROGRAM IN CAMEROON
}

\author{
A Dissertation \\ Presented in Partial Fulfillment \\ of the Requirements for the Degree \\ Doctor of Philosophy
}

By

Agnes Y. Mngo

March 2017 
(C) Copyright by Agnes Y. Mngo 2017

All Rights Reserved 


\title{
AN INVESTIGATION OF THE ATTITUDES HELD BY GENERAL EDUCATION TEACHERS TOWARD STUDENTS WITH DISABILITIES IN A PILOT INCLUSIVE EDUCATION PROGRAM IN CAMEROON
}

\author{
A dissertation \\ presented in partial fulfillment \\ of the requirements for the degree \\ Doctor of Philosophy
}

by

Agnes Y. Mngo

APPROVAL BY THE COMMITTEE:

Chair: Lee Davidson

Member: Tevni Grajales

Member: Faith-Ann McGarrell

External: Sunimal Kulasekere
Dean, School of Education

Robson Marinho 


\section{DEDICATION}

I dedicate this work to my family: my loving, patient, and understanding husband, Zachary Mngo; who stood by me and gave me the needed encouragement, and support, throughout this journey; my five long-suffering, loving, and caring children, Bwendi, Betsy, Zachary Jr., Solace, and Merabell, who kept me going and forgave me for not listening when I was immersed in my research. 


\section{TABLE OF CONTENTS}

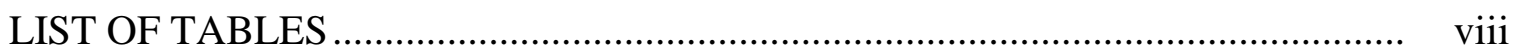

LIST OF ABBREVIATIONS .................................................................... ix

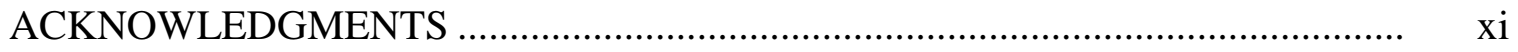

Chapter

1. INTRODUCTION TO THE STUDY ...................................................... 1

Background of the Problem ................................................................ 6

Statement of the Problem................................................................... 8

Purpose of the Study ............................................................................ 9

Research Questions ........................................................................ 10

Hypotheses ............................................................................. 11

Conceptual Framework .................................................................... 11

Importance of the Study ..................................................................... 14

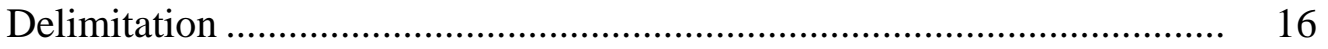

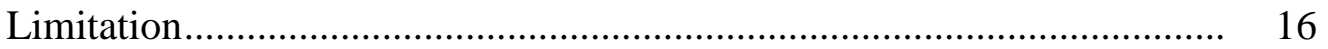

Definition of Terms.......................................................................... 17

Summary and Organization of Study ................................................. 19

2. $\quad$ LITERATURE REVIEW .................................................................. 22

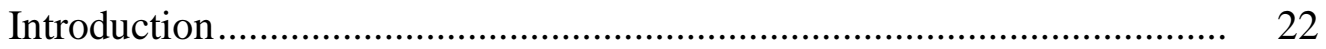

Special Education in Cameroon......................................................... 22

A Brief History of Special Education in Cameroon ......................... 23

Pre-Colonial Era................................................................. 23

Colonial Era ....................................................................... 24

Post-Colonial Era .................................................................... 25

Culture and Special Education in Cameroon ..................................... 29

Special Education Administration and Organization........................ 30

Special Education Facilities ........................................................... 31

Special Education and Inclusion-Related Laws in Cameroon ............. 33

Training of Teachers and Related Service Providers........................ 34

Prevalence and Identification of Students with Disabilities ............... 35

Inclusive Education in Cameroon ............................................... 36

The Aftermath of Salamanca ................................................... 37

Barriers to Effective Inclusive Education in Cameroon ................ 39

Emerging Inclusionary Education Activities in Cameroon .................... 42 


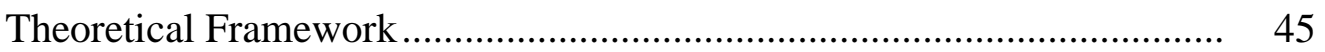

Attitudinal Theories ......................................................................... 47

Definition, Scope, and Benefits of Inclusive Education ........................... $\quad 50$

Benefits to Students ........................................................................ 52

Benefits to the School Community ……………………….................. 53

Best Practices of Inclusion ....................................................................... 54

Developing a Good Program of Inclusion .......................................... 54

Technology ...................................................................... 55

Collaboration......................................................................... 56

Instructional Strategies for Inclusion ............................................ 57

Partnership with Parents ............................................................ 61

Curriculum Accommodation and Adaptation ................................ 62

Building Community in the Classroom ........................................... 64

Classroom Management.............................................................. 64

Factors Affecting Teachers' Attitudes Toward Inclusion.......................... 65

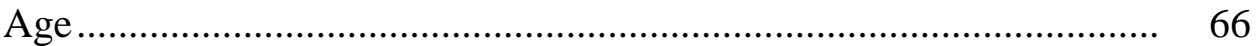

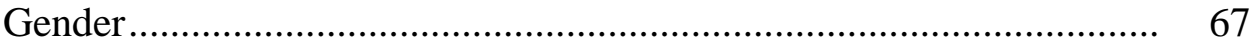

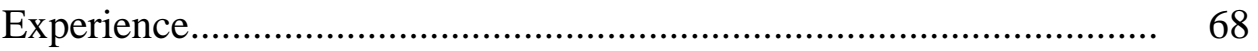

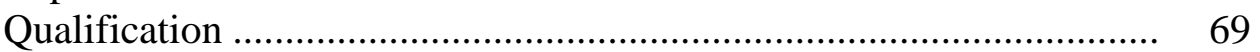

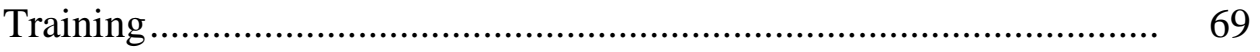

Attitudinal Variables in the Study ......................................................... 71

Outcomes/Benefits of Integration ..................................................... 71

Integrated Classroom Management …………………………............. 72

Inclusion and Teacher Perceptions of Their Teaching Ability ............. $\quad 75$

Perceptions of the Concept of Inclusion .............................................. 76

Summary of Chapter Two.................................................................... 79

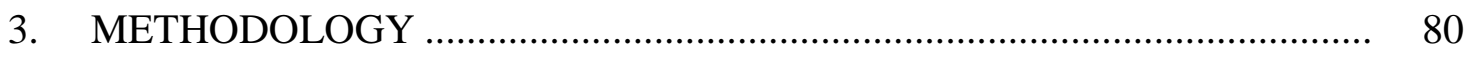

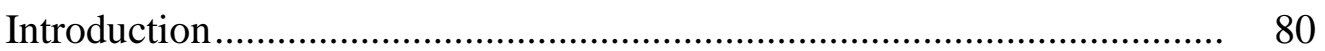

Type of Study ............................................................................ 80

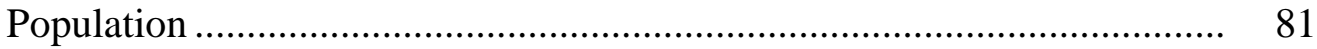

Sample

Hypothesis..................................................................................... 82

Null Hypothesis ......................................................................... 82

Research Hypothesis ..................................................................... 83

Variables Definition ............................................................................ 84

Definition of Demographic Variables................................................ 86

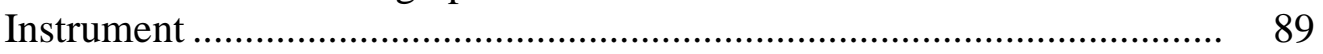

Description of the Instrument …………............................................ 89

Validity and Reliability of the Instrument ……………....................... 90

Data Collection ................................................................................. 91

Analysis of the Data ............................................................................ 93

Data Analysis of Research Question 1............................................. 94

Data Analysis of Research Question 2............................................. 95

Summary of Chapter Three...................................................................... 96 
4. DATA ANALYSIS AND RESULTS ………............................................ 97

Description of Sample and Response Rate ................................................ $\quad 97$

Participants and Variables Description .................................................... 99

Analyses and Findings ....................................................................... 100

Research Question 1 ................................................................. 102

Variable 1: The Benefits of Integration (BOI) .............................. 102

Variable 2: Integrated Classroom Management (ICM) .................. 103

Variable 3: Perceptions of Personal Ability to Teach

Students with Disabilities (ATT) ............................................. 104

Variable 4: Perceived Concept of Inclusion (COI) ........................ 105

Summary of Findings for Research Question 1 .................................. 106

Research Question 2: Hypotheses Testing .......................................... 107

Summary of Chapter Four .................................................................... 123

5. DISCUSSIONS, CONCLUSIONS, AND RECOMMENDATIONS …........... 126

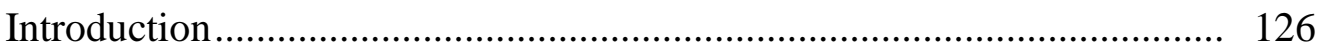

Summary of Methodology …………………………........................ 127

Summary of Major Findings................................................................ 128

Research Question 1 ............................................................. 128

Research Question 2 ................................................................. 130

Interpretations and Discussions ........................................................... 136

Limitation....................................................................................... 145

Implications and General Recommendations for Practice........................ 146

Introduction of Special Education Courses in Teacher

Training Colleges ................................................................... 147

Ongoing Professional Development .................................................. 148

Creation of Special Education Programs in Colleges and

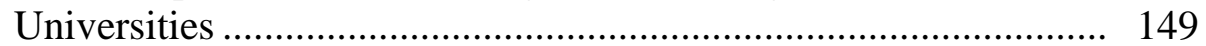

Adaptive Curriculum Development and Dissemination ...................... 150

Training and Recruitment of Professionals and

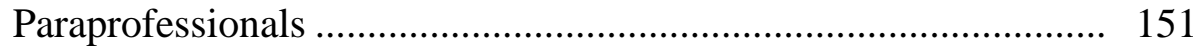

Breaking Cultural Barriers to Inclusive Education .............................. 151

Prioritizing New Funding Sources for Inclusive Education ................. 153

Specific Recommendations to the SEEPD Program

Managers ................................................................................ 153

Recommendations for Future Research ................................................ 154

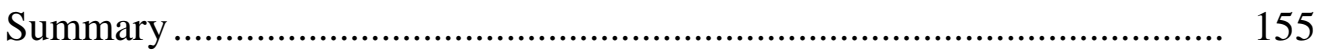

Appendix

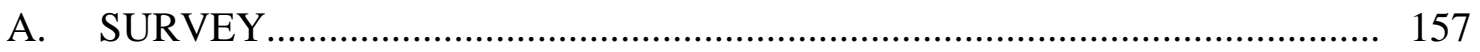

B. TABLE OF DEFINITION OF VARIABLES ................................................. 1699 
C. LETTER OF APPROVAL FROM THE INSTITUTIONAL REVIEW BOARD OF ANDREWS UNIVERSITY

D. LETTERS OF APPROVAL FROM THE REGIONAL DELEGATE OF SECONDARY EDUCATION FOR THE NORTH WEST REGION OF CAMEROON

E. INFORMED CONSENT ……………………................................... 182

REFERENCE LIST …………………………………................................ 185

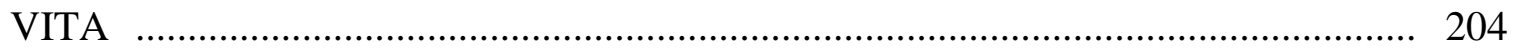




\section{LIST OF TABLES}

1. Description of Research Variables and Survey Items on the ORI....................... 86

2. Survey Participation and Response Rate by Schools ..................................... 98

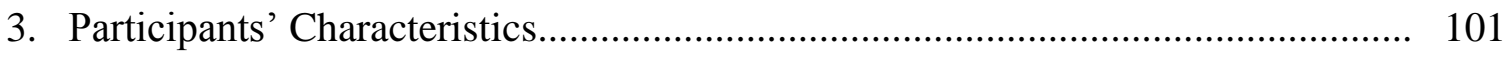

4. Benefits/Outcome of Integration (BOI) ................................................... 103

5. Integrated Classroom Management (ICM) ................................................... 104

6. Perceptions of Personal Ability to Teach Students with Disabilities (ATT) ......... 105

7. Perceptions of the Concept of Inclusive Education (COI) .............................. 106

8. Descriptive Statistics of Variables in the Study ............................................ 107

9. ANOVA for Teachers' Perceptions by Gender .............................................. 108

10. ANOVA for Teachers' Perception by Age ................................................. 110

11. ANOVA for Teachers' Perception by Level of Education ................................. 114

12. ANOVA for Teachers' Perceptions by Teaching Experience ........................... 117

13. ANOVA for Teachers' Perceptions by Inclusive Classroom Teaching

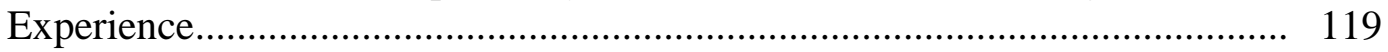

14. ANOVA for Perceptions of Teachers' Training in Special Education .................. 121

15. ANOVA for Teachers' Perceptions by Language of Instruction......................... 122 


\section{LIST OF ABBREVIATIONS}

\begin{tabular}{ll} 
ANOVA & One Way Univariate Analysis of Variance \\
APEHM & Association of Parents and Friends of Mentally Handicapped Children \\
ATT & Ability to Teach \\
BOI & Benefits of Inclusion \\
CAST & Center for Applied Special Technology \\
CBC & Cameroon Baptist Convention \\
COCADE & Cameroon National Coalition of NGOs for Children's Rights \\
COI & Concept of Inclusion \\
DI & Differentiated Instruction \\
FAPE & Free and Appropriate Public Education \\
FM & Frequency Modulation \\
GBHS & Government Bilingual High School \\
IDEIA & Individuals with Disabilities Education Improvement Act \\
IEP & Individualized Education Programs \\
IRB & Internal Review Board \\
ICM & Integrated Classroom Management \\
ICT & Information Communications Technology \\
LRE & Least Restrictive Environment \\
MANOVA & One-Way Multivariate Analysis of Variance \\
MINAS & Ministry of Social Affairs \\
\hline
\end{tabular}




$\begin{array}{ll}\text { MINEDUC } & \text { Ministry of National Education } \\ \text { MINESEC } & \text { Ministry of Secondary Education } \\ \text { NGO } & \text { Non-Governmental Organization } \\ \text { NWR } & \text { North West Region } \\ \text { PLC } & \text { Professional Learning Communities } \\ \text { ORI } & \text { Opinions Relative to the Integration of Individuals with Disabilities } \\ \text { RTI } & \text { Response to Intervention } \\ \text { SEEPD } & \text { Socio-Economic Empowerment of Persons with Disabilities } \\ \text { SEN } & \text { Special Education Needs } \\ \text { SENTTI } & \text { Special Education Needs Teachers Training Institute } \\ \text { SLD } & \text { Specific Learning Disabilities } \\ \text { UDL } & \text { Universal Design for Learning } \\ \text { UN } & \text { United Nations } \\ \text { UNESCO } & \text { United Nations Educational Scientific and Cultural Organization } \\ & \text { World Health Organization } \\ \text { WHO } & \text { S }\end{array}$




\section{ACKNOWLEDGEMENTS}

The process of writing this dissertation has been one of the most challenging yet valuable, meaningful and rewarding experiences in my life. It took a lot of hard work and patience as well as the support of others to complete it. Without the assistance of the committee members, family, and friends, it would not have been possible to arrive this stage.

Above everything else, I give thanks, honor, and glory to the Almighty, my provider, and sustainer, who has given me incredible strength and fortitude to complete this academic journey, amidst one of the most challenging experiences any one person or family could ever face. No personal effort and individual support would have produced this conclusion without the miraculous invisible compassionate hand of God.

I would like to thank my incredible loving husband, Zachary Mngo, who gave me unflagging support in prayers throughout this process. Often, he was the primary person to motivate me to work toward my doctorate. Zachary has always provided wise counsel regarding my career and education. It is his support by the grace of God that has allowed me to achieve my doctorate. I thank God for blessing me with him.

I would especially like to offer a warm and heartfelt thanks to my committee chair, Dr. Lee Davidson; my content specialist, Dr. Faith Ann McGarrell; and my statistician and methodologist, Dr. Tevni Grajales. Your invaluable spiritual and professional expertise, guidance, mentoring, nurturing, and encouragement, patience, and

feedback sustained me during this process. I would especially like to thank Dr. McGarrell 
with whom I began the dissertation journey. I appreciate her wisdom and readiness to do what it took for me to move on. She encouraged me to enhance my critical thinking skills and to challenge myself constantly. I thank Dr. Lee Davidson for accepting to join my committee at a crucial period and to be my chair. I appreciated your brief, insightful, and positive comments more than I can express. Dr. Grajales Tevni, I will be forever appreciative to you for guiding, nurturing, mentoring, and believing in me from the beginning to the very end of the dissertation process, and throughout my entire doctoral program. You are a blessing to my whole family.

I would like to thank my parents who knew that the best gift they could give me is to educate me as God permits. My father, Emmanuel Mbibeh has been a pillar in my academic pursuit for knowledge, and a source of encouragement. His energetic spirit gave me strength and kept inspired me to move on even when I did not feel like it. My mother, Martha Mbibeh, has been a great support and source of encouragement. Their love and support gave me the strength to work hard and never give up.

Further, I am grateful for the assistance of Mr. Dipene Thomas who made provisions for the questionnaires to be disseminated and collected. I could not have done this without his help. I am indebted to all my friends who encouraged me to keep on forging ahead when I was completely down.

I would be remiss if I did not mention the contributions made by my professors in the Department of Curriculum and Instruction at Andrews University, for their mentoring and expertise throughout my academic endeavor.

My hopes and wishes are that this research will provide information and knowledge that will eventually have a positive impact on the policy, practice, and 
effective implementation of inclusive education for the SEEPD project in particular, Cameroon in general, and possibly beyond. 


\section{CHAPTER 1}

\section{INTRODUCTION TO THE STUDY}

The number of students, worldwide, who have special learning needs keeps growing. The categories of students with special education needs (SEN) have also grown considerably over the years. Today almost every classroom around the world includes some students dealing with a disability, either physical, educational, psychological, or a combination of the three. There is, therefore, an increasing need for teachers to have basic knowledge of special education considering that they will have to address issues of special needs at one moment in their classrooms. In the early stages of special education in the United States, Smith (2007) admits that institutionalization of students with disabilities was preferred to any form of inclusion. Things have greatly changed for the better since the 1973 Enactment of Section 504 of the Rehabilitation Act, and with the enforcement of laws protecting the civil rights of persons with disabilities. Against this background much has been done to integrate children with disabilities into general education classrooms and curriculum.

In Cameroon, the introduction of inclusion in schools, as a solution to meeting the needs of students with disabilities, took even longer to happen. The pace of implementation of inclusive education reform has been slow despite the Cameroonian government's signing of treaties and legislations (United Nations Educational Scientific and Cultural Organization [UNESCO], 1994) aimed at promoting inclusion in all primary 
and secondary educational institutions. The first government official commitment to promote inclusion in schools was symbolized by the signing of the UNESCO Salamanca Statement which acknowledged that many countries, including Cameroon, had "wellestablished systems of special schools" for individuals with specific impairments which also could represent "a valuable resource for the development of inclusive schools" (UNESCO, 1994, p.12). Notwithstanding, the resources from special schools in Cameroon have not provided a strong springboard for the development of inclusive schools. This has not been unexpected because the policy of inclusion can only be effective if general education schools are equipped with facilities, such as self-contained classrooms, resource rooms, trained teachers and paraprofessionals needed to provide vital support to students grappling with learning. Some research came up with the conclusion that the success of inclusion depends on the knowledge, instructional skills, and in particular on the attitudes and beliefs of general education teachers toward the integration of students with disabilities in general education classrooms (Cook, 2001; Friend \& Bursick, 2006; Tanyi, 2016; Thaver \& Lim, 2014).

The issue with the introduction of inclusion in Cameroonian schools has its roots in the history of the country's special education system. The system has promoted the institutionalization of persons with disabilities since the independence of the country in the 1960s (Tukov, 2008). As a result, general educational institutions and professionals have not always been trained to handle students with special education needs. Rather, a few rehabilitation professionals or special education professionals tend to be available at the national level, and therefore are inaccessible to the majority of persons with disabilities, especially students (Disability and Rehabilitation Team, 2002). This 
inaccessibility has probably hindered the ability of schools to implement the integration of students effectively with special education needs into general education classrooms.

The first organized practice of inclusion in Cameroon, which is of interest to this study, is only just being initiated in select secondary schools in the North West Region (NWR) of the country (Socio-Economic Empowerment of Persons with Disabilities [SEEPD], 2011). The North West Region is one of the two English-speaking regions of the country. Cameroon has a total of ten regions, 2 of which are English speaking (Anglophones), and 8 are French speaking (Francophones). The initiation of the practice of inclusion by a few schools in this region of the country has not happened by accident. It is one of the first regions of the country to provide some form of accommodation to students with visual impairments in the general education classroom. This accommodation took place in Government Bilingual High School Kumbo, which has recently become one of the pioneer institutions in the practice of inclusive education. Their earlier attempts at accommodation involved bringing in students with disabilities, accompanied by special education professionals, into the general education classrooms. These professionals mostly had the limited role of transcribing the visually impaired and blind students' lessons into Braille.

The need for this study to investigate general education teachers' attitudes toward inclusion in Cameroon becomes even more crucial, considering that their knowledge of the concept of inclusion, perceived ability to teach, ability to manage inclusive classrooms, benefits and learning outcomes of students with disabilities, can serve as a springboard for the introduction of inclusive education in Cameroonian schools. Special education courses and programs have recently been introduced to the Faculty (School) of 
Education of the University of Buea (Faculty of Education University of Buea, 2010). The Teacher Training College of the newly-created University of Bamenda has also begun introductory courses in special education. For the practice of inclusion to gain roots in the country, it is important to understand the actual needs of the teachers engaged in implementation. Knowledge of these requirements will be useful to decision or policy makers at the level of the schools, education ministries, and for program and curriculum developers in tertiary educational institutions.

The United States has certainly witnessed tremendous progress in the areas of public awareness, the management of special needs students in schools, and the protection of this category of students with the adoption of various laws to cater for their needs (Casey-Hayford \& Lynch, 2003; Smith, 2007). However, many other countries of the world, including Cameroon, are only now developing structures to handle the inclusion of students with disabilities into the general education classrooms, with the help of reinforcement learning activities in resource rooms (SEEPD, 2011).

Integration of students with disabilities comprises three components: physical integration, part or full day social inclusion (that is, relationship with peers) and curricular and instructional integration. Integration of students into the general education classroom curriculum is the main goal for most students with disabilities. However, the placement into general education classrooms has been justified to a large extent by stressing the social benefits and advantages for students with disabilities namely by providing them with opportunities to learn and develop appropriate social behaviors, and friendship with peers (Friend \& Bursuck 2006). This study of secondary school teachers' attitudes toward inclusion sought to determine the extent to which the various 
components of integration of students with disabilities in the general education classroom are taken care of in the pilot schools for inclusion in Cameroon.

Different terms such as mainstreaming, integration, least restrictive environment, inclusion, and full inclusion have been attributed to the education of children with disabilities in the general education classroom. These terms reflect conceptualizations and controversies regarding the meaning of this shift in the educational system and about the most appropriate course of action. For example, should all students with disabilities be educated in the general education classroom or should a continuum of placement options be maintained (Kauffman \& Hallahan, 2005)? Furthermore, the effectiveness of inclusion is still debated and is the subject of continued research (Day \& Prunty, 2015; Engelbrecht, Noel, Norma, \& Dan, 2015; Friend \& Bursuck, 2012; Ji-Ryun, 2011; Kavale \& Forness, 2000; Lindsay, 2003).

However, within the context of Cameroon, the issues are not related to which forms of inclusion to adopt. Rather, the entire practice of inclusion is embryonic and the push by the government for all schools to adopt the practice has not yielded sufficient results. Most students with moderate disabilities are still confined to the rehabilitation centers which are ill-equipped, and most schools also do not have adequate resources to accommodate students with disabilities. On the other hand, the importance of rehabilitation centers or institutions in Cameroon cannot be neglected. Some cases of disabilities are so severe that any attempt to accommodate the individuals in the general education classroom can become counterproductive. The promotion of inclusion in every context, including Cameroon, should never lead to the neglect of the role of rehabilitation centers. The handling of students with mild to moderate disabilities in the general 
education classrooms is an important aspect of this study. Most of these students do not qualify for admission in the rehabilitation centers. They are not accommodated in the general education setting. The need to investigate teachers' preparedness to handle inclusive classrooms in Cameroon becomes even more vital.

\section{Background of the Problem}

According to United States Department of Education (1999), a major goal of education is to include students with disabilities in the general education classroom. In the literature, this practice is referred to as inclusion. The fundamental principle of the inclusive school is that all children should learn together wherever possible, regardless of any difficulties or differences they may have (Mastropieri \& Scruggs, 2007; Smith, 2007). Inclusive schools must recognize and respond to the diverse needs of students, accommodating both different styles and rates of learning and ensuring quality education to all through appropriate curricula, organizational arrangements, teaching strategies, resource use and partnerships with their communities. There should be a continuum of support and services to match the continuum of special needs encountered in every school (UNESCO, 1994). Having enough information on students with disabilities and having needed resources will help promote teacher efficacy in teaching students with special education needs in the general education classroom (Davies Rhys \& Bryant, 2005; Engelbrecht et al., 2015). Many teachers probably find themselves in a situation which demands that they look for information and resources as well as implement strategies that fit within the day-to-day routines of the students (Gersten \& Woodward, 1990; Titanji, 2008). This initiative is the case especially within contexts such as Cameroon, where the practice of inclusion is still in the initial phase. 
Several years after independence, educating students with disabilities has not been treated as a priority by the government of Cameroon. Children or persons with disabilities are still perceived, treated, and officially labeled as "handicapped persons" and are admitted into private and government-run institutions often called "Centers for Handicapped Persons" or "Rehabilitation Centers" (Disability and Rehabilitation Team, 2002). Despite Cameroon's signing of the Convention on the Rights of the Child, much is left to be done in the area of special education. The government does not have standards in place to handle the training of personnel working with persons with disabilities (Disability and Rehabilitation Team, 2002). There are no established procedures for the identification and treatment of students with disabilities in the country's education system. Integration, which is the same as mainstreaming in the Cameroonian context, was officially embraced following the enactment of the 1983 and 1994 laws, stipulating the inclusion of students with special educational needs in the general education classroom (UNESCO, 1994). This legislation stipulates multidimensional support for schools, special pedagogical assistance, training of specialized staff. and the development of curriculum materials for special education (Hegarty, 1995).

Some factors have stalled the implementation of this legislation in Cameroon. The situation has not been helped by the complicated management relations among the many government ministries involved in the training and education of persons with disabilities-Ministry of Social Welfare, Ministry of Basic Education, and the Ministry of Secondary Education. The question of which ministry is responsible for the running of what aspect of special education remains largely unanswered. Until recently, there has been a complete lack of special education programs in teacher training colleges and the 
absence of the special education component in professional development programs in schools. Also, most schools do not have the assistive technology needed and have not been able to accommodate or modify the curriculum, to cater for the needs of students with disabilities in the general education classroom (Ebontane, 2010; Tani \& Nformi, 2016). A few schools, mostly church schools, have managed to accommodate a very limited number of students with mild to moderate disabilities in the general education setting. This effort has often been carried out with very rudimentary or basic resources (Ebontane, 2010; SEEPD, 2011; Mbibeh, 2013; Tani \& Nformi, 2016).

\section{Statement of the Problem}

The Cameroonian government signed a law in 1983 covering the protection of people with disabilities and promulgated this law in 1990 (Biya, 1990). The government also committed itself, officially, to promoting inclusion in schools by signing the UNESCO Salamanca Statement, which had the purpose of furthering the objectives of inclusive education (UNESCO, 1994). As recent as 2010, another law was signed to emphasize the dispositions in the previous laws. This law insisted on the welfare and education of people with special education needs. However, there has not been an effective implementation of special education laws particularly the law related to the practice of inclusion in Cameroonian schools. This situation can be attributed to the nonreadiness of schools, caused by lack of appropriate and adequate facilities, such as selfcontained classrooms, resource rooms, and the shortage or absence of trained teachers and paraprofessionals. Considering that inclusion is still in its initial stage in a few secondary schools in Cameroon, the need to diagnose institutional and teacher readiness for it is very imperative. 
Special education is best managed when qualified teachers and related service personnel are available. This availability of professionals ensures proper identification, development of individualized education programs (IEP), and their implementation and evaluation. Academic achievement for the students is better promoted when IEP's are established taking into consideration not only the degree of impairment but also the temperament, cognitive abilities, personality, and experience of the learner (Rivera \& Smith, 1997). Even though there are services aimed at prevention and treatment of impairments, the identification, and referral of students with special needs at the level of schools are almost absent in Cameroon (Disability and Rehabilitation Team, 2002). The absence of training programs for special education professionals such as teachers and paraprofessionals, in tertiary educational institutions, has resulted in acute shortages of qualified personnel.

\section{Purpose of the Study}

This study sought to investigate attitudes held by general education teachers toward students with disabilities in a pilot inclusive education program in Cameroon. The study also sought to know if there is any relationship between teachers' gender, age, the level of education, the number of years of teaching experience, experience teaching in the inclusive classroom, and experience in teaching students with disabilities, and their attitudes toward teaching students with disabilities. 


\section{Research Questions}

The study investigates the attitudes of general secondary education teachers toward the 2010 inclusive education program in Cameroon. The following questions guided the research:

1. What are the attitudes of general education teachers toward inclusion in Cameroon, with regard to:
a. The benefits/outcomes of integration
b. Integrated classroom management
c. Perceptions of their ability to teach students with special education needs
d. Perceptions of separate versus inclusive education

2. Do differences exist in teachers' attitudes, on the basis of their:
a. Gender
b. Age
c. Level of education
d. Number of years of teaching experience
e. Experience teaching in inclusive classrooms
f. Training in teaching students with special needs in the general education classroom
g. Teachers' language of instruction. 


\section{Hypotheses}

In order to address the second question, the following research hypotheses were tested:

Hypothesis 1. Female teachers are likely to have more favorable perceptions of inclusive education than their male counterparts

Hypothesis 2: Younger instructors are likely to have more favorable perceptions of inclusive education than their older colleagues.

Hypothesis 3: Teachers with a higher level of education will have more favorable perceptions than their colleagues with a lower level of education

Hypothesis 4: Less experienced teachers are likely to be more favorable of inclusive education than more experienced teachers.

Hypothesis 5: Teachers who have experience teaching in inclusive classrooms are likely to be more favorable toward inclusive education than their colleagues without such experience.

Hypothesis 6: Teachers who have received training in teaching students with special needs will likely have a favorable attitude toward inclusive education.

Hypothesis 7: Teachers who use French as the language of instruction are likely to have a less favorable attitude toward inclusive education than teachers who use English or bilingual teachers.

\section{Conceptual Framework}

This conceptual framework for general education teacher's attitudes toward inclusion is built on the premise that including students with disabilities in the general education classroom and ensuring effective learning by all students, is primarily the work 
of teachers (Fullan, 2007). Successful inclusive programs are largely dependent upon attitudes of general education teachers toward inclusion (Cook \& Schirmer, 2003;

Fakolade, Adeniyi, \& Tella, 2009; Galović, Brojićn, \& Glumbiećt, 2014; Glock, 2016; Markova, Krolak-Schwerdt, Ocloo \& Subbeya, 2008; O ‘Toole \& Burke, 2013; Razer, Mittelberg, Motola, \& Bar-Gosen, 2015; Schultz, 1998; Waldron, Mcleskey, Pacchiano, 1999). Therefore, for children with special education needs to be successfully integrated into the general education classroom, the attitudes of general education teachers need to be assessed and necessary adjustments made (Friend \& Bursuck, 2005; Garuba, 2003; Kavale \& Formess, 2000).

The main argument guiding the study is that, the ability of the classroom teacher to adapt and accept the special needs student impacts learning outcomes and that such ability depends on some vital factors (Davies \& Florian, 2004; Muwana \& Ostrosky, 2014). The literature on inclusive and special education in Cameroon has identified factors that influence teachers' perceptions of inclusion in Cameroonian schools (Mbibeh, 2013; Tani \& Nformi, 2016; Tohnain \& Tamanjong, 2014; Tukov, 2008). The main factor is teacher's training which influences knowledge and understanding of inclusion and the best practices crucial to the success of integration. The best practices include integrative instructional strategies, curriculum accommodation, technology use, and collaboration with special education teachers, paraprofessionals, parents, and the community (Wilson' Ellerbee, \& Christian, 2011). Bahn (2009) and Ji-Ryun (2011) argue that if teachers are well-trained and well-equipped with needed resources, they tend to know more about the students with special needs, and will respond to having these students in class as a professionally exciting challenge. The absence of courses and 
programs for the education of people with disabilities in teacher training colleges in Cameroon have been identified as a major drawback to the implementation of inclusive practices in regular schools (Tohnain \& Tamanjong, 2014). Teachers' ability to adopt best special education and inclusive education practices is reliant on their professional preparedness (Tanyi, 2016).

Other factors such as cultural beliefs and large class sizes are likely to influence teachers' perceptions of the concept of inclusion and their ability to manage inclusive classrooms. Both cultural beliefs and class sizes have been known to negatively impact the development of inclusive schools in Cameroon (Tani \& Nformi, 2016; Tohnain \& Tamanjong, 2014; Tukov, 2008). The overall assumption in the study, therefore, is that Cameroonian teachers' attitudes toward inclusion are widely influenced by quality and quantity of related professional training they have received, class sizes, personal beliefs, and cultures.

The study examines teachers' attitudes about a) perceived benefits of integration, b) perceived integrated classroom management, c) perceived ability to teach special need students and c) perceived attitudes toward separate special education versus inclusive education. Figure 1 is the Conceptual Map which depicts the relationship between independent and dependent variables. 


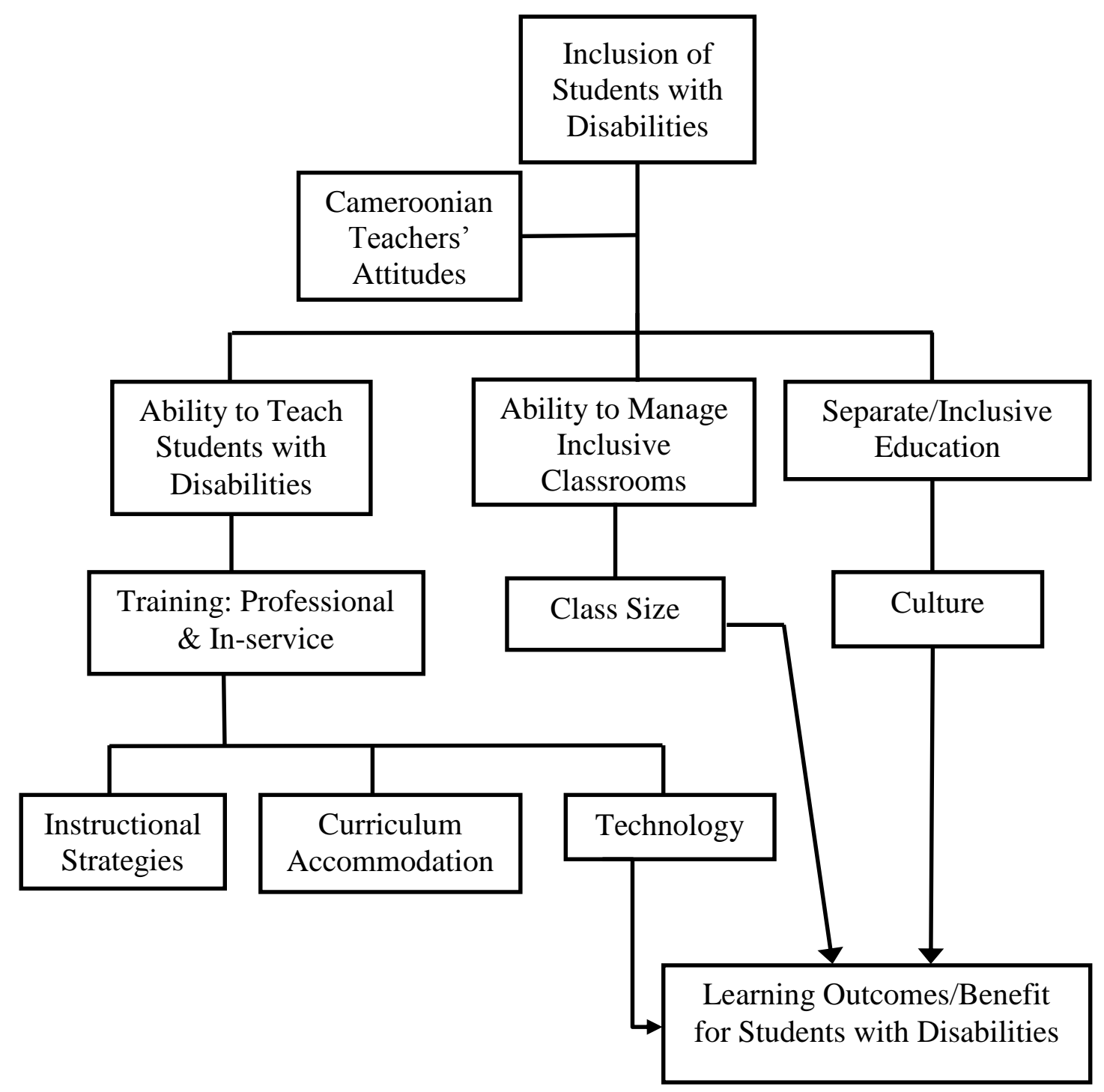

Figure 1. Conceptual Map

\section{Importance of the Study}

The findings of this study are expected to have implications for professional development, teacher training, and curriculum modification. The study reveals specific needs of inclusive schools and guides the conception and implementation of professional development programs, the acquisition of needed resources, and possibly, the development of full-fledged undergraduate and graduate programs for the training of 
special education teachers and paraprofessionals in Cameroonian colleges of education. It is anticipated therefore that the results will be particularly beneficial to the Ministry of Education and Social Welfare of Cameroon, the main sponsors of special education in Cameroon.

The findings will give Cameroon educational officials knowledge related to the levels of commitment general education teachers working with students who have disabilities. The study addresses and determines the needs and extent of investment required by educational leaders in teacher preparation for the management of inclusive classrooms. In a larger dimension, the study expands on previous research to examine teachers' perceptions of the concept of inclusion, their ability to teach students with special needs, their ability to manage inclusive classrooms and students' learning outcomes. Teachers' attitudes and perceptions can be an indication of what type of support is lacking in the classroom. Understanding educators' attitudes and perceptions about students with disabilities can help instructional leaders to restructure schools for inclusive education. The findings of the study should, therefore, guide instructional leaders as they make choices related to teacher growth and specific types of classroom adaptations and modifications that students with disabilities need in the general or regular education classroom.

Teaching students with disabilities in the general education setting is largely successful based on the abilities, enthusiasm, and approaches used by teachers to transmit knowledge (Ammah \& Hodge, 2005; Cole \& Waugh, 2001; Cook, Cameron, \& Tankersley, 2007; Dedrick, Marfo, \& Harris, 2007; Handler, 2003; Ji-Ryun, 2011; Kuester, 2000; Markova, Krolak-Schwerdt, \& Glock, 2016; McNally, Subban, \& 
Sharma, 2005; Sindelar, Shearer, Yendol-Hoppey, \& Liebert, 2006; Smith, 2008). The results of this study have a strong potential to provide valuable information for the proper management of students with disabilities in the inclusive classroom in Cameroonian schools.

\section{Delimitation}

This study seeks to examine how teachers in Cameroonian secondary schools are coping with the policy of including students with disabilities into the general education classrooms. The study focuses on the attitudes held by general education teachers in seven secondary schools in the North West Region of Cameroon. These attitudes are, vital to the implementation of inclusive education.

The study is not an attempt to compare the effectiveness of rehabilitation centers, used since 1972 as the only source of education for children with disabilities, with the inclusive schools launched in 1990 (Biya, 1990; Tukov, 2008). Rather the study intends to evoke through its findings and from the teachers' perspectives, the weaknesses, and strengths of inclusive schools (SEEPD program) in the North-West region of Cameroon, and make possible recommendations on how to improve the practice of inclusion.

\section{Limitation}

The study was conducted with general secondary education teachers (grade 6-12). Also, participants in the study came from one of the ten regions of the country. Even though this choice was motivated by the region's strong history of accommodation and recent advances in the inclusion of students with disabilities in general education schools, a concern is that teachers' attitudes toward inclusion in other regions might have significant culturally-influenced variations. 
A limitation of the study is that it only focuses on secondary school teachers. The study does not investigate attitudes of the primary school teachers even though the attitudes of teachers in primary schools could differ in some ways from those of their counterparts in secondary schools .There are more female teachers than male teachers. Consequently, there is an unequal representation of gender.

\section{Definition of Terms}

Anglophone: Anglophone in the African context is the term used to refer to a person who speaks English, usually as a second and sometimes third language. An Anglophone country is a country that has adopted English as its official language or one of its official languages. In Cameroon, Anglophone means an English-speaking person whose mother tongue is not English. The term is also used to refer to Cameroonians who are natives of two of the ten regions of the country: North West Region, and South West Region.

Free and Appropriate Public Education (FAPE): Special education and related services have to be given at public expense, under public supervision, and without charge. The education provided must meet standards of the state and have an appropriate preschool, elementary, or secondary schools that are provided in compliance with individualized educational programs (Individuals with Disabilities Education Improvement Act [IDEIA], 2004).

Francophone: Francophone in the African context is the term used to refer to a person who speaks French, usually as a second and sometimes third language. The Francophone country is a country that has adopted French as its official language or one of its official languages. In Cameroon Francophone means a French-speaking person 
whose mother tongue is not French. The term is also used to refer to Cameroonians who are natives of eight of the ten regions of the country: East Region, South Region, Center Region, West Region, Adamawa Region, North Region, Far North Region, and Littoral Region.

Full Inclusion: When students with disabilities are educated in the general education classroom full time. There is no separate special education classroom or resource room, but support may be given to the general education teacher and the student with disabilities.

Inclusion: Students with disabilities receiving services in the general education classroom under the instruction and direction of the regular education teacher. (Wolfe, \& Hall, 2003). Inclusion does not require the child to be ready to enter the general education classroom but develops the classroom support, the educational, behavioral and social needs of students who are disabled. Inclusion brings the services to the child in the general education classroom instead of moving the child to the services. Inclusion requires that the child will benefit from being in the classroom rather than keeping up.

Article 1 of the 1983 law defined a person with a disability as, someone who, stricken by physical or mental, congenital or accidental deficiency, experiences difficulties to perform his/her duties as any normal person. It should be noted that the law of 1983 concerned all the categories of disabilities that exist in Cameroon, most especially; the blind, deaf, dumb, dwarfs, retarded, etc.

Least Restrictive Environment (LRE): "To the maximum extent appropriate, children with disabilities, including children in public and private institutions or other care facilities, are educated with children who are not disabled, and special classes, 
separate schooling, or another removal of children with disabilities from the regular educational environment occurs only when the nature of severity of the disability of the child is such that education in regular classes with the use of supplementary aids and services cannot be achieved satisfactorily" (Individuals with Disabilities Education Improvement Act [IDEIA], 2004).

Mainstreaming: It refers to the participation in the general education environment when the child is academically or emotionally ready. Mainstreaming refers to the placement of a child in the general education classroom for one or more periods.

Secondary School Teachers: Refers to teachers of the middle and high school, that is, teachers teaching grades 6 to 12. In Cameroon, middle schools cover a five-year program and highs school cover a two-year program in the Anglophone education system. In the Francophone education system, middle schools cover a four-year program while high schools cover a three-year program.

General Education Teachers: This refers to teachers in the general education or regular education classrooms as opposed to those teaching students with disabilities (special education teachers). In Cameroon, general education is a program of instruction typically developing children without disabilities receive, based on national standards.

Modification: A change in instructional and testing environments that remove barriers for students with disabilities but does not change the construct being taught or assessed.

\section{Summary and Organization of Study}

The embrace of inclusive education in Cameroon's educational system is imperative now more than ever before. There are more students with special educational 
needs in Cameroonian general education classrooms today than any other time in the country's history (SEEPD, 2011). The cultural shift in beliefs has made general education schools more tolerant and open to accept students with visible disabilities than was the case in the latter part of the $20^{\text {th }}$ century.

Nonetheless, there are many students with mild to moderate disabilities whose ability to learn is compromised because of inadequate care. These students are still scorned and treated as lazy or stupid not through a fault of theirs but because of a history of special education that does not have an established system that allows for the professional identification of students with disabilities (Disability and Rehabilitation Team, 2002). Also, when students are identified as having special needs, teachers are not able to accommodate them in the general education classrooms because of their insufficient training and shortages or complete lack of adapted didactic material and resources. Even with the official launching by the government of the practice of inclusion in Cameroonian secondary schools in 1994 (UNESCO, 1994), very few schools are actively practicing inclusion. Against this background, and considering that teachers are at the center of every classroom teaching activity, there is a need to investigate the teaching and learning in inclusive secondary school classrooms from the teachers' perspective.

Chapter 1 of the study provides a background of the problem, explains the problem being studied, and outlines the research questions to be answered in subsequent chapters. Chapter 2 presents a synthesis of interconnected previous studies and scholarly writings linked to special education, the concept of inclusion, teachers' perceptions of inclusion, and the history of special education and inclusion in Cameroon. Chapter 3 
discusses the methodology of the study. Chapter 4 presents the results of the survey and the findings from the study. Finally, Chapter 5 presents a brief summary of the data analysis, interpretations, and discussions of the findings, recommendations for SEEPD program leaders, government, and future research. 


\section{CHAPTER 2}

\section{LITERATURE REVIEW}

\section{Introduction}

This chapter focuses on the review of the literature on special education, particularly the practice of inclusion and teachers' attitudes toward inclusive education. The review presents a) the overview of special education in Cameroon, including the current state of inclusive education in the country, b) the theoretical framework guiding the study, c) attitudinal theories, d) definition of the concept of inclusion, e) factors that influence teachers' perceptions pertaining to the integration of children with disabilities in the general education classroom, and f) best inclusion practices. In addition to the literature on the concept of inclusion, reviews of studies on teachers' perceived ability to teach children with special needs, the management of students with special education needs in a general education classroom and outcomes for children with disabilities, are included.

\section{Special Education in Cameroon}

This dissertation study on teacher attitudes in secondary schools fills a gap in the literature about teachers' attitudes toward inclusion in Cameroon. Teachers' attitudes vary from one context or nation to another depending, to some significant extent, on the history surrounding special education in each context. Reflected in such a history is the socio-cultural and political beliefs of the society. A better understanding of secondary 
school teachers' attitudes toward inclusive education in Cameroon is only possible when it is examined within the context of Cameroon's history of special education and worldwide trends in the practice of both special education and inclusive education in particular.

\section{A Brief History of Special Education in Cameroon}

The history of special education in Cameroon can be divided into four continuous phases namely the pre-colonial, colonial, post-colonial, and the contemporary phase. In Cameroon, as in the United States and other countries worldwide, treatment and acceptance of people with disabilities have evolved and continue to evolve with time.

\section{Pre-Colonial Era}

Attitudes toward the people with disabilities have never been identical throughout Cameroon. This disparity is due to the diverse beliefs, customs, and traditions representing about 230 tribes divided into four socio-cultural groups: the Bantu, the Bantoid or semi-Bantu, the Sudanese and the Pygmies (United Nations [UN], 2008).

Historically, most of the tribes have been known to associate disability with a curse or ill omen on the family of the person. Students with disabilities were treated as 'invalid' or outcasts and in need of very special protection (Tukov, 2008). As a result, disability called for much pity toward the disabled persons and their families. Disability, particularly severe cases, was mostly considered a burden or disgrace by family members and society (Oliver, 1990; Shey, 2003; Tohnain \& Tamajong, 2014; Yuh \& Shey, 2008).

Since families believed that it was a curse to have a child with some visible disability, some tribes preferred to continually hide the children in their houses for fear of public ridicule. Parents and relatives mostly transmitted Knowledge acquired by children 
with disabilities at home. Tabot and Ojong (2008) attest that before the arrival of European explorers, traders, and missionaries, Cameroonians educated all their children. Children with disabilities just like those without disabilities were taught how to become productive members of the society. They add that “...education existed in the Cameroonian culture. It was given to the family by parents, other family members and the society as a whole. It had its philosophy and methods" (Tabot \& Ojong, 2008, p. 44).

\section{Colonial Era}

With the introduction of Christianity in the 1800s by Western missionaries, persons with disabilities started to receive more humane treatment and consideration through Christian schools and churches (Shey, 2003; Tukov, 2008). Even though the advent of European missionaries created conflict with local cultures, customs, and traditions of Cameroon, the benefits of education for the society, especially regarding the treatment of people with disabilities, were huge (Tabot \& Ojong, 2008). Individuals with mild disabilities started to receive an education alongside those without disabilities, and they also began to join the workforce.

The vision of society brought by the European missionaries was that of fairness, love, and social justice. The church and education were perceived as synonymous, having a shared vision and mission for individuals. Every member of the society had to be treated as a child of God no matter their deficiency or disability. Tabot and Ojong (2008) report that

The missionaries who came to Cameroon brought with them the idea that any form of education must operate in the interest of faith, that is, church interest and doctrines. Education was to start with children who were regarded as a nursery in which righteousness may be implanted... (Tabot \& Ojong, 2008, p. 45) 
A new level of consciousness and compassion for persons with disabilities was undoubtedly born by the new influence of Christianity. Schools, especially parochial schools, began to accept children with mild orthopedic and visual impairments. The colonial administration partnered with churches to create and run the few existing schools, mostly, parochial schools. Considering that only a few primary and secondary schools were in existence during the colonial period, the greatest concern of colonial leaders was to train a few nationals who could assist them in the education of students with special education needs. However, educating students with disabilities was not an issue of priority for a society which was immensely illiterate. Estimates indicate that by 1914 there were about 531 primary schools - mostly elementary schools — with enrollments of about 34,117 (Doh, 2007; Ngoh, 1987; Tchombe, 2001). Most of these schools belonged to the Baptist and Catholic Missionary Societies.

The leading religious groups in the spread of Christianity and Christian education were Baptists and Catholics. The determination by the churches to stop the exclusion of persons with disabilities from being educated was adamant despite their inability to access a greater number of individuals with disabilities. This decision is evident in the following 1989 declaration of the Catholic Missionary Societies, “... all children have a right to be educated so that he or she can better achieve according to his ability and to serve the community in which he forms a part" (Tabot \& Ojong, 2008, p. 50).

\section{Post-Colonial Era}

Cameroon's independence in 1960 led to the creation of more schools and the education of leaders in different fields. Customs, beliefs, traditions and attitudes practiced by diverse ethnic groups in Cameroon influenced the approach taken by the first 
government officials to educate children with disabilities. The independence of the country led to the creation of several more primary and secondary schools, and the first National University in the country. However, the first government efforts to educate children with disabilities were seen in the creation of "Rehabilitation Centers" which provided mostly vocational-oriented education to children with disabilities (Tchnain, Fonkeng, \& Ngueffo, 2008).

The first schools created in 1972 were called Ecole Specialisée pour les Enfants Deficients Auditif-ESEDA (Special School for Children with Hearing Impairments); and Externat Medico Pedagogique-La Colombe (Special School for the Mentally

Handicapped Children). From 1975, the newly formed Ministry of Social Affairs was in charge of the formal education of students with disabilities through these specialized centers. After the creation of the Ministry of Social Affairs in 1975, a Department of National Solidarity was created to oversee the well-being of students with disabilities. This department, in collaboration with the Ministry of National Education, made strides in creating structures and funding vocational education programs for children with disabilities. In 1975, another center known by its French acronym as PROHANDICAM (Promotion des Handicapés du Cameroun) or Center for the Wellbeing of Handicapped Persons, was created. Even though the raison d'être for these centers was not to prepare children with disabilities for eventual integration into the general education system, they prepared students with disabilities for vocational training for their eventual socioeconomic integration into the society.

To train young Cameroonians with visual impairments in arts and crafts, the Ministry of Social Affairs (MINAS) created the Rehabilitation Institute for the Blind in 
Buea, South West Region, called Bulu Blind Center (MINAS, 1990). With the willingness of the Cameroon government to offer state grants to vocational schools and centers for the training of children and young adults with disabilities, many more centers were created. Churches, religious groups, and private persons have since the 1980s created more centers to provide education for children with disabilities. Today, most of these centers are owned by private individuals, churches, nongovernmental organizations (NGOs), and they are mostly found in the cities (Tukov, 2008).

In a UNESCO report titled Review of the Present Situation in Special Needs Education, information is given about the status of special education policies in 63 countries including Cameroon (Hegarty, 1995, p. 62-64). According to this report, the relevant legislation on special education in Cameroon is contained in laws passed in 1983 covering the protection of people with disabilities and a follow-up law enacted in 1990 to ensure the implementation of the 1983 law. This legislation stipulates multidimensional support for schools, special pedagogical assistance, training of specialized staff, and the development of curriculum materials for special education. Even though this law existed since 1983, the institutionalization of special needs students has occurred since Cameroon's independence. Despite its limited curricula, specialized centers for the education of children with disabilities provided a strong base for Cameroon inclusive education.

The Cameroon government recently signed another law in 2010 to emphasize on the dispositions of previously signed laws concerning special education insisting on the needs of individuals with disabilities in particular. Section 17 of the law stipulates that support should be provided to persons with special needs to strengthen them 
psychologically, help them develop self-esteem, as well as promote relationship amongst persons without disabilities. Section 29 of the law facilitates access to education for students with special needs. This law came up with a solution to finally implement inclusive education in Cameroon schools, but no implementation was evident.

In Cameroon, today, the responsibility for special education is officially shared between the ministries of education (Ministry of Secondary Education and Ministry of Basic Education) and the Ministry of Social Welfare. Increasing pressure in recent years from newly created organizations for the rights of persons with disabilities, human rights groups, the International Monetary Fund and the UN, led to the signing of the Convention on the Rights of the Child by the Cameroonian government in March 2001. Article 23 of this Convention among others calls for the protection of the "handicapped" children (Hegarty, 1995). Nothing significant has changed since the signing of this convention, and the government still has to translate its engagements into action for the progress of its young citizens with disabilities. The hope is that with the inclusive education agenda proposed by UNESCO, the Cameroon government will come up with more comprehensive legislation that takes into account the nature and types of disabilities, systematic identification as well as provide support for the education of students with special education needs (UNESCO 2009a). With a strong agenda, and teaching strategies, implementation can be feasible (UNESCO, 2009b). 


\section{Culture and Special Education in Cameroon}

The local cultures in Cameroon are both helpful and harmful to the condition of persons with disabilities. The strong family support system within the communities compensates, to some extent, for the lack special education facilities. Tukov (2008) admits that children with hearing impairments, visual impairments, autism, mental retardation, and physical or health disabilities receive invaluable support from parents and family members. There is always someone home to provide for their basic needs.

On the other hand, the tendency to view children with disabilities as a curse and burden to the family is still common throughout the country. This view is held especially by the less educated section of the population. Families with less educated parents would prefer to keep their children in the villages rather than expose their disabilities by letting them attend a general or special school. This view of leaving children at home explains why field workers sponsored by non-governmental organizations and missionary groups encounter huge opposition from parents when they attempt to convince them to allow their children go to the special education centers for free education and care. They would rather confine these children to their homes and will not give them the opportunity to attend school (Tukov, 2008; UN, 1991; UNESCO, 1990). Tohnain and Tamajong (2014) affirm that the society poses a problem to children living with disabilities since society does not readily receive them as normal human beings.

While the American family system does not seem to be as supportive to the old and persons with disabilities as in Cameroon, the American Society has taken steps to accept and integrate individuals with disabilities in different aspects of life. Families would easily associate a disability to a medical condition either acquired or genetically transmitted. It has encouraged the culture of prevention through screening for expectant 
mothers and early intervention for diagnosed children. This is not the case in Cameroon because of the tendency to attribute abnormality in the newborn as a mystery. Poverty and ignorance have contributed to this type of mindset and attitude.

\section{Special Education Administration and Organization}

In Cameroon, special education is administered by the Ministry of Social Welfare and the Ministry of Education. Most funding and provision for special education is made by private agencies, with the state confining itself largely to a supervisory role. The Ministry of Social Welfare coordinates activities of special education centers. With voluntary organizations, largely in charge of special education, this Ministry tends to play the role of "overseer" (UNESCO, 1995). The Ministry of Social Welfare also requires every organization establishing new schools to meet certain criteria and submit yearly reports to the Ministry. Nevertheless, this law is not strictly implemented, and government tends to encourage the least acceptable effort from private promoters of special education considering that the government cannot and is not doing better (Tukov, 2008).

Children and young persons with SEN are neither registered nor categorized (UNESCO, 1995). In spite of requests for reports specifying the number of children with disabilities enrolled in regular schools, the number of students that benefit from the special education programs, and the categorization of children with special needs, Cameroonian authorities have not been able to provide specific record in those areas (UN Convention on the Rights of the Child, June 2001).

One of the main concerns authorities have about the future of special education is the absence of structures. The UNESCO 1995 review of the situation in special needs 
education points to the need for Cameroon to study the experiences of other countries regarding the establishment and running of institutions of special education, inclusive schools, and training of specialist staff (UNESCO, 1995; UNESCO, 2009a).

\section{Special Education Facilities}

There is a critical lack of special education facilities such as new centers, selfcontained classrooms, resource rooms, and specialized equipment (Tohnain \& Tamajong, 2014). Assistive technology is always very inadequate. When assistive devices and equipment are needed, the cost is usually borne by municipalities or the person with a disability, while Non-Governmental Organizations (NGOs) will sometimes wholly or partially subsidize the cost of equipment (Disability and Rehabilitation Team, 2002).

The government of Cameroon is not actively involved in the acquisition and distribution of assistive technology and devices. The 1983 law stipulating government aid to special education and the development of inclusive education clearly states that such aid will only depend on the means available to the authorities (Biya, 1984). A good example of the inadequacy of government support for special education is manifested in the highly publicized prime ministerial circular (No. 003/CAB/PM) which ordered the supply of 63 crutches, two electric wheelchairs, five hearing aids, 45 tricycles, and four mechanical wheelchairs to persons with disabilities in the entire country. The assistance of this nature is limited both in quantity and variety considering the number of students or individuals with disabilities in the country, and that covers only individuals with orthopedic and hearing impairments. Shey (2003) points out that special education schools in Cameroon are limited in scope_covering principally three main categories of disabilities, namely deafness/hearing impairments, visual impairments, and 
deaf/blindness. Children with other types of disabilities like specific learning disabilities, speech and language impairments, mental retardation, autism, orthopedic impairments, and developmental delays are left by themselves in the general education classrooms.

There is usually lack of means to diagnose students' levels of disability, including diagnoses for the most represented categories of disability like visual and auditory impairments. The plight of children with disabilities in Africa and specifically Cameroon is huge because of this situation (Casey-Hayford \& Lynch, 2003). Children with disabilities have very few special education centers ready to accept them. The overwhelmed, mostly privately owned, special education centers constitute the only source of hope for children with disabilities and their parents but remain largely insufficient.

The visually impaired, blind, deaf and hard of hearing children are better served in the rehabilitation centers because only a few regular schools are practicing inclusion at a slow pace or have the capacity to implement the reform. With a population of approximately 20.5 million people living in 10 regions, it was estimated that there was an average of one special education facility for the blind and deaf per province of Cameroon (MINAS, 1990). This situation has not changed significantly today. Rather, even with the addition of few more schools, the need for special education services is likely going to be higher considering that the blind and deaf categories of disability constitute the highincident visible categories in Cameroon. 


\section{Special Education and Inclusion-Related Laws in}

\section{Cameroon}

The 1983 law number 83/013 was the first legislation from the Cameroonian government at protecting educational and human rights for people with disabilities. As a follow-up, another law was passed in 1990 enforcing the implementation of the 1983 law (Biya, 1984). This legislation contains provisions for various grants to support special education schools, special pedagogical assistance, training of specialized staff, and the development of adapted curricula. Article 6 of the law specifically mentions government support for the education of children with disabilities by admitting them in public schools but also cautions that the extent of the support will only be according to available means.

Many other laws have been introduced by ministers to enforce the July 21, 1983, law. On April 10, 2006, a meeting was held between the Ministers of Social Affairs and Public Works to ensure the smooth application of the 1983 Act to grant individuals with disabilities access to public buildings, and of the full implementation Decree No. 90/1516 of 26 November 1990. Furthermore, the joint circular letter No. 34/06/LC signed on 2 August 2006 by the Ministers of Secondary Education, and Social Affairs sought to facilitate the registration of children with disabilities or born to poor parents with disabilities in public secondary schools. It also exempts these students and their parents from paying registration and parent association fees in general or technical establishments (International Disability Alliance, 2011).

Another circular (No. 003/CAB/PM) from the office of the Prime Minister signed on April 18, 2008, requested that all public building contractors adopt construction norms that accommodate persons with disabilities by facilitating their accessibility to schools, public buildings and facilities, and roads (International Disability Alliance, 2011). 
Recently, the 2010 Law No. 2010/002 of April 13 emphasized on the dispositions of the previous laws to cater for the needs of individuals with disabilities. This law insists on the welfare of disabled persons and the psychological support which according to section 17 will improve their self-esteem, and strengthen relationships amongst persons without disabilities. Section 29 of this law facilitates access to education for students with special education needs (Mbibeh, 2013).

\section{Training of Teachers and Related Service Providers}

There is also a big problem of staffing in special education facilities in Cameroon. Special education teachers are scarce, and this accounts for students with disabilities performing poorly in school. There is a pressing need for the opening of special education teacher training schools or programs in one of the universities of Cameroon. So far there is no single training facility for special education teachers. The few qualified teachers are primarily trained in Europe. The Special Educational Needs Training Institute (SENTTI) which commenced in February 2007 in the North West Regional capital of Bamenda was expected to be the first teacher training institute for special education personnel in Cameroon. The institute, run by the Information Technology Common Initiative Group (ITCIG), opened its doors, but the huge reliance on external goodwill support of volunteer lecturers from the British Voluntary Services Overseas Organization (Tukov, 2008) is a disadvantage. The school has expressed the need for volunteer faculty in specialties where they lack staff (e.g., speech therapy), and for materials such as styluses, Braille frames, educational software, interactive boards, computers, and even shoes (Omprakash Foundation, 2011). 
It is crucial to have trained teachers considering that students with disabilities achieve more when qualified teachers and related service personnel are available (Bishop \& Jones, 2002; Burstein, Sears, Wilcoxen, Cabello, \& Spagna., 2004; Davies \& Florian, 2006; Ji-Ryun, 2011; Kim, 2011; Kirby, Davies, \& Brian, 2005; Muwana \& Ostrosky, 2014; Savolainen \& Woolfolk Hoy, 2012; Thaver \& Lim, 2014; Tindall, MacDonald, Carroll, \& Moody, 2015 ). The training of teachers entails proper identification of students with special needs, development of IEPs, and their implementation and evaluation. Academic achievement for the student is better promoted when IEP's are established taking into consideration not only the degree of impairment but also the temperament, cognitive abilities, personality, and experience of the learner (Rivera \& Smith, 1997; Smith, 2007). These processes do not apply in Cameroon due to lack of adequately trained professionals and proper legislation.

\section{Prevalence and Identification of Students with Disabilities}

In Cameroon, categories of students with special needs have not yet been defined in legislation. The demands from UNESCO for statistics on the number of children with disabilities enrolled in general education and those benefiting from the special education system have not been met. This situation is not resolved despite efforts by the government ministries responsible for the education of children with disabilities (UN Convention on the Rights of the Child, June 2008; Tanyi, 2016). The common Ministerial Circular No. 283/07/LC/MINESEC/MINAS of August 14, 2007, relating to the identification of individuals with disabilities and children of poor parents with disabilities, and their enrollment in government colleges and high schools, still did not provide relevant details (Ngoh, 2007). 
Ondoua Abah (as cited in Tohnain \& Tamajong, 2014) purports that only 5\% of children living with disabilities in Cameroon attend school, and less than 2\% complete the secondary education cycle. This low enrollment can be attributed the inability of families of children living with disabilities to afford or fund their studies (Tohnain \& Tamanjong, 2014). As recent as 2010 the report from the Cameroon National Coalition of NGOs for Children's Rights (COCADE) underscores that there is an absence of real data on the number, types, and mapping of children with disabilities in Cameroon (COCADE, 2010).

Notwithstanding, the number of persons with disabilities in Cameroon was estimated at 700,000 in 1993 (Disability and Rehabilitation Team, 2004) Data from the Ministry of Social Affairs affirm that 1.6 million individuals are living with disabilities in Cameroon (Tohnain et al., 2008). Similar statistics are echoed by the World Health Organization (WHO) report (International Disability Alliance, December 2011; Tanyi, 2016).

\section{Inclusive Education in Cameroon}

The Salamanca Statement of 1994 marked a new phase in the history of special education in Cameroon. The signing of the accord by the government meant that schools were legally required to admit students with mild to moderate disabilities in the general education classrooms. The law urged all governments to "adopt as a matter of law or policy the principle of inclusive education, enrolling all children in regular schools unless there are compelling reasons for doing otherwise" (UNESCO, 1994, p. 9). 


\section{The Aftermath of Salamanca}

As follow-up to the World Conference on Special Education Needs (UNESCO, 1994), the Cameroon government and eleven other countries committed to the UNESCO Inclusive Schools and Community Support Programs which sought to "support action and disseminate information on small-scale innovations at the national, regional and local level, promoting the inclusion of children with disabilities and learning difficulties in regular schools" (UNESCO 2001, p. 7). The two-phase program (1996-97 and 19982001) gave participating countries the opportunity to choose the exact nature of their activity from a list of target areas.

Cameroon's involvement in the project became visible during its second phase, but its management was more complicated than anywhere else because responsibility for the provision of education is split between the Ministry of National Education and the Ministry of Social Affairs (Association of Parents and Friends of Mentally Handicapped Children [APEHM]-UNESCO, 2000). While the Ministry of National Education (now Ministry of Secondary Education and Ministry of Basic Education) was responsible for the regular schools, the Ministry of Social Affairs is responsible for special education. The Cameroonian government's perspective on the reform was essential to promote the training of inclusive education personnel and to establish the foundation for inclusive schools by developing and revising legislations. The objectives were described as follows:

- A change in discriminatory attitudes

- the introduction of a child-centered instruction, capable of educating all children 
- the creation of communities which are more receptive, just and inclusive ([APEHM]-UNESCO, 2000), p.3).

The following outcomes were expected:

- A greater awareness of decision-makers of the need for inclusive education

- training of teachers for inclusive schools in Yaounde

- the development of strategies for the diffusion of information about the inclusive education approaches throughout Cameroon ([APEHM]-UNESCO, 2000), p.3). The Ministry of National Education decided to place the management and implementation of the UNESCO Inclusive Schools and Community Support Programs in the hands of NGOs, The APEHM, which was already fighting marginalization and promoting the inclusion of children with disabilities in regular classrooms (UNESCO 2001). The start-up phase of the project involved sensitization movements through direct contacts with the schools in the capital city of Yaounde, with families of both impaired and non-impaired children, the utilization of the media, followed by a reflection workshop which included parents, teachers from regular schools, and the representatives of the Ministries. Only nine schools already involved in mainstreaming were included in the project. The first training workshop for teachers held in October 1998 with 65 participants was followed by the sharing of information, distribution of materials, and monthly meetings organized by the APEHM. The second workshop took place in November 1998 with only 44 participants, including representatives of the Ministry of National Education and the Ministry of Social Affairs who grappled with propositions and reflections on how to coordinate and introduce inclusion in special education institutions and regular schools run respectively by the two ministries. Initially, the 
projects gained popularity among participating schools and teachers who came to see it as means of facilitating instruction for all teachers and not an additional burden. United Nations Educational Scientific and Cultural Organization consultants assisted in the 1998 and 1999 training sessions which resulted in a range of recommendations, including the need for a new policy, programs, materials, and teacher training for the process of developing more inclusive schools (UNESCO, 2000).

\section{Barriers to Effective Inclusive Education in Cameroon}

The scope of the UNESCO Inclusive Schools and Community Support Programmes in Cameroon was very limited and beleaguered by a series of endemic issues. The project was limited to the capital city, covering an insignificant number of schools and participants ([APEHM]-UNESCO, 2000).

The first inclusion initiative in Cameroon was put in the hands of the APEHM involved in the education of only mentally impaired children in a special education school but had no experience or expertise in inclusive education. No matter the commitment of the NGO, lapses were bound to occur (UNESCO, 2013). The Ministry of National Education, which was supposed to head the inclusive education initiative, could not engage fully because local laws put the education of children with a disability under the responsibility of the Ministry of Social Affairs (UNESCO, 1999). Confusion on this management issue continues to plague the coordination or promotion of inclusive education initiatives today (UNESCO, 2013). There is a need for laws regarding education for children/students with disabilities to be revised and the responsibility given to the Ministry of Secondary Education and the Ministry of Basic Education. 
The Ministry of Education's initial teacher training programs did not prepare and equip teachers to work with children having special education needs. Rather, initial teacher education programs were developed for regular students and school. Educators had very little or no knowledge of special education. As a result, teachers in regular classes did not feel ready to manage differences in their classrooms (UNESCO, 1999). Also, existing school facilities were not made to accommodate students with disabilities and curricula not developed to cater for their needs (UNESCO, 2001).

Class sizes in regular schools were also identified initially as a potential obstacle to inclusive education. It is a commonplace for classrooms to contain between 70 and 100 students, and even above. Lack of special facilities, related services, and support were major obstacles to the success of SEN children in regular schools.

The UNESCO Inclusive Schools and Community Support Programmes Project reported that one major obstacle from the commencement was the culturally-influenced views of parents of children with disabilities in regular schools. The report stated that parents of children with disabilities had a strong conviction that their children were best served in special schools or separate provisions, not in the mainstream schools. Parents of children already in the regular system acknowledged fear that there would be a possible 'contamination' of their children through the process of inclusion and that their children's progress at school would be jeopardized (UNESCO, 2001).

A major problem with expanding inclusive education in Cameroon today is the passive supervisory role of the state as well as the complex functions of the ministries of Basic Education, Secondary Education, and Social Affairs. By conferring a major leadership role during the initial implementation phase of inclusive education to the 
APEHM, with no expertise in the domain, the government laid a weak foundation for inclusion in general education schools. This drawback depicts why several years after the initiation of inclusion; inclusionary schools are barely beginning to emerge.

Cameroonian non-governmental organizations have long tried to raise awareness about the plight of children with disabilities and have pointed to the delay in the implementation of present laws. In their report of December 17, 2000, the Coalition of NGOs for the Rights of the Child, indicated the need for the Cameroonian government to ensure the application of the United Nations Convention on the Rights of the Child to which it is signatory (Coalition des ONG Camerounaises pour les Droits des Enfants, 2000). These rights, among others, include the right to education for children with disabilities. This group decried government's failure to implement new legislation despite challenges in Cameroon and called the government to revise the laws and apply the previous law on special education. The government has listened to these complaints, and in its 2010 report to the UN Commission on the Rights of the Child, the government of Cameroon cited access to special education and inclusive education for children with disabilities as one of the most important priorities. The report concluded that the priorities needed to be addressed to ensure the actual implementation of the stipulations of UN Convention on the Rights of the Child (Comité des Droits de L'Enfant, 2010). The report also admitted to the existence of difficulties with the implementation of inclusive education and pointed out that the creation of structures to facilitate the education of children with disabilities in the country remains a moving target. 


\section{Emerging Inclusionary Education Activities in Cameroon}

Eventually, no inclusive schools emerged from the 1998-2001 UNESCO Inclusive Schools and Community Support Programmes initiative in Cameroon. Only a few regular schools around the country collaborated with special education schools by mainstreaming mostly students with visual and hearing impairments (APEHM, as cited in UNESCO, 2001). Government Bilingual High school Kumbo (GBHS), for instance, has worked in partnership with the Cameroon Baptist Convention (CBC) Church's Banso School for the Blind, since the late 1990s, by mainstreaming a handful of students from the center in their classrooms. Collaboration between the Adventist Secondary School in Yaounde and a few special education centers also led to the mainstreaming of some students with visual and aural impairments in Yaounde (College Adventiste, 2000). However, the most sustained integrative effort in the country was the one realized through the cooperation between the CBC Church special education center in Kumbo and GBHS Kumbo, aimed at mainstreaming blind students.

The promotion of special education and efforts toward the development of inclusive schools in Cameroon continue to be led by nongovernmental organizations, including churches and private individuals (Tohnain \& Tamanjong, 2014). Today, the development of inclusive schools is spearheaded by a regional NGO in the North West region of the country. The SEEPD, a CBC Church NGO, has been working with bilingual public schools to promote inclusive education in the area (Muffih, 2010). The SEEPD program known as the "14 School Project" initially began with 14 participating schools and a workshop for the training of 116 teachers in October 2010. 
The initial or test phase of the project involved the inclusion of mostly students with visual impairments. The principal of GBHS Kumbo, one of the participating schools, expressed his satisfaction with the program stating that his school "was privileged to be the one in the country that integrates students with visual impairments" (Muffih, 2010, p. 3). He also added that the first group of visually impaired students participating in the program was performing well in class and certificate examinations. The testimony is indicative of the overall performance of students with disabilities involved in the 14-school inclusive education project. The government of Cameroon has not been directly involved in the realization of this project. Their role has been supervisory, including the provision of targeted support to the SEEPD program. The government, through the North West Regional Delegate of Secondary Education, has commended SEEPD for its leading role in the promotion of inclusive education in the region (Muffih, 2011a).

The construction of the first resource center in GBHS Bamenda marked a significant stage in the SEEPD project. According to SEEPD leaders, the resource center is expected to serve as a center for seminars and workshops, provide a library, Information and Communications Technology (ICT), Braille services, books and equipment related to the education of students with disabilities (Muffih, 2011a).

Socio-Economic Empowerment of Persons with Disabilities' efforts to train teachers in inclusive education has been huge but limited to workshops and seminars. These seminars have certainly improved teachers' knowledge on the teaching of students with disabilities and the management of inclusive classrooms. However, the need for special education professionals and college programs that train would-be teachers on 
special education, and inclusive education remains dire. In 2011, the SEEPD Program in collaboration with the Bambili Higher Teachers' Training College agreed to collaborate in the training of student teachers on inclusive education (Muffin, 2011b). In line with its twin-track approach - the promotion of special education and the promotion of inclusive education - SEEPD sensitized a total of 64 primary and secondary schools on the need to facilitate overall school access for pupils and students with disabilities.

On the whole, SEEPD has reported a largely successful outcome for the 14-school inclusive project despite personnel, material, and logistical difficulties. There is even greater hope for the success of the inclusive education program in this region of the country because of the active community involvement. As early as 2007 the Information Technology Common Initiative Group (ITCIG) and the Special Educational Needs Teachers Training Institute (SENTTI) became the first community partnership in the country created to educate special education teachers (Laurin-Bowie, 2009). Information Technology Common Initiative Group-SENTTI started through the association of local advocates and the NGO Spire International, with the primary goal of training qualified special education teachers, who can return to their regions and villages to educate children with special education needs. The government indicated appreciation for the work of this group through an announcement in August 2009 stating that it: "will employ 200 graduates from SENTTI within the public school system to ensure children with disabilities can be included in the education system" (Laurin-Bowie, 2009, p. 107).

The activities of SEEPD, ITCIG-SENTTI, and the apparent community embrace of the education of children with disabilities, especially their inclusion in regular schools, is an indication that inclusive education is gaining grounds in Cameroon. Even though 
most of the inclusive education activities are limited to the North-West Region, there is hope and expectation that other regions of the country with existing special education facilities such as the West, Center, Littoral, and South West Regions, will follow suit.

\section{Theoretical Framework}

The theoretical concept underlying this study concurs with Fazio's 1986 theory which supports the idea that teachers' attitudes determine whether their behaviors will be positive or negative toward particular tasks required of them. Like many other theorists, Fazio (1986) supports the view that attitudes have an evaluative component. "He believed that the meaning an object has for a person is ultimately reflected in their subsequent behavior. He explained further that social stimuli could have many implications and the process of applying personal meaning to the stimuli results in a definition of the attitude object. Variables such as an individual's knowledge structures, beliefs, and expectations affect values that influence personal interpretation or perception. When such knowledge structure is lacking because of ignorance and ill-preparedness for special tasks, teachers' perceptions tend to be negative (Stubbs, 2009).

Fazio, Powell, and Williams (1989) argue that people with highly accessible attitudes toward a given product tend to display greater attitude-behavior correspondence than those with attitudes that are less accessible. This study is done on the basis that teachers' attitudes toward students with disabilities are accessible and that those attitudes are very indicative of their behavior toward students with disabilities in their classrooms. The theoretical model of the attitude to behavior relationship as explained by Fazio, 1986 is that there is a process which must occur before observing behavioral responses to attitude objects. First, the attitude must be assessed through the observation of the attitude 
object. Secondly, the activation of the attitude results in selective perception. This selective perception implies that teachers whose attitudes have been assessed as negative attitudes toward inclusion will pay attention to the weaknesses of inclusion. Thirdly, the immediate perception, which is biased by the selective perception, infiltrates the individual's definition of the attitude object, revealing that previously held thoughts toward the attitude object significantly impact the way in which a person develops their definition of the attitude object. Fourthly, the definition that the object has for an individual is clarified and impacts the direction of behavior. Therefore a study of teachers' attitudes toward students with disabilities would influence the teachers' behavior toward them as well.

According to the attitude-to-behavior relationship theory, it is clear that the activation of general education teachers' attitudes toward inclusion will expose their selective and immediate perceptions of inclusion, and eventually their potential attitudes toward inclusion in Cameroon because attitudes tend to impact behavior. Teachers who have a definition of inclusion that is largely negative or focuses on the disadvantages of inclusion will not be supportive of inclusion. On the other hand, teachers who have positive attitudes toward inclusion will be supportive of inclusion.

The application of the above theory depicts that the attitudes of general education teachers in Cameroon toward inclusion have the potential to eventually impact, through their behavior, the education of children with disabilities in the general education classroom. The professional attitudes of teachers affect not only the learning outcome of these groups of students but "may well act to facilitate or constrain the implementation of policies which may be radical or controversial, for the success of innovative and 
challenging programmes must surely depend upon the cooperation and commitment of those directly involved" (Avramidis, Bayliss, \& Burden, 2002).

Positive attitudes toward inclusion can result in changes in the curriculum and instruction through accommodations and adaptations to meet the individual needs of the diverse population of students in the general education classroom. Additionally, positive attitudes can stimulate productive collaboration between general education and special education professionals, teachers and parents. On the other hand, negative attitudes can have unfavorable outcomes for students with special education needs. General education teachers may sometimes be unwilling to teach or modify instruction to the individual needs of children with disabilities, or they may be reluctant to work with other professionals or related service providers (speech, occupational, physical therapists), or parents. When teachers have positive attitudes toward teaching students with disabilities, these perceptions lead to improvement in students' self-concept, social recognition development, increased tolerance of difference, and better interpersonal acceptance (Peck, Donaldson, \& Pezzoli, 1990; Stubbs, 2009).

\section{Attitudinal Theories}

According to research on attitudes, social psychologists have always shown a strong interest in that realm of human behavior (Eagly, 1993). They postulate that an attitude can control one's thoughts and perceptions, and can potentially become the lens through which reality is interpreted eventually influencing a person's behavior (Pallas, 2001). Research shows that attitudinal theorists have not agreed upon a universal definition of attitude. Therefore several definitions of attitude appear in the literature (Fazio, 1986). Thurston (1928) postulates that an attitude is the combination of a person's 
feelings, prejudice, biases, threats, and conviction about a topic while Eagly (1993) explains that an attitude is a tendency of state internal to an individual. Besides, Fazio (1986) submits that an attitude is an association or mental connection between an object and evaluation. It is in this later definition that an evaluative component of attitude has been identified and cited as the main element through definitions of attitude (Eagly, 1983; Fazio, 1986; Saucier, 2000; Stubbs, 2009).

Substantial improvements have been made in gleaning more information about the nature of the evaluative characteristic of attitudes (Wilson, Lindsey, \& Schooler, 2000). Developing an attitude is preempted by an evaluative process in which an individual examines and appraises an attitude object and decides whether to take a negative or positive stance toward the attitude object (Eagly, 1993; Schwarz \& Bohner, 2001, Stubbs, 2009). An attitude object is anything that a person discriminates; examples include acts of behavior, particular tasks, people, and concepts such as inclusion (Eagly, 1993). More often than not people gravitate toward either a favorable or unfavorable outlook toward the object of examination rather than go back and forth between having a negative or positive attitude toward the attitude object (Wilson et al., 2000). Inevitably, the formation of a particular attitude prompts people to act in a certain way because attitudes perform an approach-avoidance function (Wilson et al., 2000). That is, individuals tend to support and implement ideas toward which their attitude is favorable and turn away from those ideas toward which their attitude is unfavorable. Essentially, attitude guides behavior.

Contrary to the view that attitudes change behavior is the belief that intention and not attitude is the direct cause of the behavior. Fishbein and Ajzen (1980) contend that an 
individual's decision to act in a certain way toward an attitude object is the result of the impact of intention on attitudes. Their theory of reasoned action further explains that before initiating action an individual considers his/her opinion along with the views of others to determine to act in a particular way. This decision determines if a person is of the view that acting positively toward an attitude object will result in benefits, and if others perceive that it is beneficial for that person to respond positively toward attitude object, then a positive stance is taken by the individual toward the attitude object.

The successor to the Ajzen theory of reasoned action is the theory of planned positive behavior devised by Ajzen (1991). It maintains the view that an individual's intention influences or causes behavior and upholds the belief that behavior can be planned. Moreover, in planning one's behavior, a person ponders the consequences of the behavior, factors that propel or hinder the conduct, and the expectation of others. An important variable in the attitude-behavior relationship is an individual's view of how easy or difficult it is to carry out the behavior.

In opposition to the theories mentioned above is the theory of dual attitudes developed by Wilson et al. (2000). They are of the opinion that a person can have more than one attitude object. They explain that a new attitude does not simply replace an old one; rather a new attitude overpowers an old attitude. Both attitudes exist simultaneously. Therefore, there is the likelihood that teachers' attitudes toward inclusive education would constantly change depending on some evolving factors. Reform that involves the training of teachers in special education and an upgrade of working conditions, for instance, can result in teachers' attitude change toward inclusion from negative to 
positive. However, switching to the former negative attitude is possible if conditions are reversed.

Some researchers believe that attitudes are unidimensional (Wilson et al., 2000). However, Kavale and Forness (2000) explain that attitudes toward the integration of individuals with special needs have historically been multidimensional. According to Antonak and Larrivee (1995), attitudes toward people with disabilities are multidimensional and complicated. The stance taken in this research is that teachers' attitudes toward inclusion are multidimensional. Instructional leaders and policy makers' understanding of these attitudes can bring about proper planning and facilitation of activities geared toward assisting teachers in their endeavor to provide successful experiences for students with special education needs. Antonak and Larrivee (1995) designed the Opinions Relative to the Integration of Individuals with Disabilities (ORI) to examine the complex, multidimensional attitudes of teachers. These include attitude toward the concept of inclusion (special verses inclusive classrooms), attitude toward teachers' perceived ability to teach children with SEN in their general education classroom, attitude toward management of inclusive classrooms, and attitude toward outcomes or benefits for children with SEN included in their classroom. The ORI instrument was used in this research study.

\section{Definition, Scope, and Benefits of Inclusive Education}

Inclusion or inclusive education is defined and perceived in the industrialized world, including the United States, as the philosophy and practice of educating students with disabilities in general education settings (Bryant, Smith, \& Bryant, 2008; Lipsky \& Gartner, 1997; Salend, 2001). Inclusive education is the commitment to educate each 
child, to the maximum extent appropriate, in the school and classroom, he/she would otherwise attend. It requires a commitment to move essential resources to the child with a disability rather than placing the child in an isolated setting where services are located (Ajuwon, 2008; Smith, 2007).

The debate about inclusive education in Cameroon is influenced and guided more by international organizations, treaties, and conventions than by any national consciousness. Like in most other developing countries, ideas and strategies about the best way to educate children, especially those with disabilities, are influenced by external rather than internal circumstances (Ajuwon, 2008). Armstrong, Armstrong, and Spandagou (2011) underscore that in the countries of the Southern hemisphere (less developed countries), the meaning of inclusive education is situated by post-colonial social identities and policies for economic development that are often generated and financed by international organizations. They also point out that inclusion has remained highly contestable both in the Northern and Southern hemisphere as well as within and across educational systems and its implementation is problematic groups of countries.

Despite the contested nature of inclusion and the difficulty involved in defining inclusion and questions raised by the concept of inclusion, there is ever growing consensus that many benefits are derived from educating children with disabilities alongside their peers without disabilities in general education settings. Research demonstrates benefits for both students and the school community (Berry, 2006; Boling, 2007; D’Alonzo, Giordano, \& Cross, 1996). 


\section{Benefits to Students}

The level of advantages inclusive classrooms provide to students with disabilities may be disproportionately higher than the benefits to their peers without disability. Notwithstanding, most governments are embracing and promoting inclusive education because of its overall benefits to all students in particular and society in general. Ajuwon (2008) points out that there is a growing recognition that including students with disabilities in general education classrooms can provide them with the opportunity to learn in natural and stimulating settings which may also lead to increased acceptance and appreciation of differences. Wiener (2009) also argues that students with special education needs gain much confidence and sense of acceptance among others when they are partially or entirely included in the same classrooms with their non-disabled peers. Inclusive classrooms give non-disabled students the opportunity to get to know their peers with disabilities (Bigham, 2010). As a result, they can confront stereotypes they may hold by engaging in social activities with their peers and form positive friendships (Berry, 2006; Dixon 2005).

Ajuwon (2008) purports that the practice of inclusive education is based on the notion that every child should be an equally valued member of the school culture. He adds that children with disabilities benefit from learning in a regular classroom, while their peers without disabilities gain from being exposed to children with diverse characteristics, talents, and temperaments. Students with a disability are only able to benefit from inclusion if general education teachers have the competence to teach a wider range of children, including those with varying disabilities, and to collaborate and plan effectively with special educators. Children tend to learn social skills with ease when placed in environments that are relatively normal. Mitchell and Brown (1991) argue that 
children develop language more efficiently during their formative years if they associate with the students that speak normally and appropriately. The development of inclusive school culture implies building schools and communities that are physically more accessible for children and youth with disabilities and also for children without a disability who can access their environment with even more ease (Ferguson, 1996).

\section{Benefits to the School Community}

A shared sense of community exists within schools when everyone feels welcome, accepted, and integrated. Just like children that learn together, learn to live together, teachers, leaders, and every other member of the school community also develop a sense of belonging when best inclusion practices are adopted. This feeling of belonging takes place when the practice of inclusion is considered and treated as a shared goal, vision, and mission by all its members (Matthews, 1996). The School of a Caring Community website mentions several benefits of building a classroom community to special needs students, general education students, teachers, and society. Wilson et al. (2011) point to successful inclusive activities as a way to build a community in the classroom and the school—adding that a classroom community is a classroom of students, teacher(s), and others who all share in the responsibilities and rewards of being in that community. Everyone is accepted as he or she is, and differences are not ignored but embraced and used as learning tools.

Teachers have a greater chance to broaden their knowledge of students with disabilities and related services and to learn to collaborate successfully with other professionals when they operate in an inclusive setting (Vakil, Welton, Connor, \& Kline, 2008). The larger school community stands to gain when all parents, teachers, and staff 
feel a sense of belonging, and when all students experience meaningful learning outcomes. Wiener (2009) echoes the belief that real inclusion has to do with the “presence, participation, and achievement of all students" (p. 17).

\section{Best Practices of Inclusion}

Even though benefits of implementing inclusion are indefinite, there are limitations to inclusion in special education. There are two major limitations of inclusion. First, practices are not always adopted, and second, it is not a good fit for all students with disabilities — some students with severe disabilities need very special care in adapted environments. Wilson et al. (2011) emphasize that "some students' disabilities are so extensive, that being in the inclusive or collaborative setting does not work for them" (p. 1). They add that cognitive abilities may be so low, that students with severe disabilities do not gain from the whole group experience, and are entirely lost, even with assistance and support. Such students tend to need extra time and support that is not always available in the inclusive classroom (Perry, 1997).

Best practices in inclusion enable instructional leaders, teachers, and paraprofessionals to ensure reliable student placement procedures, fruitful collaboration, and the use of great pedagogical practices.

\section{Developing a Good Program of Inclusion}

An excellent program of inclusion for a school has to be part of its overall mission and vision. In addition to a clear vision and mission, the program developers need to take into consideration all the components of the investment, including investments in infrastructure, materials, and personnel. Instructional leaders have to be guided by the understanding that all students, including students with disabilities, have the right to 
expect the best learning environment—good teaching practices for "normal" students will equally be good for students with disabilities (Daniel, 1997). The goals of the program should have the following elements: the belief that all children have the potential to learn and grow, the ability to respond to the cultural and socio-economic needs of the students, the ability to be supportive of behavior in and out of the classroom, a dedication to seeing each child as a unique individual, and the modification of curriculum and activities to include all students (Wiscon Education Association Council [WEAC], 2012).

Researchers have identified a variety of best practices including the following: (a) the role of technology, (b) collaboration, (c) instruction strategies, (d) partnering with parents, (e) accommodation and adaptation, (f) building community in the classroom, and (g) classroom management (Wilson et al., 2011).

\section{Technology}

The role of technology in inclusive education is huge. Students with disabilities use a range of technological devices depending on the type and intensity of their disability. Some technology devices such as computers, augmentative communication devices, and adaptive technology devices are provided by some schools, especially in developed countries of Europe and North America. These technology devices are crucial for any teaching and learning environment. The choices made in the purchase of these appliances are as important as the appliances themselves because they have to meet the particular needs of the person with the disability, whether hearing impaired, visually impaired or another form of disability. Onsite training for teachers and students in how to use assistive technology devices is also of tremendous importance (Sisk, 2006). It is for this reason that persons involved in educating hearing-impaired students, for example, 
have to be aware of what to look for when purchasing and mastering the use of these devices (Mngo, 2007).

Technology enhances the ability of students with special education needs to keep up with everyone else in an inclusive classroom (Wilson et al., 2011). Technology will also help by making the general education classroom the LRE for the students. While student access to technology in Western countries, particularly the United States, is facilitated by federal and state government funding, students and schools in developing countries such as Cameroon, in the initial stage of inclusive education, experience acute shortages of technology supplies (Adera \& Asimeng-Boahene, 2011).

\section{Collaboration}

A successful inclusive education process requires collaborative interaction between general education teachers and special education teachers, counselors, social workers, speech/language therapists, physical and occupational therapists, nurses,

administrators, paraprofessionals, and other specialists (Smith, 2010; Wilson et al., 2011). The cooperation between special education teachers and general education teachers is essential to any inclusive education activity in school. The ability of general education teachers to accommodate special needs students is contingent on guidance from resource teachers or special education teachers who coordinate student services and IEPs for each special education student (Friend \& Bursuck, 1999).

Wagner and Muller (2011) echo that collaboration happens when as few as two people double up to accomplish an objective. The characteristics of good collaboration include voluntary participation, teamwork, parity in relationships, shared goals, shared 
responsibility in decision making, shared accountability for outcomes, shared resources, and ever growing trust and respect (Friend \& Bursuck, 1999; WEAC, 2012).

According to Smith (2007), collaboration in an inclusive education process can take many forms such as team meetings and shared teacher responsibilities, which are basic collaborative activities. Other types of cooperation often used in inclusive classroom settings are: teaming (special education teacher shares knowledge on instructional strategies, adaptations, and behavior management strategies), team teaching/co-teaching (teachers work together in teaching the whole class), parallel teaching (each teacher teaches the same material to half the class simultaneously), station teaching (educators or students rotate with different content), and alternative teaching (one teacher re-teaches a small group while the other teaches a different activity).

\section{Instructional Strategies for Inclusion}

The presence of a very diverse population of students in today's classrooms requires that teachers be aware of the uniqueness of each student to provide the best learning environment for everyone. Teachers need to learn and understand the differences in race, culture, gender, family, religions and holidays, skills and ability, and discrimination to be able to meet students' individual and collective learning needs (Salend, 2005; Wilson et al., 2011). Recent research has identified some instructional strategies to help teachers manage student diversity and uniqueness in inclusive classrooms. These strategies include differentiated instruction, universal design for learning, and response to intervention.

Differentiated Instruction (DI): Teachers in inclusive classrooms have to practice differentiated instruction (also known as multi-level instruction). Differentiated 
instruction means tailoring instruction to meet individual needs. This successful inclusive teaching method involves teachers' differentiation of content, process, product, learning environment, and the use of ongoing assessment and flexible grouping of students to meet their individual needs (Tomlinson, 2000).

According to the Wisconsin Education Association Council (as cited in Wilson et al., 2011), some of the acceptable steps involved in differentiated instruction include:

1. Identify concepts and student objectives

2. Clarify the concepts and content used to develop the concepts

3. Select a method of presentation

4. Incorporate adaptations to environment, materials, and teacher presentation

5. Consider learning styles and provide guided choices

6. Adapt student participation as needed

7. Select method of evaluation

Wilson et al. (2011) point out that a crucial aspect of differentiated instruction is that it allows each student to participate actively at his or her level and to meet individualized outcomes. It permits the teacher to offer different materials on the same topic but at different reading levels. In all, the same curriculum goals are expected of all students, but differences are taken into consideration to accommodate each student.

Universal Design for Learning (UDL): For successful inclusive education to take place teachers need to tailor the curriculum to suit the needs of all students. The curriculum can be modified by using the universal design for learning strategy. Universal Design for Learning is a theoretical framework that guides the development of curricula that are flexible and supportive of students (Dolan \& Hall, 2001; Rose, 2002; Rose, 
Sethuraman, \& Meo, 2000). The concept calls for structures designed to anticipate the needs of individuals with disabilities and accommodates these needs from the onset (Smith, 2007). The curriculum aims to be innately flexible and enriched with multiple media so that the alternatives can be assessed whenever necessary. The UDL requires adaptation:

1. To support recognition learning and provide multiple, flexible methods of presentation.

2. To support strategic learning and provide multiple flexible methods of expression and apprenticeship.

3. To support affective learning and provide multiple, flexible options for engagement.

The joint recommendation of these principles is to select goals, methods, assessments, and materials in a way that will be beneficial for all students.

Response to Intervention (RTI): Response to Intervention is a multi-tiered method of service delivery in which all students are provided appropriate levels of evidencebased instruction according to their individual needs (Barnes \& Harlacher, 2008; Dykeman, 2006). The notion of RTI is not new. What is new is the legal provision for its use as an evaluation tool. Response to Intervention allows teams comprised of education professionals the ability to make educational decisions based on the premise that all students have received adequate research-based instruction. Results of this process can be used to make eligibility decisions for students with specific learning disabilities (SLD). Response to Intervention varies among states and individual districts. However, most models of RTI include the following components: 
4. Screening: Response to Intervention involves some form of general education screening to identify students at-risk for failure, as well as the learning needs of all students.

5. Interventions: Response to Intervention includes the implementation of scientifically-based curriculum and multi-level interventions.

6. Progress Monitoring: Response to Intervention includes some form of assessment to identify the student's response to intervention

7. Data-Based Decision Making: Response to Intervention incorporates the use of data to modify the type, frequency, and intensity of interventions for students failing to respond (Berninger, 2006; Dykeman, 2006; Feifer, 2008).

Response to Intervention is criticized for lack of clear guidelines and descriptions regarding its implementation (Kavale \& Spaulding, 2008; Ofiesh, 2006). It is based on fixed principles, but how it is implemented varies among states and individual school districts. This type of flexibility creates a sense of ambiguity because there are no commonly held standards for its implementation. Varying features of RTI include the number of tiers of interventions, the roles of the teacher and psychologist, the type of interventions used (Fuchs \& Fuchs, 2006), and how data from RTI is used when determining SLD eligibility (Holdnack \& Weiss, 2006). Response to Intervention data does not provide information about why a student failed to respond to the interventions. Opponents of RTI believe that, when used alone, it does not provide sufficient data for identifying learning disabilities.

Despite these criticisms, RTI allows teams to focus on results and outcomes of interventions rather than on the process of determining eligibility. The primary purpose 
of RTI is on teaching the student, not on what the student has failed to learn. This strategy has been promoted as a process to provide services to struggling students without delays. It can, therefore, alleviate the "wait to fail" approach often associated with the achievement discrepancy model by offering early interventions to all students without the need for a special education evaluation (Dykeman, 2006).

\section{Partnership with Parents}

A good working relationship between teachers and parents, especially parents of students with significant needs, is one of the best practices of inclusive education. Educators worldwide have affirmed the importance of family involvement in children's education, pointing to a strong family-school partnership as a factor for improving both academic and behavioral outcomes for children (Callender \& Hansen, 2004). To eliminate the reluctance of some parents to expose their children to an unknown environment, parents need to be educated about inclusion and the necessity of the homeschool partnership. This effort can be accomplished by inviting parents to "observe inclusive classrooms to gain an understanding of how important inclusion is to the academic, social, and personal needs of their special needs child" (Wilson et al., 2011, p. 10). Trust can further gain grounds when teachers do home visitations to learn and share more about and with their students and their families. Parents are best positioned to tell the teacher their child's strengths, and areas of need as well as assist in getting the services a teacher needs because parents know their child better than anyone else (Wilson et al., 2011). Friend and Bursuck (1999) go even further in affirming the role of parents in school-parent partnerships by asserting that parents sometimes act as the teacher at 
home by being consistent with communication, rewards, and practicing skills at home (Friend and Bursuck, 1999).

Barnes (2009) echoes that schools only function well as professional learning communities (PLC) when effective collaboration between parents and school is standard practice. She adds that the PLC is designed to develop the collective capacity of the staff as well as the family to work together to achieve a shared purpose- - high levels of learning for all students, especially those with special needs. Constantino (2008) believes that the school gains by initiating and nurturing relationships with all families and providing tools to participate in their children's education.

\section{Curriculum Accommodation and Adaptation}

Students with disabilities that are included in the general education classroom "need to feel they are part of the class and to be challenged academically at their level" (Wilson et al., 2011, p. 10). Curriculum accommodation and adaptation can significantly impact teachers' attitude toward inclusive education (Tanyi, 2016). When students with disabilities are included in general education classes, general education teachers need to adapt the curriculum to fit their ability levels, individualized education program goals, and other requirements unique to the individual student (Voltz, 2001). For this to happen, educators need to make adjustments to the curriculum and learning activities to provide students with special needs an accommodating yet challenging learning environment. General strategies to individualize instruction for students with special needs include the varying of learning objectives, an adaptation of materials and resources, varying of teaching strategies, providing flexible time, and using technology (Kauchak \& Eggen, as cited in Wilson et al., 2011). 
Educators have identified nine types (forms or areas) of adaptations that are believed to make a difference in the learning ability of students with disabilities:

8. Size, number, or amount of work.

9. Time for learning tasks and tests.

10. The level of support: peer buddies, teaching assistants.

11. Input/Instruction: hands-on, cooperative groups, concrete examples, visual aids.

12. Difficulty: skill level, simplify directions.

13. Output/task: verbal, written, hands-on material.

14. Participation: extent and amount.

15. Alternate same material with adapted goals.

16. Substitute curriculum, differentiate instruction, and material (Wisconsin Education Association Council, as cited in Wilson et al., 2011, p. 11).

The need to make accommodations for students with physical and sensory challenges is critical in inclusive classrooms. This urge is crucial particularly the case in Cameroon where these categories of students with disabilities constitute more than $95 \%$ of students with disabilities in general education classrooms (Shey, 2003). These kinds of disabilities include hearing impairment, vision impairment, and physical disabilities. Physical disabilities may include muscular dystrophy, cerebral palsy, spinal cord injury, or impairments related to the bones, joints, or muscles. Learning tools such as large print materials, low vision devices (magnifying glasses), bright lights, closed-circuit televisions, and portable note takers have been known to assist students with sensory or physical disabilities (Friend \& Bursuck, 1999). 


\section{Building Community in the Classroom}

Another best practice of inclusion and education, in general, is the teacher's responsibility for building community in the classroom. Schools take diverse groups of students in each classroom and teach them in ways that meet their needs on every level: academic, emotional, and social (Hittie, 2000). A community is a group of people who work with one another building a sense of trust, care, and support. Therefore for classrooms to be communities, educators need to provide opportunities and structures by which students can help and support each other even as they help teachers assist them. In the classroom community, everyone is accepted, and differences are not ignored but embraced and used as learning tools (Wilson et al., 2011).

Teachers can help build a classroom community by creating a safe learning environment for all students and planning opportunities for social interaction, nurturing friendships and supportive behavior, and above all provide a positive role model. The benefits of building classroom communities are many and go beyond the classroom to society as a whole. Stainback \& Stainback (1996) indicate that beneficiaries of a caring classroom community include special needs students, general education students, teachers, and society.

\section{Classroom Management}

Classroom management is one final best practices not only for the inclusive classroom but also in the general education classroom. Even the best teachers find it a challenge handling students with individual needs and different attention spans. General education teachers need to have the ability to effectively manage inclusive classrooms to 
ensure that students with and without SEN obtain maximum educational experiences (Stubbs, 2009).

There is no single formula or model for effective classroom management considering that students come to class with a range of learning, social, and emotional needs. Classroom management is therefore not only about creating rules and discipline (Jones \& Jones, 2009). It is more specifically about creating an environment that favors learning for all students. Wilson et al. (2011) underscore that the goals of an effective management plan are to promote learning and to develop independence in students, not to control students. A good plan should demonstrate the teacher's ability to: (a) design rules and procedures to develop a stronger sense of responsibility in students, (b) integrate social skills and civic values to foster cooperation, (c) understand and apply basic categories of behavior management models, (d) use preventive and not reactive management strategies, (e) resolve conflict in a systematic manner, and (f) involve parental support of student learning and good behavior.

An implication of this study is that teachers need more knowledge about inclusion, especially information about the types of disabilities and strategies for managing children with different kinds of disabilities in their classes. Classroom management plans tend to work well when they are clear and implemented at the beginning of the school year and used consistently for students to understand what is expected of them.

\section{Factors Affecting Teachers' Attitudes Toward Inclusion}

Researchers from around the world have identified several socio-cultural, legal, professional, and demographic factors that can influence general education teachers' 
attitudes toward inclusion (Leatherman \& Niemeyer, 2005; Leyser \& Kirk, 2004). These include the following factors: support from administrators, collaboration between general and special education teachers, the severity of the disability, appropriate training, support from resource personnel, age, experience, gender, qualification, and training (Avramidis \& Norwich, 2002). This study focuses on some of the factors as seen in the instrument.

\section{Age}

Many studies have identified age as a factor influencing teachers' attitudes toward the practice of inclusion in schools, with most findings indicating that older teachers tend to have a negative attitude toward students with SEN than younger teachers. It appears that as teachers gain professional experience their attitudes toward inclusion diminish, possibly due to their self-reported limits in knowledge regarding practices to enhance outcomes for students with disabilities. There is, therefore, a need for ongoing professional learning opportunities for teachers (Hwang \& Evans, 2011). The implication of these findings is that professional development activities on inclusion for teachers must have a unique emphasis on older teachers to gain their support for inclusion.

Burge, Ouellette-Kuntz, \& Hutchinson (2008), in an Ontario study involving 680 adult participants, conclude that younger persons show more positive views toward the inclusion of students with disabilities in the general education classrooms. In some cases, however, school reform, such as the recent launch of inclusive education in Cameroon, faced more resistance from older teachers who wished to preserve the status-quo (Clarke, 1997). The resistance could stem from a lack of training to work with students who have special educational needs in the general education classroom. This study reveals that older teachers were more positive toward inclusive education. This positive mindset may 
be explained by the fact that the research is done on a pilot inclusive education program (SEEPD) and not in schools that are not implementing the reform. Another reason may also be due to in-service professional development programs, and seminars geared towards teaching students with SEN. Notwithstanding, a few studies have reported the finding that age does not influence teachers' attitudes toward inclusion (Avramidis et al., 2000).

\section{Gender}

Evidence regarding gender as a factor affecting teachers' attitudes toward inclusion is inconsistent. Avramidis and Norwich (2002) explains that while the results of some studies reveal that male teachers have more positive attitudes than female teachers, results of other studies indicate that female teachers have more positive attitudes toward inclusion. Jobe and Rust (1996) reached the conclusion that male teachers had more favorable attitudes toward inclusion (mean score 79.44) than female teachers (mean score 73.73). Their findings do not concur with those of Leyser and Tappendorf (2001) who found that female teachers had more positive attitudes toward inclusion $($ mean $=13.37)$ than male teachers (mean $=11.88)$. On the other hand, Avramidis et al. $(2000)$ found that gender was not significantly related to teachers' attitudes toward inclusion.

Ellins and Porter (2005) argue that female teachers have commonly been found to have a greater tolerance for implementing inclusive education and associate this attitude with the higher levels of sympathy and lower levels of fear reported in female teachers in other studies (Carroll, Forlin, \& Jobling, 2003). Unlike previous research findings where male teachers have recorded less tolerance for implementing inclusion (Ellins \& Porter, 2005) and lower levels of sympathy (Carroll et al., 2003), male teachers in Hong Kong 
initially reported significantly more positive attitudes and sentiments toward inclusion with higher levels of self-efficacy than did the female teachers (Forlin \& Sin 2010). The results of the study on Hong Kong teachers tie in with those of this study because male teachers were positive about inclusive education than their female colleagues

\section{Experience}

Some studies have demonstrated that teachers with more years of experience have been found to be less willing than teachers with fewer years of experience to include children with disabilities into their general education classrooms. Avramidis and Norwich (2002) conducted a review of the literature on teachers' attitudes toward inclusion to determine factors that influence their attitudes. Results of the review of studies found that teachers with more years of teaching experience were less supportive of inclusion than teachers with fewer years of teaching experience. Leyser and Tappendorf (2001) found similar results when they examined the attitudes and practices of inclusion of 91 regular and special education teachers in two small school districts in a rural county in a Midwestern state in the United States.

Taylor, Smiley, and Ramasamy (2003) also found the experience of teachers as a variable impacting teachers' attitudes (experienced and inexperienced general and special education teachers) toward inclusion when they investigated the attitudes of students enrolled in special and general education courses at a state university in Florida. They, like Moberg and Savolainen (2003), also concluded that teachers with more years of experience have a more negative attitude toward inclusion than teachers with fewer years of teaching experience. 


\section{Qualification}

Many attitudinal studies indicate that general education teachers with higher levels of education tend to be more supportive of inclusion than general education teachers with lower levels of education. An investigation by Dupoux, Hammond, Ingalls, and Wolman (2006) of the attitudes of 183 elementary and secondary teachers in urban and rural Haiti in public, Catholic, and non-denominational schools revealed that teachers with a master's degree had a more positive attitude toward integration $(M=86.43, S D=$ 15.37) than teachers who had less than a master's degree $(M=77.60, S D=12.47)$. Similarly, Moberg and Savolainen (2003) conclude that teachers with higher qualifications have a positive attitude toward inclusion than teachers with lower qualifications. This conclusion implies that incentives and provision must be made for general education teachers to pursue higher levels of education. The more they are educated, the more likely they will be exposed to training related to the teaching of students with special education needs.

\section{Training}

Inclusion is a positive step for students receiving special education services; however, the amount of training and support received by general educators to be familiar with educating students with disabilities is frequently found to be inadequate (Ambei, 2016; McNally et al., 2001; Obeng, 2007; Yuh \& Shey, 2008). General educators' poor attitudes toward full inclusion have been associated with their lack of training (Bishop and Jones, 2001). Forlin (2001) reported that $89 \%$ of general educators indicated that they were not receiving adequate training to meet the individual needs of students with disabilities included in their classrooms, and $91 \%$ of teachers reported not receiving 
training specific enough to the individual students currently included in their classrooms. Other studies have identified the lack of appropriate teacher training as a huge drawback to inclusion in schools when teachers are required to implement new practices with ongoing inadequate training and without necessary organizational resources (Forlin, 2001). Tohnain and Tamajong (2014) identify the absence of courses and programs for educating people with disabilities in teacher training colleges in Cameroon as a major drawback to the implementation of inclusive practices in regular school.

Teacher preparation programs for general education teachers in some cases briefly touch on meeting the needs of diverse learners, but rarely go in depth about how to teach students with disabilities (Bishop and Jones, 2002). Multiple training sessions and workshops for general education teachers have been known to transform the attitudes of teachers from concern and anxiety to satisfaction and embrace of their roles in inclusionary classrooms (Bishop and Jones, 2002; Burstein et al., 2004). Training exposes teachers to varying levels of student disabilities including, mild to moderate disabilities, multiple learning disabilities, and profound learning disabilities (Simmons \& Bayliss, 2007). However, basic knowledge of students with mild to moderate disabilities is more vital to general education teachers since inclusive classrooms do not have the capacity to accommodate students with severe disabilities.

The first step in preparing teachers for including students with disabilities into the general classroom is to convince them that inclusion is worthwhile (Hamre \& Oyler, 2004). The teachers must fully understand the reasons behind inclusion to support the change and additional responsibilities that come with inclusion (Burstein et al., 2004). Next, teachers need to be provided with preparation programs to familiarize them with 
the needs of students, introduce them to the support staff, and educate them regarding the laws and their personal responsibilities (Bishop and Jones, 2002). After inclusion begins, teachers need to receive ongoing training that is more specific to the students in their classes (Hamre \& Oyler, 2004). When constant support is available, the teachers feel more appreciated, more competent, and more prepared to provide quality education to all students in their classrooms. (Menlove, Hudson, \& Suter, 2001).

\section{Attitudinal Variables in the Study}

Four variables guide this study's investigation of Cameroonian general education teachers' attitudes toward the inclusion of students with disabilities in their classrooms. A good measurement of teachers' attitudes in a context such as Cameroon, where the concept of inclusion is still nascent, necessarily seeks to know their perceived a) benefits of integration, b) integrated classroom management, c) ability to teach special needs students and c) attitudes toward separate special education versus inclusive education.

\section{Outcomes/Benefits of Integration}

The goal of integrating students with disabilities into the general education classroom is to provide them with maximum academic and social experiences. Findings from studies about teachers' attitudes toward outcomes for students with disabilities have been inconsistent. While some studies reveal that general education teachers believe there are benefits for children with disabilities in the inclusive classrooms, others say that general education teachers do not believe in such benefits for children with disabilities in the general education classrooms.

D’Alonzo, Giordano, and VanLeerven (1997) conclude that there are benefits of

inclusion. The majority of teachers in the study agree that inclusion would be problematic 
but showed mixed feelings regarding the benefits of inclusion for children with disabilities. Seventy percent believe that the quality of education would also be negatively impacted. In essence, they indicate that there would not be positive learning outcomes for students with special education needs included in the general education classroom. However, most of the teachers also agree that there are social benefits to inclusion - that inclusion would eliminate labeling of children with disabilities even if problems of socialization and self-esteem persist.

Even though there is no consensus regarding the academic achievements of students with special educational needs in inclusive settings (Daane, Beirne-Smith, \& Latham, 2000; Monahan, Marino, Miller, \& Cronic, 1997; Snyder, Garriott, \& Williams Aylor, 2001), there is vast agreement on its moral and social benefits to special needs students, non-special needs students, and society as a whole (Knight, 1999; Osgood; 2005; Perry, 1997).While some research report that there is evidence of general education teachers' feelings that children with disabilities will not improve or perform better in the general education classroom, others report that there are benefits for children with disabilities in general education.

\section{Integrated Classroom Management}

Research on inclusion has shown that general education teachers do not only need but express the need to acquire the ability to effectively manage inclusive classrooms to ensure that students with and without SEN obtain maximum educational experiences (Stubbs, 2009; Wilson et al., 2011). Meeting the diverse needs of students in inclusive classrooms involves effectively using time and having the ability to keep order in the general education classroom. 
A few studies on teacher attitudes indicate that general education teachers do not perceive themselves as having the capacity to manage inclusive classrooms. In a study by Forlin (2001), he finds out that $96 \%$ of teachers indicate that it would be difficult to monitor or manage other students while working with a student with special needs. The diminished amount of time to work with the other students as a result of having a student with a special need in their classroom is viewed as a stressful issue for them. The study shows that general education teachers have many concerns about the integration of children with disabilities which impacts their ability to manage to inclusive classrooms.

In a similar study, Snyder et al. (2001) most teachers (64\%) express the feeling that teaching in an inclusive environment was more challenging. The teachers cited difficulties related to management such as time, increased paperwork, burnout, academic and behavioral problems brought into the general education classroom by children with emotional disabilities, and the fear that children with emotional disabilities would cause children without special needs to misbehave. On the whole, teachers feel that the problems caused by students with disabilities negatively impact learning for students without disabilities in the general education classroom. Teachers in this study express frustration with the inability of students with special education needs to keep up with their work and complete their assignments despite their efforts to facilitate learning for all students.

According to Daane et al. (2000), teachers feel that more management problems are inevitable once children with special education needs are included in their classrooms. Additionally, teachers express the feeling that inclusion increases the instructional load of the general education teacher. Other studies have also indicated 
teachers' concerns related to the management of inclusive classrooms. Teachers point out that disruptive children and children with emotional and behavioral problems would require a significant amount of the teachers' time and attention which is not always available (Leonardi, 2001). Moreover, teachers have also conveyed feelings that inclusion would not be successfully implemented if children with emotional and behavioral problems are included in the general education classroom because it would be unfair to students without disabilities and negatively impacts learning (Daane et al. 2000, Leonardi, 2001). On the other hand, few studies indicate that teachers believe in the benefits of inclusion for children with special needs in general education —-they agree that children with special needs would achieve more academically and socially in the general education classroom (Idol, 2006; Monahan et al., 1997; Osgood, 2006; Wilson et., 2011). Despite teachers' fears regarding the magnitude of work in inclusive classrooms and their ability to manage such classrooms, inclusive education has come to stay. It is supported by most governments and international organizations concerned about human rights (UNESCO, 1994). There is also consensus that management is critical to successful inclusionary experiences for students with disabilities and the general education teacher. The management of inclusive classrooms is important for both the general education teacher and the special education teacher. Successful inclusion will not exist if teachers are not positive about their ability to manage inclusive classrooms.

Based on past literature concerning this subject, an implication of this study is that teachers need more knowledge on inclusion, precisely information about the types of disabilities and strategies for managing children with different kinds of disabilities in their classrooms. It is apparent that management is critical to successful inclusionary 
experiences for students with disabilities and the general education teacher. If teachers acquire knowledge through training on how to manage inclusive classrooms, there is a tendency that management issues will obviously be minimized in the general education classroom (Guner, 2012, \& Secer, 2010).

Inclusion and Teacher Perceptions of Their

Teaching Ability

Teachers' perceived ability to handle inclusive classrooms come through when they express both their understanding of the concept of inclusion and their previous training or lack thereof in the area of special education. This perceived ability falls within the domain of metacognition which has to do with the capacity to know about knowing or a self-evaluation of one's knowledge of something.

Teachers' perceived ability to teach is associated with their sense of self-efficacy. Self-efficacy, one of the major characteristics linked to teacher behavior is the teachers' attitude (Bandura 1977, 1989). Bandura gives prominence to the concept of self-efficacy in his social learning theory. Perceived self-efficacy is defined as people's beliefs about their capacities to produce designated levels of performance that exercise influence over events that affect their lives. Self-efficacy beliefs determine how people feel, think, motivate themselves and behave. Such beliefs produce these diverse effects through four major processes. They include cognitive, motivational, affective and selection processes. The general education teacher's feelings about his/her abilities to teach students with disabilities can be a source of motivation as well as a source of discouragement. General education teachers who are not trained to handle inclusive classrooms are likely going to have lower expectations for their teaching than those with some form of training (Avramidis \& Kalyva, 2007; Leatherman \& Niemeyer 2005). 
Training and experience give knowledge to the general education teachers which in turn influence their perceived ability (or sense of self-efficacy) to teach students with special needs (Ambei, 2016). Knowledge about inclusive practices is vital and comes from various sources such as revelation, our minds, intuition, authority, or reason; however, all of these sources complement each other to aid humans in their knowing. Knowledge is the cognitive outcome of education and consists of concepts, theories, empirical results, and other information that is acquired from the educational experience (Ernest, 1989). Knowledge requires general or group consensus to ensure validity and appropriateness and is open to evaluation and critical examination (Nespor, 1987). Knowledge is based on what can be verified empirically, thus judged as true or false (Knight, 1997). Pajares (1992) stated: "Knowledge is based on objective fact" (p. 313). Based on these definitions, knowledge is true evidence that derives from various sources, can be judged as true or false, and requires consensus to ensure validity and appropriateness. General education teachers' perceived ability to teach students with special needs reveal their knowledge of inclusive education and gives the researcher the possibility to evaluate the knowledge and possible reasons for the knowledge or lack thereof (Ambei, 2016).

\section{Perceptions of the Concept of Inclusion}

Teachers' perceptions of integrated schools sometimes come from the lack of knowledge on how such schools work. Both ongoing training and teacher education programs would help teachers and would-be teachers develop positive attitudes, and maybe change their attitudes toward integrated classrooms and schools. To improve teachers' attitudes toward disabilities in general educational institutions, there is the need 
for introductory courses in teacher training programs, emphasis on the special education element in college, teacher training schools, and professional development programs for in-service teachers.

The inclusive classroom is a worldwide phenomenon and has been one of the major topics in education that has gained traction during the past two decades (Rudd, 2002; Smietana, 2001). Recently, however, teachers' attitudes toward inclusion of students with disabilities in the general education classroom have become the focus of extensive research (Bradley, 2009; Cramer, 2014; Cagney, 2009; Greene, 2007; Stubbs, 2008; Talmor, Reiter \& Freigin, 2005). With the implementation of inclusion, education of children with disabilities has shifted from segregated special schools to the inclusion of all students with mild to moderate disabilities into the general classroom (Parasuram, 2006). Classrooms are becoming more of a melting pot, containing students with diverse abilities and disabilities. However, some education stakeholders, including teachers, still prefer non-inclusive schools. Despite efforts by educators to ensure successful inclusion of all students in general education, research shows general education teachers still hold negative beliefs toward the academic and social benefits of including students with disabilities in the general classroom (Peetsma, 2001; Stainback \& Stainback, 1991; Voltz, Brazil \& Ford, 2001).

According to Parasuram (2006), a teacher's attitude affects the educator's daily interactions with students, and the teacher's knowledge, beliefs, concerns, and philosophy regarding inclusion plays a major role in predicting the outcomes of inclusion. Considering the influence that teachers have on the academic success of students with disabilities and the success of inclusive classrooms, it is necessary to study teacher 
attitudes toward including students in the general education classrooms. This study is vital because teachers' perceptions of inclusive education are essential if we are to anticipate possible difficulties of implementation which will in turn guide, help, and prepare for successful inclusive practices. For that reason, this study is interested in investigating the attitudes and perceptions of the general education teachers as their roles are likely to influence the quality of integration in schools. General education teachers' attitudes are vital to successful inclusion because they are the main implementers of the policy of inclusion. These teachers are directly involved with the students, and their attitudes and knowledge of the concept of inclusion determine if students with disabilities in grade level appropriate classes can be educated alongside their peers without disabilities in the general education classroom. They are also better placed to determine if this type of learning is beneficial to all students participating in an inclusive setting (Bradley, 2009; Stubbs, 2008).

As long as general education teachers are not receiving the education and support necessary to change their attitudes toward inclusion, this practice cannot be successful for students with and without disabilities (Burke \& Suthermand, 2004). It is, therefore, necessary that general education teachers receive appropriate training and support programs before teaching in inclusive classrooms. It is important to know how current general education teachers perceive inclusion to ensure effective implementation of inclusive practices. This knowledge is needed in the conception and development of teacher training programs and sensitization programs. Knowledge of general education teachers' attitudes toward inclusion provides information necessary to design academic and professional learning programs. 


\section{Summary of Chapter Two}

This chapter has reviewed literature related to special education and inclusive education, including theories and factors that influence teachers' attitudes toward the practice of inclusion. Particular attention is paid to the budding practice of inclusion in Cameroon and the issues that have plagued the initiative since the country's landmark 1983 legislation protecting individuals with disabilities and promoting inclusion at all levels of society (Biya, 1984). Considering that the study seeks to evaluate inclusive pioneer programs in general secondary schools, a review of best inclusive practices is done. These best practices provide the barometer with which teachers' attitudes toward the inclusion of students with disabilities in the regular school classrooms are measured. 


\section{CHAPTER 3}

\section{METHODOLOGY}

\section{Introduction}

The purpose of this quantitative descriptive non-experimental study was to examine the attitudes of general education secondary school teachers in grades six through twelve in seven public secondary schools engaged in a pilot inclusive education program in the North-West Region of Cameroon. The study sought to examine if there was a relationship between teachers' characteristics (gender, age, the level of education, years of teaching experience, experience teaching in inclusive classrooms, training, and teachers' language of instruction) and the attitudes they held toward inclusive education. The teachers included in this study all possess the following characteristics: full-time employee, currently teaching, certified or has a degree and teaches a class between levels six through 12 (form one - upper sixth).

This chapter describes the research design, population and sample, instrumentation, variables, procedure, and data collection and analysis

\section{Type of Study}

The purpose of this quantitative descriptive study was to investigate attitudes. Opinions Relative to the Integration of Students with Disabilities instrument developed by Antonak and Larrivee (1995) was used to collect data. This questionnaire, consisting of twenty-five questions, was used to answer research questions about general educators' 
attitudes toward the concept of inclusion, perceived ability to teach children with disabilities in the general education classroom, perception toward managing inclusive classrooms, and perceived benefits/outcomes for students with disabilities. The demographic questionnaire was used to gather data about factors known to affect general education teachers' attitudes toward inclusion.

The researcher employed a quantitative descriptive research design for the study because it has been used in several studies examining teachers' attitudes toward inclusion (Burke \& Sutherland, 2003; Dupoux, Hammond, Ingalls, \& Wolman, 2006; Hammond \& Ingalls, 2003; Jobe \& Rust, 1996). The quantitative descriptive research design was also preferred because it permitted the researcher to sample a broad range of opinions from teachers of different types of educational institutions engaged in inclusion. This design allowed for an objective scoring of data and the statistics could be used to make inferences from the sample population about secondary education teachers in Cameroon (Galvan, 2004). By giving the respondents the freedom to reflect and choose their responses without the influence of the researcher's physical presence, the responses resulting from analyses were expected to be more reliable than responses obtained through interviews (Patten, 2004).

\section{Population}

Two main types of secondary schools exist in Cameroon, namely, public and private schools. This study will not include private schools because SEEPD 14-school inclusive education pilot project, which was the source of data for the study, involves only public bilingual schools. The target population for this study consisted of full-time public bilingual secondary school teachers from grade six through twelve. Teachers from 
the seven secondary schools involved in the SEEPD project were surveyed. Teachers from the seven primary or elementary schools (grades 1 to 5) involved in the project were not considered in the study.

\section{Sample}

A convenience sample of about 500 full-time teachers was drawn from a population of about 1200 teachers (Ministry of National Education [MINEDUC], 2005). The study sample was made of teachers from the seven bilingual public schools involved in the SEEPD pilot program in the NorthWest Region of Cameroon. The schools were: Government Bilingual High School (GBHS) Bamenda, GBHS Kumbo, GBHS Wum, GBHS Fundung, GBHS Ndop, GBHS Ndu, and GBHS Mbengwi. All full-time teachers from the seven schools constituted the sample because of the limited number of full-time teachers employed by the schools (Miffih, 2011a). To minimize the risk of having a biased sample (Bryman \& Cramer, 1990; Fowler, 2002), the representativeness of the data was enhanced by including teachers of the two systems of education (Francophone/Anglophone). It is worth noting that all the SEEPD schools included in the program were bilingual which eliminated bias.

\section{Hypothesis}

\section{Null Hypothesis}

Hypothesis 1.Female teachers are likely not to have a more favorable perception of inclusive education than their male counterparts

Hypothesis 2.Younger instructors are likely not to have a more favorable perception of inclusive education than their older colleagues 
Hypothesis 3.Teachers with a higher level of education will not have a more favorable perception of inclusion than their colleagues with a lower level of education Hypothesis 4.Less experienced teachers are not likely to be more favorable of inclusive education than more experienced teachers.

Hypothesis 5.Teachers who have experience teaching in inclusive classrooms are not likely to be more favorable of inclusive education than their colleagues without such experience.

Hypothesis 6.Teachers who have received training in teaching students with special needs will not likely have a favorable attitude toward inclusive education.

Hypothesis 7.Teachers who use French as the language of instruction are not likely to have a less favorable attitude toward inclusive education than teachers who use English or both languages (bilingual teachers).

\section{Research Hypothesis}

The following research hypotheses are formulated to help answer question 2 :

Hypothesis 1: Female teachers are likely to have a more favorable perception of inclusive education than their male counterparts.

Hypothesis 2: Younger instructors are likely to have a more favorable perception of inclusive education than their older colleagues.

Hypothesis 3: Teachers with a higher level of education will have a more favorable perception than their colleagues with a lower level of education.

Hypothesis 4: Less experienced teachers are likely to be more favorable of inclusive education than more experienced teachers. 
Hypothesis 5: Teachers who have experience teaching in inclusive classrooms are likely to be more favorable of inclusive education than their colleagues without such experience.

Hypothesis 6: Teachers who have received training in teaching students with special needs will likely have a favorable attitude toward inclusive education.

Hypothesis 7: Teachers who use French as the language of instruction are likely to have a less favorable attitude toward inclusive education than teachers who use English or both languages (bilingual).

\section{Variables Definition}

Overall Teachers' Attitudes: The purpose of the study was to investigate attitudes held by general education teachers toward students with disabilities in a pilot inclusive education program in the North West Region of Cameroon. In accordance with the developers of the instrument, overall teachers' attitudes toward inclusion was determined using twelve negatively worded items $(2,4,6,8,9,11,12,14,18,20,23,24)$ and thirteen positively worded items $(1,3,5,7,10,13,15,16,17,19,21,22,25)$.

The range of the scores on the ORI is 0 to 150 . A higher score as opposed to a lower one on the ORI represents a more favorable attitude toward the inclusion of students with special needs in the general education classroom. Surveys with five or more items omitted were not scored.

Attitudes toward Benefits/Outcomes of Integration: This factor measured teachers' perceptions of the benefits or lack thereof of inclusive classrooms and schools to both students with disabilities and general education students taught in the integrated classroom. 
Items $3,7,11,14,17,20,21$, and 24 related to the factor, Benefits/Outcomes of Integration, were used to ascertain general education teachers' attitudes toward the outcomes for children with disabilities in the general education classroom (Table 1). The factor (Outcomes/Benefits of Integration) was made of four positively worded items and four negatively worded items. Positively-scored item responses were summed to determine a score for this factor. The scores can range from zero to forty-eight.

Attitudes toward Integrated Classroom Management: This variable measures teachers' ability to manage inclusive classrooms - classrooms containing both regular students and students with special needs. It is the teachers' ability to use time efficiently and to keep order in the general education classroom.

Items $1,4,6,9,12,15,16,18,22$, and 25 related to the variable Classroom Management, were used to determine general education teachers' attitudes toward the management of children with disabilities in the general education classroom. This factor (Classroom Management) comprised five positively worded items and five negatively worded items. Positively-scored item responses were summed up to obtain a score for this factor. The scores can range from zero to sixty.

Attitudes toward Perceived Ability to Teach: This variable measured teachers' perception of their capability to teach students with disabilities - appropriate skills and strategies. Their choice of responses on items measuring a variable demonstrates their sense of self-efficacy associated with the task of teaching students with disabilities.

Items 2, 10, and 19 were used to find out general education teachers' attitudes toward their perceived ability to teach children with special needs in the general education classroom. The factor was made of two positively worded items and one 
Table 1

Description of Research Variables and Survey Items on the ORI

Research Variable

Attitudes Toward Benefit/Outcomes of Integration

Attitudes Toward Integrated Classroom Management

Attitudes Toward Perceived Ability to Teach Children with Special Needs

Attitudes Toward Concept of Inclusion
Survey Items

$3,7,11,14,17,20,21$,

24

$1,4,6,9,12,15,16,18$ 22,25

$2,10,19$

$5,8,13,23$

negatively worded item. Positively-scored item responses were summed to determine a score for this factor. The range of scores for this variable is zero to eighteen.

Attitudes toward the concept of inclusion (Separate Special Education versus Inclusive Education): This factor/variable measured teachers' preference between inclusive and non-inclusive schools.

Items $5,8,13$, and 23 were used to determine general education teachers' attitudes toward the concept of inclusion. The factor was made of two positively worded items and two negatively worded items. Positively-scored item responses were summed to obtain a score for this factor. The range of scores is zero to twenty-four.

\section{Definition of Demographic Variables}

The data collected applied to 7 demographic variables, namely gender, age, the level of education, years of teaching experience, experience teaching in inclusive classrooms, training in teaching students with special needs in the general education classroom, and teacher's language of instruction. 
Gender: Overall scores on the ORI of all female participants were compared to the overall scores of all male participants to determine which group had more favorable attitudes toward inclusion. Factor scores for females were compared to factor scores of males to determine which group had more favorable attitudes toward each factor (Concept of Inclusion, Perceived Ability to Teach Children with Disabilities, Integrated Classroom Management, and Benefits of Integration).

Age: The overall scores on the ORI scores of older participants (e.g. 45 years and older) were compared to the overall score on the ORI of younger participants (e.g. 44 years and younger). The scores of younger teachers for each factor (factor one through four) were compared to factor scores of older teachers. These continuous variables were compared to determine if younger teachers had a more favorable attitude toward inclusion than older teachers. The results were also used to determine if younger teachers had more favorable attitudes toward each factor on the ORI than older teachers.

The level of Education: The overall scores of respondents on the ORI with higher level degrees (e.g. Master's Degree) were compared to the overall scores of respondents with lower level degrees (e.g. Bachelor's Degree). Also, factor scores for participants with higher level degrees were compared with factor scores of participants with lower degrees. Overall scores and factor scores were then compared to determine if respondents with a higher degree had more favorable attitudes toward inclusion than respondents with a lower level degree. The results were used to determine if respondents with a higher degree had a more favorable attitude toward each factor than respondents with a lower degree. 
Years of Teaching Experience: The overall scores and factor scores of teachers with more years (e.g. 20 years) of teaching experience were compared to the overall scores and factor scores of teachers with few years (6 years) of teaching experience to determine if teachers with more years of teaching experience had more favorable attitudes toward inclusion. Factor scores were compared to determine if teachers with more years of teaching experience had more favorable attitudes toward each factor than teachers with few years of teaching experience.

Experience Teaching Children with Special Needs: The overall ORI scores and factor scores of teachers who had experience teaching children with special needs in the general education classroom were compared to the overall ORI scores and factor scores of teachers with no or little experience teaching children with special needs in the general education classroom. The comparison of ORI scores and factor scores helped to determine if teachers with experience teaching children in the general education classroom had more favorable attitudes toward inclusion on each factor than teachers who did not have the experience to teach children with special needs in the general education classroom.

Training for Teaching Children with Special Needs: The overall scores and factor scores on the ORI, for teachers who did not have training teaching children with special needs in the general education classroom, were compared to the overall scores and factor scores on the ORI for teachers who did not have training to teach children with special needs in the general education classroom. These scores were assessed to determine if teachers who did not have the training to teach children with special needs in the general education classroom had more favorable attitudes toward inclusion. Factor scores were 
compared to decide if teachers who had the training to teach children with special needs in the general education classroom had more favorable attitudes toward each factor than teachers who did not have the training to teach children with special needs in the general education classroom.

The language of Instruction: Overall scores on the ORI of all teachers were grouped according to the language of instruction they use, and the groups' overall scores were compared with each other to determine if teachers' language of instruction influenced their perceptions toward inclusion. Teachers in the bilingual schools participating in the study used either English, French or both languages to teach.

\section{Instrument}

An investigation into the existing literature on the research topic was done to determine the instruments that measured the attitudes of general education teachers toward inclusion. After much consideration, the instrument titled "The Opinions Relative to the Integration of Students with Disabilities" developed by Antonak and Larrivee (1995) is chosen. This instrument is a revised and upgraded version of the Opinions Relative to Mainstreaming Scale created by Larrivee and Cook (1979). This earlier version of the instrument was used to investigate teachers' attitudes toward mainstreaming students with disabilities into general education classrooms. Opinions Relative to the Integration of Students with Disabilities is a 25-item instrument with six possible responses ranging from (-3) I disagree very much to (+3) I agree very much.

\section{Description of the Instrument}

The ORI was used to measure general education teachers' attitudes toward the inclusion of students with disabilities in the general education schools in the North-West 
Region of Cameroon. The questionnaire is made of two sections. The first section consists of 25 items and the second section comprises seven demographic questions on their gender, age, the level of education, years of teaching experience, experience teaching in inclusive classrooms, training in teaching students with special needs in the general education classroom, and teacher's language of instruction.

The first section of the instrument has questions that require the participants to indicate their level of agreement or disagreement to the items on the 6-point Likert-type scale. Respondents were asked to choose from the following options: 1 (strongly disagree), 2 (disagree), 3 (not sure but tend to disagree), 4 (not sure but tend to agree), 5 (agree) and 6 (strongly agree).

\section{Validity and Reliability of the Instrument}

The need for a valid instrument is crucial because it measures what it says is being measured (Blunch, 2008). The ORI is chosen for this study after careful consideration of the purpose and the context of the study, including the history of special education and issues linked to the practice of inclusion.

The ORI is one of the most tested instruments in research related to teachers' attitudes toward the inclusion of special needs students in the general education classrooms (Avramidis et al., 2000; Cramer, 2014; Dupoux, Hammond, Ingalls, \& Wolman, 2006; Jobe \& Rust, 1996; Stubbs, 2009). The creators of the instrument, Antonak and Larrivee (1995), tested the validity of the instrument using a hierarchical multiple regression analysis with variables such as age, sex, education, profession and relationship. Results indicated that the split-half reliability was 0.87 and the Cronbach's coefficient alpha homogeneity alpha was 0.83 . Antonak \& Larrivee (1995) have also 
argued for the use of psychometrically sound 6-point Likert scale instruments, pointing to its efficacy in measuring teachers' complex and multidimensional attitudes.

\section{Data Collection}

The study used a quantitative non-experimental survey design. In order to carry out the study, permission was first obtained from the government of Cameroon through the Regional Delegate of Education for the North-West Region of Cameroon. This was followed by authorization from the Andrews University's Institutional Review Board (IRB).

It was necessary to obtain a letter of the Regional Delegate of Education in charge of all public schools in the region to avoid the tedious and inconvenient task of obtaining multiple authorizations from the principals of all the seven schools taking part in the study. The Regional Delegate of Education would be considered, in other words, as the Superintendent of public schools in the region.

When the Delegate of Education returned the signed letter of approval to conduct the study, it was submitted to the Andrews University IRB office with a completed research protocol and the instrument to be used in the study. The package sent to the IRB also contained a letter addressed to the participants, informed consent, and instructions for completing the survey.

After securing the IRB approval for the study, 600 scannable copies of the survey were made and mailed to the researcher's representative, together with a copy of the cover letter (introduction letter from the researcher written to the seven schools with a full description of the benefits of the study to the schools and the participants) and a copy of the authorization letter. The researcher's representative collected the survey forms, 
contacted the principals, and worked closely with their schedules and executed the collection of data.

The principals and the researcher's representative agreed to administer the survey on faculty professional development days. This was considered the most appropriate day for administration of the survey because it was the one day the most teachers would be available. The researcher's representative contacted some of the teachers that could not be reached during the professional development days.

In order to ensure that the confidentiality or anonymity clause was respected, the researchers' representative was a teacher from the non-participating schools. At no time in the data collection process were respondents asked to provide their name or other forms of identification that tied them to their responses on the questionnaire. A thank you letter from the researcher was also submitted to the principals of each of the schools at the end of the data collection process.

During the data collection process, the researcher's representative was available to explain and clarify details whenever needed. The survey had two versions (English/French). The original version, which is English, was administered to Englishspeaking teachers and the translated French version was administered to French-speaking teachers. The French version was translated by a professional translator in Cameroon and proofread by two readers with sound knowledge in both English and French and the subject under study.

Upon completion of the survey, each teacher sealed the completed survey form in the same envelope that contained the uncompleted survey form and the researchers' representative collected them. At the end of the data collection, my representative 
combined all the packages and mailed them to me in Berrien Springs, Michigan through DHL mail service delivery.

\section{Analysis of the Data}

The data gathered from the survey was entered in the Statistical Package for Social Sciences program and analyzed by use of descriptive statistics - means scores, standard deviations, frequencies, and crosstabs. After scanning the questionnaires, the numbers checked by respondents for the positively phrased statements were maintained exactly as checked, but the negatively phrased statements were reversed as follows: $(1=6$, $2=5,3=4,4=3,5=2$, and $6=1$ ). Data from each subgroup (factor) was averaged to determine the teachers' attitudes of the reform about the group. An average score of 3.5 was considered a neutral attitude toward the statement. An average score below 3.5 was considered a negative attitude toward the statement, and an average score of above 3.5 was considered a positive attitude toward the statement. Surveys with five or more items omitted were not scored.

The association between the demographic variables and the dependent perception variables (the concept of inclusion, their perceived ability to teach students with special needs in the general education classroom, the management of students with special education needs in the general education classroom, and the outcomes for students with special needs in the general education classroom) were analyzed with the One-Way Multivariate Analysis of Variance; MANOVA and ANOVA to test the differences between teachers' gender, age, level of education, years of teaching experience, experience teaching in inclusive classrooms, training in teaching students with disabilities in the general education classroom, and teacher's language of instruction. 
These analyses helped to answer the following questions posed in the study:

\section{Data Analysis of Research Question 1}

What are the attitudes of general education teachers toward inclusion in

Cameroon, with regard to (a) benefits of integration, (b) concept of integration, (c)

integrated classroom management, and (d) perceptions of their ability to teach special needs students?

The average mean score, standard deviation, and the range of scores on the ORI, representing teachers' overall perceptions of inclusion were calculated. Frequency distributions were generated for survey items about each of the following four research variables:

1. The benefits/outcomes of integration (items 3, 7, 11, 14, 17, 20, 21, 24);

2. The concept of inclusion (items 5, 8, 13, 23);

3. Integrated classroom management (items 1, 4, 6, 9, 12, 15, 16, 18, 22, 25);

4. Perceptions of their ability to teach students with special needs (items 2, 10 , $19)$;

Means were calculated to determine the average for each item in each variable, and standard deviations calculated to determine the spread of scores around the mean. The highest possible overall score on the ORI was 150. An overall score above 75 was interpreted as having a positive attitude toward inclusion while an overall score below 75 was interpreted to be a negative attitude toward inclusion. An overall score of exactly 75 was construed as a neutral attitude toward inclusion. 


\section{Data Analysis of Research Question 2}

Do differences exist in teachers' perceptions, on the basis of their (a) gender, (b) age, (c) level of education, (d) years of teaching experience, (e) experience teaching in inclusive classrooms, (f) training in teaching students with special needs in the general education classroom, and ( $\mathrm{g}$ ) teacher's language of instruction?

Research Question 2 dealt with the demographic variables of the study. In order to answer the question, a MANOVA was used to test the differences in teachers' attitudes toward inclusion on the basis of their gender, age, level of education, years of teaching experience, experience teaching in inclusive classrooms, training in teaching students with special needs in the general education classroom, and teacher's language of instruction.

Seven hypotheses, one for each demographic variable, was tested using MANOVA. One-Way Multivariate Analysis of Variance results that are significant for each independent variable were followed up by One Way Univariate Analysis of Variance (ANOVA) and posthoc multiple comparison tests to determine the extent of the differences in group perceptions with regard to teachers' attitudes about (a) the concept of inclusion, (b) ability to teach, (c) classroom management and (d) outcomes of inclusion. Twenty-eight follow-up hypotheses were tested, one for each of the four dependent variables (factors) per demographic variable, using Univariate ANOVAs with a Bonferroni alpha correction to account for the multiple ANOVAs. The ANOVA was tested at the .05 level (.05 divided by four ANOVAs conducted) to control for Type I error across multiple ANOVAs (Green \& Salkind, 2008). 


\section{Summary of Chapter Three}

The purpose of this study was to investigate attitudes held by general education teachers' attitude toward students with disabilities in a pilot inclusive education program in the North-West Region of Cameroon. The ORI, developed by Richard Antonak and Barbara Larrivee in 1995 consists of twenty-five questions used to evaluate the attitudes of three hundred and forty-six general education teachers. Four factors on the ORI (the concept of inclusion, ability to teach children in inclusive classes, management of inclusive classrooms and the outcomes/benefits for children with disabilities) were used to determine teachers' perceptions about including students with disabilities in their classrooms. 


\section{CHAPTER 4}

\section{DATA ANALYSIS AND RESULTS}

The purpose of this study was to investigate attitudes held by general education teachers toward students with disabilities in a pilot inclusive education program in the North-West Region of Cameroon. The study sampled teachers' attitudes using the instrument titled "Opinions Relative to the Integration of Students with Disabilities (ORI)," developed by Richard F. Antonak and Barbara Larrivee (1995). Also, the study sought to discover if there were any differences between teachers' gender, age, the level of education, the number of years of teaching experience, experience in teaching students with special needs, training on special education, the language of instruction, and their attitudes toward teaching students with disabilities.

This chapter presents the results of the data analysis in four sections, namely (a) description of the population and sample, (b) demographic description of the sample, (c) research questions and statistical analyses, and (d) summary of findings. The hypotheses related to the research questions are tested using Multivariate Analysis of Variance, Univariate Analysis of Variance, and Post Hoc Tests (Ryan-Einot-Gabriel-Welsch Range).

\section{Description of Sample and Response Rate}

The convenience sample of full-time, grade 6 through 12, teachers came from seven public bilingual schools involved in the SEEPD inclusive education pilot project, 
in the North-West Region of Cameroon. A total of 400 surveys were administered to willing participants, and 348 were returned, indicating a response rate of $87 \%$. Of the 348 returned surveys, two were not included because they had 2 or more omitted responses.

The study population, comprised of teachers at schools included in SEEPD inclusive pilot education program, was bilingual. To minimize the risk of having a biased sample (Bryman \& Cramer, 1990; Fowler, 2002), teachers were representative of the two systems (Francophone and Anglophone) of the education in Cameroon. Two versions of the survey, French, and English, were distributed. Table 2 presents the number of surveys distributed per school, the number returned, and the response rate.

Table 2

Survey Participation and Response Rate by Schools

\begin{tabular}{|c|c|c|c|c|}
\hline Participating Institution & $\begin{array}{c}\text { Surveys } \\
\text { Distributed }\end{array}$ & $\begin{array}{l}\text { Surveys } \\
\text { Returned }\end{array}$ & $\begin{array}{l}\text { Surveys } \\
\text { Used }\end{array}$ & $\begin{array}{c}\text { Percentage } \\
\text { Response Rate }\end{array}$ \\
\hline $\begin{array}{l}\text { 1. Government Bilingual High School } \\
\text { Bamenda }\end{array}$ & 50 & 46 & 45 & 92.00 \\
\hline $\begin{array}{l}\text { 2. Government Bilingual High School } \\
\text { Funding }\end{array}$ & 54 & 50 & 50 & 92.50 \\
\hline $\begin{array}{l}\text { 3. Government Bilingual High School } \\
\text { Kumbo }\end{array}$ & 48 & 48 & 48 & 100.00 \\
\hline $\begin{array}{l}\text { 4. Government Bilingual High School } \\
\text { Mbengwi }\end{array}$ & 61 & 51 & 51 & 83.60 \\
\hline $\begin{array}{l}\text { 5. Government Bilingual High School } \\
\text { Ndop }\end{array}$ & 64 & 52 & 52 & 81.30 \\
\hline $\begin{array}{l}\text { 6. Government Bilingual High School } \\
\text { Ndu }\end{array}$ & 56 & 49 & 49 & 87.50 \\
\hline $\begin{array}{l}\text { 7. Government Bilingual High School } \\
\text { Wum }\end{array}$ & 67 & 52 & 51 & 77.60 \\
\hline Total & 400 & 348 & 346 & 87.75 \\
\hline
\end{tabular}

Note. Surveys with 1 or more items omitted were eliminated 


\section{Participants and Variables Description}

The demographic information solicited from the respondents included gender, age, the level of education, years of teaching experience, experience teaching in inclusive classrooms, training, and attitudes toward inclusive education.

A total number of 346 full-time state licensed teachers from seven government bilingual high schools took part in the survey. Of the total number of respondents, there were 182 males (52.6\%) and 164 females (47.4\%). About $68 \%$ of the surveys were completed by participants between the ages of 30 and 44 years. Results for age groups were as follows: 8 teachers $(2.3 \%)$ were aged 20 to 24 years old, $55(15.9 \%)$ were aged 25 to $29,78(22.5 \%)$ were aged 30 to $34,88(25.4 \%)$ were aged 38 to 39,71 (20.5) were aged 40 to 44 , and $46(13.3 \%)$ were aged 45 years old and above.

Regarding the participants' level of education, 212 (61.3\%) teachers said they had a Bachelor's degree in teaching while $126(36.4 \%)$ had a Master's in teaching. Only eight teachers $(2.3 \%)$ had an academic Master's degree.

More than half the teachers $(52.3 \%)$ had six to 15 years of teaching experience. Eighty (23.1\%) teachers had five years or less of teaching experience, $116(33.5 \%)$ had six to $10,65(18.8 \%)$ had 11 to 15 years of experience. Then $43(12.4 \%)$ had 16 to 20 years, $20(5.8 \%)$ had 21 to $25,16(4.6 \%)$ had $26-30$, and only $6(1.7 \%)$ had 31 years or more of professional experience.

Regarding the specific experience of teaching children with special education needs (disabilities), 185 teachers $(53.5 \%)$ said they had experience teaching students with special education needs and $161(46.5 \%)$ had no experience teaching students with disabilities. Most of the teachers $(81.5 \%)$ said they did not have any training in how to 
teach students with special education needs while only $18.5 \%$ stated that they had training in special education.

Considering that the location of the SEEPD inclusive education program is in the English-speaking part of Cameroon, only 25 teachers (7.2\%) said the language of instruction they used in class was French while 273 (78.9\%) used English as the language of instruction. On the other hand, 48 teachers (13.9\%) used both languages interchangeably in their classrooms. Table 3 depicts the demographic data on respondents.

\section{Analyses and Findings}

The analyses of data had the objective of finding answers to the following research questions:

1. What are the attitudes of general education teachers toward inclusion in Cameroon, with regards to (a) the benefits/outcomes of integration, (b) integrated classroom management, (c) perceptions of teachers' ability to teach students with special needs, and (d) perceptions of separate versus inclusive education?

2. Do differences exist in teachers' attitudes on the basis of their (a) gender, (b) age, (c) level of education, (d) number of years of teaching experience, (e) experience teaching in inclusive classrooms, (f) training in teaching students with disabilities in the general education classroom, and (g) teacher's language of instruction?

In accordance with the developers of the instrument, overall teachers' attitudes toward inclusion were determined using twelve negatively worded items $(2,4,6,8,9,11$, $12,14,18,20,23,24)$ and thirteen positively worded items $(1,3,5,7,10,13,15,16,17$, $19,21,22,25)$. 
Table 3

Participants' Characteristics $(\mathrm{n}=346)$

\begin{tabular}{|c|c|c|c|}
\hline Item & Description & Frequency & Valid Percent \\
\hline \multicolumn{4}{|l|}{ Gender } \\
\hline & Female & 164 & 47.4 \\
\hline & Male & 182 & 52.6 \\
\hline \multicolumn{4}{|l|}{ Degree } \\
\hline & Bachelor/DIPESI & 212 & 61.3 \\
\hline & Master/DIPESII & 126 & 36.4 \\
\hline & Master/DEA & 8 & 2.3 \\
\hline \multicolumn{4}{|l|}{ Age (years) } \\
\hline & $20-24$ & 8 & 2.3 \\
\hline & $25-39$ & 55 & 15.9 \\
\hline & $30-34$ & 78 & 22.5 \\
\hline & $35-39$ & 88 & 25.4 \\
\hline & $40-44$ & 71 & 20.5 \\
\hline & $45+$ & 46 & 13.3 \\
\hline \multicolumn{4}{|c|}{ Teaching Experience (years) } \\
\hline & $<5$ & 80 & 23.1 \\
\hline & $06-10$ & 116 & 33.5 \\
\hline & $11-15$ & 65 & 18.8 \\
\hline & $16-20$ & 43 & 12.4 \\
\hline & $21-25$ & 20 & 5.8 \\
\hline & $26-30$ & 16 & 4.6 \\
\hline & $31+$ & 6 & 1.7 \\
\hline \multicolumn{4}{|c|}{ Special Needs Experience } \\
\hline & Yes & 185 & 53.5 \\
\hline & No & 161 & 46.5 \\
\hline \multicolumn{4}{|c|}{ Training in Special Needs } \\
\hline & Yes & 64 & 18.5 \\
\hline & No & 282 & 81.5 \\
\hline \multicolumn{4}{|c|}{ Language of Instruction } \\
\hline & French & 25 & 7.2 \\
\hline & English & 273 & 78.9 \\
\hline & Both & 48 & 13.9 \\
\hline \multicolumn{4}{|l|}{ Form } \\
\hline & English Form & 304 & 87.9 \\
\hline & French Form & 42 & 12.1 \\
\hline
\end{tabular}




\section{Research Question 1}

A six-point Likert-type rating scale was used in the study with participants choosing alternatives ranging from strongly disagree, disagree, not sure but tend to disagree, not sure but tend to agree, agree, and strongly agree. After scanning the data, the numbers checked by respondents for the positively phrased statements were maintained as checked, but the negatively phrased statements were reversed as follows: 1 $=6,2=5,3=4,4=3,5=2$, and $6=1$.

Overall, the greater the mean score, the more positive was the perception on a particular issue (variable). For the purpose of this study, mean scores of 3.5 represented neutral attitudes. Mean scores less than 3.5 were judged negative, and mean scores above 3.5 were judged positively.

Research Question number 1 had four variables namely: benefits/outcomes of integration, integrated classroom management, perceptions of teachers' ability to teach students with special needs, and perceptions of separate versus inclusive education.

\section{Variable 1: The Benefits of Integration (BOI)}

Teachers' attitudes regarding the benefits derived from the practice of inclusive education were measured using items $3,7,11,14,17,20,21$, and 24 . Table 4 shows that the mean score for teachers' perceived benefits of inclusion was 4.28, and the standard deviation was 0.68 . About $78.42 \%$ of teachers (respondents) reported positive attitudes about the benefits of inclusion or integration of special needs students in the general education classroom. Table 4 describes the scores for teachers 'perceived benefits/outcomes for integration 


\section{Variable 2: Integrated Classroom Management (ICM)}

Teachers' attitudes toward the concept of integrated classroom management were measured using items $1,4,6,9,12,15,16,18,22$, and 25 . The attitudes mean score for this variable was 3.68 , and the standard deviation was 0.60 . Table 5 shows that in the area of teachers' attitudes toward integrated classroom management $61.50 \%$ of respondents had positive attitudes. Table 5 shows descriptive statistics for perceived integrated classroom management.

Table 4

Benefit/Outcomes of Integration - BOI $(N=346)$

\begin{tabular}{lllc}
\hline Attitudes Statement & $M$ & $S D$ & $\begin{array}{c}\% \text { Positive } \\
\text { Attitude }\end{array}$ \\
\hline $3 \quad \begin{array}{l}\text { Integration offers mixed group interaction that will foster } \\
\text { understanding and acceptance of differences among students }\end{array}$ & 4.98 & 1.04 & 93.00 \\
$7 \quad \begin{array}{l}\text { The challenge of being in a general classroom will promote the } \\
\text { academic growth of the student with a disability }\end{array}$ & 4.46 & 1.38 & 76.58 \\
$11 \quad \begin{array}{l}\text { The presence of students with disabilities will not promote } \\
\text { acceptance of difference on the part of students without } \\
\text { disabilities. (R) }\end{array}$ & 4.21 & 1.30 & 72.83 \\
$14 \quad \begin{array}{l}\text { Integration of student with disability will not promote his or her } \\
\text { social independence }\end{array}$ & 4.48 & 1.29 & 78.90 \\
$17 \quad \begin{array}{l}\text { The integration of students with disabilities can be beneficial } \\
\text { for students without disabilities. }\end{array}$ & 4.45 & 1.23 & 80.92 \\
$20 \quad \begin{array}{l}\text { Integration will likely have a negative effect on the emotional } \\
\text { development of the student with a disability. (R) }\end{array}$ & 4.10 & 1.40 & 68.78 \\
$\begin{array}{l}\text { Students with disabilities should be given every opportunity to } \\
\text { function in the general classroom where possible. }\end{array}$ & 4.68 & 1.25 & 83.52 \\
$\begin{array}{l}\text { Isolation in a special classroom has a beneficial effect on the } \\
\text { social and emotional development of the student with a } \\
\text { disability. (R) }\end{array}$ & 4.26 & 1.51 & 72.84 \\
\hline Totals Subscale & 4.28 & 0.68 & 78.42 \\
\hline
\end{tabular}

Note. $\mathrm{R}=$ reversed items. 
Table 5

Integrated Classroom Management-ICM $(N=346)$

\begin{tabular}{|c|c|c|c|}
\hline Attitudes Statement & $M$ & $S D$ & $\begin{array}{l}\% \text { Positive } \\
\text { Attitude }\end{array}$ \\
\hline $\begin{array}{l}\text { 1. Most students with disabilities will make an adequate attempt to } \\
\text { complete their assignments }\end{array}$ & 4.29 & 0.12 & 78.90 \\
\hline $\begin{array}{l}\text { 4. It is likely that a student with a disability will exhibit behavior } \\
\text { problems in a general classroom. (R) }\end{array}$ & 2.71 & 0.13 & 74.85 \\
\hline $\begin{array}{l}\text { 6. The extra attention students with disabilities require will be to the } \\
\text { detriment of the other students. (R) }\end{array}$ & 3.60 & 0.15 & 23.98 \\
\hline $\begin{array}{l}\text { 9. Increased freedom in the general classroom creates too much } \\
\text { confusion for the student with a disability. (R) }\end{array}$ & 3.60 & 0.15 & 52.31 \\
\hline $\begin{array}{l}\text { 12. The behavior of students with disabilities will set a bad example for } \\
\text { students without disabilities. (R) }\end{array}$ & 4.80 & $0 . .19$ & 87.57 \\
\hline $\begin{array}{l}\text { 15. It is not more difficult to maintain order in a general classroom that } \\
\text { contains a student with a disability than in one that does not contain a } \\
\text { student with a disability. }\end{array}$ & 3.01 & 1.47 & 35.54 \\
\hline $\begin{array}{l}\text { 16. Students with disabilities will not monopolize the general classroom } \\
\text { teacher's time. }(\mathrm{R})\end{array}$ & 3.89 & 1.42 & 62.42 \\
\hline $\begin{array}{l}\text { 18. Students with disabilities are likely to create confusion in the general } \\
\text { education classroom. (R) }\end{array}$ & 4.15 & 1.46 & 69.36 \\
\hline $\begin{array}{l}\text { 22. The classroom behavior of the student with a disability generally does } \\
\text { not require more patience from the teacher than does the classroom } \\
\text { behavior of a student without a disability. }\end{array}$ & 2.52 & 1.35 & 77.45 \\
\hline $\begin{array}{l}\text { 25. The student with a disability will not be socially isolated in the } \\
\text { general classroom. }\end{array}$ & 4.47 & 1.38 & 77.45 \\
\hline Totals Subscale & 3.68 & 0.60 & 61.50 \\
\hline
\end{tabular}

Variable 3: Perceptions of Personal Ability to Teach Students with Disabilities (ATT)

Teachers' self-perception of their ability to teach students with special needs were considered negative; the mean score was 2.55 , and the standard deviation was 0.95 . Items 2, 10, and 19 measured teachers' perceptions of their capacity to teach students with 
special education needs. Only $29.37 \%$ of teachers showed positive attitudes in their personal abilities to teach students with disabilities. Table 6 displays the results.

Table 6

Perceptions of Personal Ability to Teach Students with Disabilities-ATT $(\mathrm{N}=346)$

\begin{tabular}{|c|c|c|c|}
\hline Perceptions Statement & $M$ & $S D$ & $\begin{array}{l}\% \\
\text { Positive } \\
\text { Attitude }\end{array}$ \\
\hline $\begin{array}{l}\text { 2. Integration of students with disabilities will necessitate extensive } \\
\text { retraining of general classroom teachers. (R) }\end{array}$ & 2.17 & 1.31 & 13.87 \\
\hline $\begin{array}{l}\text { 10. General education teachers have the ability necessary to work with } \\
\text { students with disabilities. }\end{array}$ & 3.06 & 1.50 & 56.06 \\
\hline $\begin{array}{l}\text { 19. General education teachers have sufficient training to teach students } \\
\text { with disabilities }\end{array}$ & 2.43 & 1.37 & 18.20 \\
\hline Totals Subscale & 2.55 & 0.95 & 29.37 \\
\hline
\end{tabular}

\section{Variable 4: Perceived Concept of Inclusion (COI)}

Teachers attitudes toward special education compared to inclusive education were negative, the mean score was 3.07 , and the standard deviation was 0.91 . These perceptions, based on teachers' responses to questions $5,8,13$, and 23 , indicated negative attitudes by the teachers' idea of inclusion. They overwhelmingly thought that inclusion would not be beneficial to both students with disabilities and those within the general education system. Only 39\% of teachers saw that inclusion had an impact on both general education and special education students. Table 7 representing the perceptions related to teachers' perception of the concept of inclusion, indicates negative teacher attitudes. 
Table 7

Perceptions of Concept of Inclusive Education-COI $(\mathrm{N}=346)$

\begin{tabular}{lccc}
\hline Perceptions Statement & $\boldsymbol{M}$ & $\boldsymbol{S D}$ & $\begin{array}{c}\text { \% Positive } \\
\text { Attitude }\end{array}$ \\
\hline $\begin{array}{l}\text { 5. Students with disabilities can best be served in the general education } \\
\text { classroom. }\end{array}$ & 3.58 & 1.47 & 54.91 \\
$\begin{array}{l}\text { 8. Integration of students with disabilities will require significant } \\
\text { changes in the general classroom procedure. (R) }\end{array}$ & 2.36 & 1.32 & 17.05 \\
$\begin{array}{l}\text { 13. The student with a disability will probably develop academic skills } \\
\text { more rapidly in a general education classroom than in a special } \\
\text { classroom. }\end{array}$ & 3.64 & 1.66 & 56.06 \\
$\begin{array}{l}\text { 23. Teaching students with disabilities is better done by special than by } \\
\text { general education teachers. (R) }\end{array}$ & 2.69 & 1.58 & 29.03 \\
\hline Totals Subscale & 3.07 & 0.91 & 39.00 \\
\hline
\end{tabular}

\section{Summary of Findings for Research Question 1}

What are the attitudes of general education teachers toward inclusion in Cameroon, with regards to (a) benefits of integration, (b) concept of integration, (c) integrated classroom management, (d) perceptions of their ability to teach special needs students?

Overall teachers' attitudes toward inclusion were considered to be negative, $M=$ 3.40, $S D=0.54$. Nevertheless, significant results were found in 2 of the 4 dependent variables. A majority of teachers, about $78.42 \%$, thought that inclusive education could have some BOI, $M=4.28, S D=0.68$. About $63.98 \%$ of teachers, $M=3.68, S D=0.60$, showed positive attitudes toward ICM. Most teachers, about $70.63 \%$, had negative attitudes about their ATT students with special needs, $M=2.55, S D=0.95$. Teachers' perceived COI was negative, $M=3.07, S D=0.91$ with only $39.9 \%$ of positive attitudes 
shown by teachers' perception of inclusion as opposed to separate schools for students with a disability.

Teachers' negative attitudes toward their perceived ATT children with disabilities and negative perceptions of the concept of inclusion were corroborated by the finding that only $18.5 \%$ of the teachers had received any training in special education, and $53.5 \%$ had experience in teaching a student with special education needs. Table 8 presents the mean scores and teachers' perceptions of inclusive education by variable.

Table 8

Descriptive Statistics of Variables in the Study $(n=346)$

\begin{tabular}{lcccccc}
\hline Variable & Min-Max & Mean & SD & Median & Mode & Skewness \\
\hline Benefits of Inclusion & $2.25-5.88$ & 4.28 & 0.68 & 4.25 & 4.25 & -.017 \\
Integrated Classroom & $1.70-5.40$ & 3.68 & 0.60 & 3.70 & 3.70 & -.022 \\
Management & & & & & & \\
Perceived Ability to Teach & $1.00-5.33$ & 2.55 & 0.95 & 2.33 & 2.33 & .146 \\
Perceived Concept of Inclusion & $1.00-5.50$ & 3.07 & 0.91 & 3.00 & 3.25 & .039 \\
Total Scale & $2.00-4.97$ & 3.40 & 0.54 & 3.35 & 3.08 & .288 \\
\hline
\end{tabular}

Research Question 2: Hypotheses Testing

Null Hypothesis 1: There will be no significant difference in the perception of inclusive education based on teachers' gender (see Table 9). 
Table 9

ANOVA for Teachers' Perceptions by Gender

\begin{tabular}{|c|c|c|c|c|c|c|c|}
\hline Gender & $N$ & Mean & $S D$ & $F$ & $d f$ & $P$ & Effect Size \\
\hline \multicolumn{8}{|c|}{ Benefits of Inclusion (BOI) } \\
\hline Female & 164 & 4.36 & 0.69 & 6.12 & 1,344 & .014 & .017 \\
\hline Male & 182 & 4.54 & 0.63 & & & & \\
\hline \multicolumn{8}{|c|}{ Integrated Classroom Management(ICM) } \\
\hline Female & 164 & 3.61 & 0.62 & 4.32 & 1,344 & .038 & .012 \\
\hline Male & 182 & 3.75 & 0.57 & & & & \\
\hline \multicolumn{8}{|c|}{ Perceived Ability to Teach(ATT) } \\
\hline Female & 164 & 2.60 & 0.99 & .714 & 1,344 & .339 & .002 \\
\hline Male & 182 & 2.51 & 0.92 & & & & \\
\hline \multicolumn{8}{|c|}{ Perceived Concept of Inclusion(COI) } \\
\hline Female & 164 & 3.80 & 0.91 & .383 & 1,344 & .536 & .001 \\
\hline Male & 182 & 3.89 & 0.92 & & & & \\
\hline
\end{tabular}

Note. $p<.05$.

A two-group one-way between-subjects multivariate analysis of variance was performed on four perceptions of inclusive education subscales variables: BOI, ICM, ATT, and COI. The independent variable was teacher's gender (male, female).

A total of 346 teachers participated in this study, 53\% males and $47 \%$ females. A statistically non-significant Box's M test $(p=.356)$ indicated equal variance-covariance matrices of the dependent variables across levels of gender, signifying the convenience to use Wilks' Lambda in assessing the multivariate effect.

Using the Wilks' Lambda as the criterion, the dependent variate was significantly affected by gender, Wilks' Lambda $=.969 F(4,341)=2.709, p=.030$. Univariate analysis was conducted in each dependent measure separately to determine the locus of 
the statistically significant multivariate effect. Neither perceived ATT nor perceived COI was statistically significant, (Fs >.1 and sig.>.05). Teachers' genders significantly affected their perceived BOI for students $(p=.014$, partial eta squared $=.017)$ and perceived ICM $(p=.038$, partial eta squared $=.012)$.

In the case of BOI, the partial eta square $=.017$ indicates that approximately $1.7 \%$ of the multivariate variance of the dependent variable was associated with the gender factor while the partial eta square $=.012$ for ICM also shows that roughly $1.2 \%$ of the multivariate variance of the dependent variable was related to the gender factor. The partial eta square for teachers' perceived ATT $=.002$ and perceived COI was .001 . The results indicate that the dependent variables were not significantly affected by gender because the effect size for these variables was considered to be small.

Null Hypothesis 2: There will be no significant difference in the perception of inclusive education based on teachers' age.

A seven-group one-way between-subjects multivariate analysis of variance was performed on four perceptions of inclusive education subscales variables: BOI, ICM, ATT, and COI. The independent variable was teacher's ages (20-24, 25-29, 30-43, 35-39, 40-44, and 45+).

Table 10 depicts that out of the total of 346 teachers participating in this study, $41 \%$ were younger than 35 years, $46 \%$ were between 35 to 44 years old, and $13 \%$ were 45 years and older. A statistically significant Box's M test $(p=.000)$ indicated unequal variance-covariance matrices of the dependent variables across levels of age and thus necessitated the use of Pillai's trace in assessing the multivariate effect. 
Table 10

ANOVA for Teachers' Perceptions by Age

\begin{tabular}{|c|c|c|c|c|c|c|c|}
\hline Age & $N$ & Mean & $S D$ & $F$ & $d f$ & $P$ & Effect Size \\
\hline & \multicolumn{7}{|c|}{ Benefits of Inclusion (BOI) } \\
\hline $20-24$ & 8 & 4.17 & 0.65 & & & & \\
\hline $25-29$ & 55 & 4.26 & 0.62 & & & & \\
\hline $30-34$ & 78 & 4.31 & 0.65 & 5.19 & 5,340 & .000 & .071 \\
\hline $35-39$ & 88 & 4.45 & 0.70 & & & & \\
\hline $40-44$ & 71 & 4.58 & 0.59 & & & & \\
\hline \multirow[t]{2}{*}{$45+$} & 46 & 4.80 & 0.62 & & & & \\
\hline & \multicolumn{7}{|c|}{ Integrated Classroom Management(ICM) } \\
\hline $20-24$ & 8 & 3.86 & 0.55 & & & & \\
\hline $25-29$ & 55 & 3.77 & 0.61 & & & & \\
\hline $30-34$ & 78 & 3.55 & 0.53 & 2.41 & 5,340 & .036 & .034 \\
\hline $35-39$ & 88 & 3.63 & 0.62 & & & & \\
\hline $40-44$ & 71 & 3.69 & 0.63 & & & & \\
\hline \multirow[t]{2}{*}{$45+$} & 46 & 3.88 & 0.54 & & & & \\
\hline & \multicolumn{7}{|c|}{ Perceived Ability to Teach(ATT) } \\
\hline $20-24$ & 8 & 3.67 & 0.62 & & & & \\
\hline $25-29$ & 55 & 2.57 & 0.96 & & & & \\
\hline $30-34$ & 78 & 2.45 & 0.93 & 1.05 & 5,340 & .387 & .015 \\
\hline $35-39$ & 88 & 2.50 & 0.91 & & & & \\
\hline $40-44$ & 71 & 2.65 & 1.01 & & & & \\
\hline \multirow[t]{2}{*}{$45+$} & 46 & 2.54 & 0.99 & & & & \\
\hline & \multicolumn{7}{|c|}{ Perceived Concept of Inclusion(COI) } \\
\hline $20-24$ & 8 & 2.75 & 1.19 & & & & \\
\hline $25-29$ & 55 & 3.31 & 0.97 & & & & \\
\hline $30-34$ & 78 & 2.67 & 0.76 & 5.35 & 5,340 & .00 & .073 \\
\hline $35-39$ & 88 & 3.19 & 0.87 & & & & \\
\hline $40-44$ & 71 & 3.04 & 0.85 & & & & \\
\hline $45+$ & 46 & 3.34 & 1.03 & & & & \\
\hline
\end{tabular}

Note. $p<.05$. 
Using the Pillai's as the criterion, the dependent variate was significantly affected by age, Pillai's trace $=.186, F(20,1360)=3.316, p=.000,1$-Wilks' Lambda $=.175$. Univariate analysis was conducted in each dependent measure separately to determine the locus of the statistically significant multivariate effect. Perceived ATT was not statistically significant $p>.05$, and the other three dependent variables were found to be significantly affected by age. Perceived $\operatorname{ICM} F(5,340)=2.413, p=.036$, partial eta squared $=.034$, perceived BOI $F(5,340)=5.197, p=.000$, partial eta squared $=.071$, and perceived COI $F(5,340)=5.357, p=.000$, partial eta squared $=.073$.

The partial eta squared outputs indicate the following about the percentage of the multivariate variance of the dependent variables associated with the age factor in the various dependent measures: $\mathrm{ICM}=3.6 \%\left(\eta^{2}=.036\right), \mathrm{BOI}=7.1 \%\left(\eta^{2}=.071\right)$, and COI $=$ $7.3 \%\left(\eta^{2}=.073\right)$.

Levene's test of equality of error variances shows that error variances of the dependent variables are equal across groups $(p<.10)$ suggesting the use of Post Hoc Test (Ryan-Einot-Gabriel-Welsch Range). The Post Hoc Test found a significant difference in attitudes between teachers aged 40 to 44 and teachers aged 20-24, 25-29, 30-34, 35-39 ( $p$ $<.05)$ for perceived BOI for students with disabilities. Teachers 40 years old and above tended to have more positive attitudes than their younger colleagues. Teachers aged 45 and older were more positive about the benefits of inclusion than any other group. The positive perception of teachers 45 years and older may be explained due to their experiences working and interacting with students that have special needs over time. 
Perceptions about the ICM indicated that teachers 45 years old and above were more at ease with the management of integrated classrooms than teachers 20 to 44 years old, $p<.05$.

Perceptions related to the whole COI showed significantly lower mean scores for teachers aged 30-34, 20-24, 40-44 compared to those aged 35-39, 25-29, and 45 and above.

Attitudes toward inclusion indicated that older teachers tended to be accepting of inclusive education than younger ones. Teachers 40 years old and above were more supportive of inclusive education than their younger colleagues, $F(5,340)=4.62, p=$ $.00, \eta^{2}($ effect size $)=.064$. The effect size of $64 \%$ is considered significant.

Null Hypothesis 3: There will be no significant difference in the perception of inclusive education based on teachers' level of education

A 3-group one-way between-subjects multivariate analysis of variance was performed on four perceptions of inclusive education subscales variables: BOI, ICM, ATT, and COI. The independent variable was teacher's level of education or qualification (bachelor's degree or, master's degree, doctoral diploma).

Out of the total of 346 teachers participating in this study $61 \%$ were holders of a bachelor's degree, $36.5 \%$ held a master's degree, while $2.5 \%$ held a doctoral diploma or higher. A statistically non-significant Box's M test $(p=.423)$ indicated equal variancecovariance matrices of the dependent variables across levels of qualification, showing the convenience to use Wilks' Lambda in assessing the multivariate effect.

Using the Wilks' Lambda as the criterion, the dependent variate was significantly affected by the teachers' level of education or qualification, Wilks' Lambda $=.941 \mathrm{~F}$ 
$(8,680)=2.630, p=.008$. Univariate analysis was conducted in each dependent measure separately to determine the locus of the statistically significant multivariate effect. Perceived ICM was not statistically significant, $p>.05$. However, significant differences in attitudes that could be attributed to teachers' levels of education were seen in their perceived BOI $(p=.020$, partial eta squared $=.023)$, perceived ATT children with disabilities $(p=.012$, partial eta squared $=.026)$, and perceived COI $(p=.002$, partial eta squared $=.035)$.

Levene's test of equality of error variances shows that error variances of the dependent variables are equal across groups $(p>.05)$ suggesting the use of Post Hoc Test (Ryan-Einot-Gabriel-Welsch Range) for further verification. The Post Hoc Test found a significant difference in attitudes between teachers with the bachelor's degree qualification and those with master's degrees or doctoral degrees for both perceived ATT children with disabilities and perceived COI. Teachers with master's or doctoral degrees had more significantly positive attitudes in both cases. The Post Hoc Test results refuted the Univariate Test results which indicated a significant difference in perceptions by qualification, for BOI.

Table 11 shows ANOVA for teachers' perception and descriptive statistics for the level of education. 
Table 11

ANOVA for Teachers' Perceptions by Level of Education

\begin{tabular}{|c|c|c|c|c|c|c|c|}
\hline Degree & $N$ & Mean & $S D$ & $F$ & $d f$ & $P$ & Effect Size \\
\hline \multicolumn{8}{|c|}{ Benefits of Inclusion(BOI) } \\
\hline Bachelor & 212 & 4.40 & 0.65 & 3.96 & 2,343 & .020 & .023 \\
\hline Masters & 126 & 4.52 & 0.64 & & & & \\
\hline DEA & 8 & 4.98 & 0.95 & & & & \\
\hline \multicolumn{8}{|c|}{ Integrated Classroom Management(ICM) } \\
\hline Bachelor & 212 & 3.64 & 0.61 & 2.07 & 2,343 & .127 & .012 \\
\hline Masters & 126 & 3.75 & 0.56 & & & & \\
\hline DEA & 8 & 3.91 & 0.66 & & & & \\
\hline \multicolumn{8}{|c|}{ Perceived Ability to Teach(ATT) } \\
\hline Bachelor & 212 & 2.43 & 0.76 & 4.52 & 2,343 & .012 & .026 \\
\hline Masters & 126 & 2.72 & 0.94 & & & & \\
\hline DEA & 8 & $3 . .00$ & 1.31 & & & & \\
\hline \multicolumn{8}{|c|}{ Perceived Concept of Inclusion(COI) } \\
\hline Bachelor & 212 & 2.94 & 0.93 & 6.18 & 2,343 & .002 & .035 \\
\hline Masters & 126 & 3.27 & 0.87 & & & & \\
\hline DEA & 8 & 3.50 & 0.65 & & & & \\
\hline
\end{tabular}

Note. $p<.05$.

The attitudes toward inclusion by the level of education indicated that the more educated teachers tended to be more supportive of inclusive education than lesser educated ones. The higher the level of education, the more likely teachers were going to be supportive of inclusive education, $F(2,340)=7.95, p=.00, \eta^{2}($ effect size $)=.044$.

Null Hypothesis 4: There will be no significant difference in the perception of inclusive education based on teacher's years of teaching experience. 
A 7-group one-way between-subjects multivariate analysis of variance was performed on four perceptions of inclusive education subscales variables: BOI, ICM, ATT, and COI. The independent variable was teachers' teaching experience $(-5,6-12,11$ $15,16-20,21-25,26-30,31+)$.

Out of the total of 346 teachers participating in this study $23 \%$ had 5 years of teaching experience or less, $33.5 \%$ had 6-10 years of teaching experience, $18 . \%$ had $11-$ 15 years, $12.5 \%$ had $16-20$ years, $5.8 \%$ had $21-25$ years, $4.6 \%$ had $26-30$ years, and $0.7 \%$ had 31 years of experience or above. A statistically significant Box's M test ( $p=$ $.005)$ indicated unequal variance-covariance matrices of the dependent variables across levels of teaching experience and thus necessitated the use of Pillai's trace in assessing the multivariate effect.

Using the Pillai's as the criterion, the dependent variate was significantly affected by teaching experience, Pillai's trace $=.163, F(24,13560=2.396, p=.000$. Univariate analysis was conducted in each dependent measure separately to determine the locus of the statistically significant multivariate effect. Perceived ICM was not statistically significant $p>.05$, and the other three dependent variables were found to be significantly affected by teachers' years of teaching experience. Perceived ATT $F(6,339)=2.561, p=$ .019 , partial eta squared $=.043$, perceived BOI $F(6,339)=3.901, p=.001$, partial eta squared $=.065$, and perceived COI $F(6,339)=3.941, p=.001$, partial eta squared $=.065$.

The multivariate $\prod^{2}$ or partial eta squared outputs indicate the percentage of the multivariate variance of the dependent variables associated with the experience factor in the various dependent measures: ATT $=1.9 \%\left(\Pi^{2}=.019\right)$, BOI $=6.5 \%\left(\eta^{2}=.065\right)$, and $\mathrm{COI}=6.5 \%\left(\eta^{2}=.065\right)$ 
Levene's test of equality of error variances shows that error variances of the dependent variables are equal across groups $(p<.10)$ suggesting the use of Post Hoc Test (Ryan-Einot-Gabriel-Welsch Range). The Post Hoc Test found a significant difference in attitudes between teachers with teaching experience 6-10 years and those with teaching experience 16-20, 21-25, 31+ for perceived BOI for students with disabilities. There were significantly higher means for teachers 16-20, 21-25, 31+.

Teachers with 6-10 years and 31 or more years of teaching experience had significantly lower mean scores than those with 16-20 years for COI. Perceived ATT children with disabilities mean scores per experience category were not significantly different from each other $(p=.121)$.

The attitudes toward inclusive education on the basis of teaching experience indicated that teachers' support grew in the early years of their career (6 years to about 25 years), but the support steadily falls after 30 years of teaching, $F(6,340)=4.08, p=.001$, $\eta^{2}($ effect size $)=.067$. Table 12 represents the ANOVA for teachers' perception by teaching experience.

Null Hypothesis 5: There will be no significant difference in the perception of inclusive education based on teachers' experience teaching in the inclusive classroom.

A two-group one-way between-subjects multivariate analysis of variance was performed on four perceptions of inclusive education subscales variables: BOI, ICM, ATT, and COI. The independent variable was teacher's special education teaching experience (yes, no).

A total of 346 teachers participated in this study, 53.5\% of teachers said they had some experience teaching children with special needs while $46.5 \%$ said they did not. 
Table 12

ANOVA for Teachers' Perceptions by Teaching Experience

\begin{tabular}{|c|c|c|c|c|c|c|c|}
\hline Experience & $N$ & Mean & $S D$ & $F$ & $d f$ & $P$ & Effect Size \\
\hline \multicolumn{8}{|c|}{ Benefits of Inclusion (BOI) } \\
\hline-5 & 80 & 4.47 & 0.65 & & & & \\
\hline $6-10$ & 116 & 4.21 & 0.66 & & & & \\
\hline $11-15$ & 65 & 4.50 & 0.65 & 3.90 & 6,339 & .001 & .065 \\
\hline $16-20$ & 43 & 4.70 & 0.59 & & & & \\
\hline $21-25$ & 20 & 4.80 & 0.51 & & & & \\
\hline $26-30$ & 16 & 4.63 & 0.80 & & & & \\
\hline $31+$ & 6 & 4.71 & 05.99 & & & & \\
\hline \multicolumn{8}{|c|}{ Integrated Classroom Management(ICM) } \\
\hline-5 & 80 & 3.72 & 0.56 & & & & \\
\hline $6-10$ & 116 & 3.63 & 0.55 & & & & \\
\hline $11-15$ & 65 & 3.63 & 0.73 & 1.08 & 6,339 & .371 & .019 \\
\hline $16-20$ & 43 & 3.69 & 0.65 & & & & \\
\hline $21-25$ & 20 & 3.83 & 0.60 & & & & \\
\hline $26-30$ & 16 & 3.96 & 0.39 & & & & \\
\hline $31+$ & 6 & 3.68 & 0.16 & & & & \\
\hline \multicolumn{8}{|c|}{ Perceived Ability to Teach(ATT) } \\
\hline-5 & 80 & 2.79 & 0.99 & & & & \\
\hline $6-10$ & 116 & 2.40 & 0.85 & & & & \\
\hline $11-15$ & 65 & 2.51 & 1.07 & 2.56 & 6,339 & .019 & .043 \\
\hline $16-20$ & 43 & 2.43 & 0.16 & & & & \\
\hline $21-25$ & 20 & 2.85 & 0.96 & & & & \\
\hline $26-30$ & 16 & 2.87 & 1.21 & & & & \\
\hline $31+$ & 6 & 1.94 & 0.74 & & & & \\
\hline
\end{tabular}


Table 12-Continued

\begin{tabular}{|c|c|c|c|c|c|c|c|}
\hline Experience & $N$ & Mean & $S D$ & $F$ & $d f$ & $P$ & Effect Size \\
\hline \multicolumn{8}{|c|}{ Perceived Concept of Inclusion(COI) } \\
\hline-5 & 80 & 3.19 & 1.02 & & & & \\
\hline $6-10$ & 116 & 2.80 & 0.83 & & & & \\
\hline $11-15$ & 65 & 3.12 & 0.86 & 3.94 & 6,339 & .001 & .065 \\
\hline $16-20$ & 43 & 3.46 & 0.70 & & & & \\
\hline $21-25$ & 20 & 3.26 & 0.93 & & & & \\
\hline $26-30$ & 16 & 3.09 & 1.22 & & & & \\
\hline $31+$ & 6 & 2.63 & 0.72 & & & & \\
\hline
\end{tabular}

A statistically non-significant Box's M test $(p=.505)$ indicated equal variancecovariance matrices of the dependent variables across levels of experience teaching students with special needs, showing the convenience to use Wilks' Lambda in assessing the multivariate effect.

Using the Wilks' Lambda as the criterion, the dependent variate was significantly affected by gender, Wilks' Lambda $=.963 F(4,341)=3.233, p=.037$. Univariate analysis was conducted in each dependent measure separately to determine the locus of the statistically significant multivariate effect. Neither perceived BOI nor perceived ICM was statistically significant $p>.05$. Teachers' teaching experience in special education was significantly affected by their perceived ATT $(p=.022$, partial eta squared $=.015)$ and their COI $(p=.001$, partial eta squared $=.031)$.

In the case of ATT, the partial eta square $=.015$ indicates that approximately $1.5 \%$ of multivariate variance of the dependent variables were concomitant with teachers' special education teaching experience factor while the $\eta^{2}=.031$ for COI also indicates 
that approximately $3.1 \%$ of multivariate variance of the dependent variables were associated with the special education teaching experience factor.

Table 13 presents the ANOVA of teachers' perceptions by their classroom teaching experience. On the whole, teachers who said they had some experience teaching special needs students in an inclusive classroom $(M=3.49, S D=0.54)$ tended to be more supportive of inclusive education than those who stated that they had no experience $(M$ $=3.29, S D=0.53), F(1,34)=11.99, p=.001, \eta^{2}($ effect size $)=.025$.

Table 13

ANOVA for Teachers' Perceptions by Inclusive Classroom Teaching Experience

\begin{tabular}{|c|c|c|c|c|c|c|c|}
\hline $\begin{array}{l}\text { Inclusive } \\
\text { Experience }\end{array}$ & $N$ & Mean & $S D$ & $F$ & $d f$ & $P$ & Effect Size \\
\hline \multicolumn{8}{|c|}{ Benefits of Inclusion(BOI) } \\
\hline Yes & 185 & 4.50 & 0.67 & 2.14 & 1,344 & .144 & .006 \\
\hline No & 161 & 4.41 & 0.65 & & & & \\
\hline \multicolumn{8}{|c|}{ Integrated Classroom Management(ICM) } \\
\hline Yes & 185 & 3.73 & 0.57 & 2.26 & 1,344 & .133 & .007 \\
\hline No & 161 & 3.63 & 0.62 & & & & \\
\hline \multicolumn{8}{|c|}{ Perceived Ability to Teach(ATT) } \\
\hline Yes & 185 & 2.66 & 0.94 & 5.27 & 1,344 & .022 & .015 \\
\hline No & 161 & 2.43 & 0.95 & & & & \\
\hline \multicolumn{8}{|c|}{ Perceived Concept of Inclusion(COI) } \\
\hline Yes & 185 & 3.22 & 0.89 & 10.99 & 1,344 & .001 & .031 \\
\hline No & 161 & 2.90 & 0.92 & & & & \\
\hline
\end{tabular}

Note. $p<.05$. 
Null Hypothesis 6: There will be no significant difference in the perception of inclusive education based on teachers' training.

A two-group one-way between-subjects multivariate analysis of variance was performed on four perceptions of inclusive education subscales variables: BOI, ICM, ATT, and COI. The independent variable was training in special education (yes, no).

A total of 346 teachers participated in this study, $18.5 \%$ of teachers said they had received some form of training in special education while $81.5 \%$ stated that they had never trained in special education. A statistically non-significant Box's M test $(p=.599)$ indicated equal variance-covariance matrices of the dependent variables across levels of training in special education, showing the convenience to use Wilks' Lambda in assessing the multivariate effect.

Using the Wilks' Lambda as the criterion, the dependent variate was significantly affected by gender, Wilks' Lambda $=.968, F(4,341)=2.793, p=.032$. Univariate analysis was conducted in each dependent measure separately to determine the locus of the statistically significant multivariate effect. Teachers' training or lack thereof in special education significantly affected their perceptions of inclusive education in one of the four inclusive education subscales variables-COI, $p=.015$. The $\eta^{2}=.015$ indicates that approximately $1.5 \%$ of the multivariate variance of the dependent variables associated with teachers' or lack thereof in special education.

There were no statistically significant differences in perceptions by training in special education for BOI, ICM, and ATT, $p>.05$ in each of the three variables.

The mean scores for teachers who said they had never received any training in special education, $M=3.68, S D=.46$, was significantly lower than mean scores for those 
who stated that they had received some form of training in special education, $M=3.76$, $S D=.52$. It implies that teachers were more likely to be supportive of inclusive education if they had training in special education as opposed to those who did not have any training (See Table 14).

Table 14

ANOVA for Perceptions of Teachers' Training in Special Education

\begin{tabular}{|c|c|c|c|c|c|c|c|}
\hline $\begin{array}{l}\text { Special Ed. } \\
\text { Training }\end{array}$ & $N$ & Mean & $S D$ & $F$ & $d f$ & $P$ & Effect Size \\
\hline \multicolumn{8}{|c|}{ Benefits of Inclusion(BOI) } \\
\hline Yes & 64 & 4.56 & 0.70 & 2.01 & 1,346 & .157 & .006 \\
\hline No & 282 & 4.43 & 0.65 & & & & \\
\hline \multicolumn{8}{|c|}{ Integrated Classroom Management(ICM) } \\
\hline Yes & 64 & 3.62 & 0.67 & 1.04 & 1,346 & .306 & .003 \\
\hline No & 282 & 3.70 & 0.58 & & & & \\
\hline \multicolumn{8}{|c|}{ Perceived Ability to Teach(ATT) } \\
\hline Yes & 64 & 2.72 & 0.98 & 2.50 & 1,346 & .114 & .007 \\
\hline No & 282 & 2.51 & 0.94 & & & & \\
\hline \multicolumn{8}{|c|}{ Perceived Concept of Inclusion(COI) } \\
\hline Yes & 64 & 3.31 & 0.88 & 5.33 & 1,346 & .022 & .015 \\
\hline No & 282 & 3.02 & 0.92 & & & & \\
\hline
\end{tabular}

Note. $p<.05$.

Null Hypothesis 7: There will be no significant difference in the perception of inclusive education based on teachers' language of instruction.

A 3-group one-way between-subjects multivariate analysis of variance was performed on four perceptions of inclusive education subscales variables: BOI, ICM, 
ATT, and COI. The independent variable was teacher's language of instruction (English, French, or both).

Table 15 illustrates the ANOVA for teachers' perception by the language of instruction.

Table 15

ANOVA for Teachers' Perceptions by Language of Instruction

\begin{tabular}{|c|c|c|c|c|c|c|c|}
\hline $\begin{array}{l}\text { Language of } \\
\text { Instruction }\end{array}$ & $N$ & Mean & $S D$ & $F$ & $d f$ & $P$ & Effect Size \\
\hline \multicolumn{8}{|c|}{ Benefits of Inclusion(BOI) } \\
\hline French & 25 & 4.42 & 0.56 & .348 & 2,343 & .707 & .002 \\
\hline English & 273 & 4.46 & 0.66 & & & & \\
\hline Both & 48 & 4.38 & 0.68 & & & & \\
\hline \multicolumn{8}{|c|}{ Integrated Classroom Management(ICM) } \\
\hline French & 25 & 3.72 & 0.58 & .348 & 2,343 & .707 & .000 \\
\hline English & 273 & 3.67 & 0.60 & & & & \\
\hline Both & 48 & 3.74 & 0.59 & & & & \\
\hline \multicolumn{8}{|c|}{ Perceived Ability to Teach(ATT) } \\
\hline French & 25 & 2.44 & 0.88 & 2.85 & 2,343 & .059 & .008 \\
\hline English & 273 & 2.51 & 0.93 & & & & \\
\hline Both & 48 & 2.85 & 1.04 & & & & \\
\hline \multicolumn{8}{|c|}{ Perceived Concept of Inclusion(COI) } \\
\hline French & 25 & 3.14 & 0.85 & .31 & 2,343 & .729 & .002 \\
\hline English & 273 & 3.05 & 0.92 & & & & \\
\hline Both & 48 & 3.15 & 0.93 & & & & \\
\hline
\end{tabular}

Note. $p<.05$.

Out of the total of 346 teachers participating in this study, $7.3 \%$ used French as the language of instruction, 78.9\% used English, and 13.88\% used both English and 
French. A statistically non-significant Box's M test $(p=.877)$ indicated equal variancecovariance matrices of the dependent variables across levels of the language of instruction, showing the convenience to use Wilks' Lambda in assessing the multivariate effect.

Using the Wilks' Lambda as the criterion, the dependent variate was significantly affected teacher's level of education or qualification, Wilks' Lambda $=.977 F(8,680)=$ $.999, p=.012$. Univariate analysis was conducted in each dependent measure separately to determine the locus of the statistically significant multivariate effect. Test results indicated that there were no statistically significant differences in perceptions based on teachers' language of instruction in all the four perceptions of inclusive education subscales variables combined (BOI, ICM, ATT, COI), $F(2,340)=.319, p=.727, \eta^{2}$ $($ effect size $)=.002$.

\section{Summary of Chapter Four}

The purpose of this study was to investigate the attitudes of general education secondary school teachers in Grades 6 -12 twelve in seven public secondary schools engaged in a pilot inclusive education program in the North-West Region of Cameroon. Of the 400 questionnaires that were disseminated, 348 were returned, and 346 were used for a return rate of $87.75 \%$. One hundred and sixty-four of the respondents were females, and one hundred and eighty-two were males with $65.80 \%$ of participants being 39 years and younger. About $61.27 \%$ of participants had Bachelor's degree while $36.41 \%$ percent had a Master's degree and only $2.31 \%$ had a doctoral qualification. Only $18.50 \%$ (64) of the participants had experience teaching students with special education needs. 
The highest possible overall score on the ORI is 150 . Scores for Cameroonian general education teachers involved in the inclusive education pilot program ranged from 62 to 130. The average scores for BOI, ICM, ATT and COI were 35.64 (4.45), 36.85 (3.68), $7.66(2.55)$, and $12.28(3.00)$ respectively.

The analysis of demographic variables data depicted a strong correlation between total score on the ORI and gender, age, the level of education, teaching experience, experience teaching students with special education needs, and training for teaching students with disabilities in inclusive settings. There was no correlation between the language of instruction (French, English, or both) used by the teachers and their perceptions of inclusive education. Males had a more positive attitude toward inclusion than females, and general education teachers with higher levels of education had a more positive attitude toward inclusion than general education teachers with lower levels of education. General education teachers with experience teaching students with disabilities had a more positive attitude toward inclusion than general education teachers without experience teaching students with disabilities. General education teachers with training had more positive attitudes toward inclusion than general education teachers without such training.

Chapter 5 provides the recommendations to support the SEEPD program managers and the Cameroonian government in their effort to promote inclusive education and provide training and professional development opportunities in special education and the management of inclusive classrooms. Chapter 5 also offers recommendations to help general education teachers, especially those in schools running inclusive pilot education programs, develop an appreciation for inclusive education. It is the hope that a more 
positive attitude from general education teachers would increase opportunities for the success of students with disabilities included in general education classrooms in Cameroonian schools. 


\section{CHAPTER 5}

\section{DISCUSSIONS, CONCLUSIONS, AND RECOMMENDATIONS}

\section{Introduction}

The purpose of this study was to examine the attitudes of general education secondary school teachers in Grades 6-12 in seven public secondary schools engaged in a pilot inclusive education program in the North-West Region of Cameroon. The study sought to examine if there was a relationship between teachers' characteristics (gender, age, the level of education, years of teaching experience, experience teaching in inclusive classrooms, training, and teachers' language of instruction), and the attitudes they held toward inclusive education. The teachers included in this study all possess the following characteristics: full-time employee, currently teaching, certified or have a degree and teaches a class between Grades 6-12 (Form 1-7).

The state of special education in Cameroon is still rudimentary despite the country's signing of the UNESCO Salamanca Statement, which had the purpose of furthering the objectives of inclusive education (UNESCO, 1994). There has not been an effective implementation of special education laws particularly the law related to the practice of inclusion in Cameroonian schools. The weakness in implementation can be attributed to the non-readiness of schools, caused by lack of appropriate and adequate facilities, such as self-contained classrooms, resource rooms, and the shortage or absence 
of trained teachers and paraprofessionals. Considering that inclusion is still in its initial stage in a few secondary schools in Cameroon, the need to diagnose institutional and teacher readiness for the reform is the motivation behind this study.

The major premise of the study is teachers' perceptions of inclusive education and their ability to support students with disabilities in an inclusive classroom setting. Knowing teachers' perceptions is key to understanding the problems of inclusive education and special education, in general, in Cameroon. Teachers' preparedness to handle inclusive classrooms or lack thereof should help all government and education stakeholders understand the magnitude of need for the training of special education teachers and paraprofessionals.

\section{Summary of Methodology}

The study used a quantitative descriptive non-experimental research design. The instrument used to collect data was the ORI developed by Antonak and Larrivee (1995). The questionnaire, consisting of twenty-five questions, was used to gather information about general educators' perceptions of the BOI, COI, ICM, and ATT. A demographic questionnaire was utilized by the researcher to gather data about factors known to affect general education teachers' attitudes toward inclusion.

Two main types of secondary schools exist in Cameroon, namely, public and private schools. However, the study did not include private schools because of the fact that the SEEPD 14-school inclusive education pilot project, which is the source of data for the study, involves only public bilingual schools. Teachers from the seven secondary schools involved in 14-school SEEPD project were surveyed. Teachers from the seven primary schools (Grades 1 to 5) involved in the project were not included in the study. 
The study focused on the secondary school level teachers because they are all trained for service in tertiary education institutions while all teachers of kindergarten to elementary schools are trained in non-tertiary educational training institutions. As a result, the study of attitudes of kindergarten and elementary school teachers in Cameroon can constitute a separate research.

The data obtained through the scanning of each survey were processed by the Statistical Package for Social Sciences (SPSS) and analyzed by the use of descriptive statistics (mean score, standard deviations, frequencies, crosstabs). The hypotheses related to the research questions were tested using the Multivariate Analysis of Variance, Univariate Analysis of Variance, and Post Hoc Tests (Ryan-Einot-Gabriel-Welsch Range).

\section{Summary of Major Findings}

Overall, SEEPD program general education teachers' attitudes were negative, $M$ $=3.40, S D=0.54$. Further discussion of the findings in this study is summarized according to the two research questions which were answered by the use of statistical procedures listed in the methodology summary.

\section{Research Question 1}

What are the attitudes of general education teachers toward inclusion in Cameroon, with regard to (a) BOI, (b) COI, (c) ICM, and (d) ATT?

Overall teachers' attitudes toward inclusion were considered to be negative, $M=$ 3.40, $S D=0.54$. Teachers' attitudes toward the COI were negative, with only about $39 \%$ of teachers showing a positive attitude, $M=3.07, S D=0.91$. About $71 \%$ of teachers thought that integration would likely have a negative effect on the emotional 
development of the student with a disability in an inclusive classroom while $82.95 \%$ of teachers believed that most students with disabilities would not make an adequate attempt to complete their assignment in an inclusive learning environment.

Teachers' assessment of their personal ATT was largely negative, with only $29.3 \%$ of teachers showing a positive attitude, $M=2.55, S D=0.95$. Only $13.87 \%$ of teachers thought that students with disabilities could best be served in the general education classroom, and $18.20 \%$ said that general education teachers have the ability necessary to work with students with disabilities, $M=2.43, S D=1.37$.

The two variables indicating largely positive attitudes toward inclusion were teachers' perceived BOI, $M=4.28, S D=0.68$, and the concept of ICM, $M=3.68, S D=$ 0.60 .

About $93 \%$ of teachers thought that students might develop academic skills more rapidly in a general education classroom than in a special education classroom, and $78.90 \%$ agreed that students with disabilities are not likely to monopolize the general education classroom teacher's time, $M=4.48, S D=1.29$. About $68.78 \%$ of teachers thought that the practice of inclusion would promote acceptance of difference on the part of students without disabilities, $M=4.10, S D=1.40$.

Regarding the concept of ICM, most teachers (78.9\%) believed that students with disabilities could best be served in the general education classroom, $M=4.29, S D=1.24$. About $77.45 \%$ of teachers also said that integration offers mixed group interaction that will foster understanding and acceptance of differences among students, $M=4.15, S D=$ 1.46 (Integration of students with disabilities can be beneficial for students without disabilities, $\mathrm{M}=4.47, \mathrm{SD}=1.38)$. 


\section{Research Question 2}

Do differences exist in teachers' attitudes, on the basis of their (a) gender, (b) age, (c) level of education, (d) number of years of teaching experience, (e) experience teaching in inclusive classrooms, (f) training in teaching students with special needs in the general education classroom, and (g) Teacher's language of instruction?

The results suggest that participants' perceptions of inclusive education were significantly different by their gender, age, the level of education, teaching experience, experience teaching in the inclusive classroom, and training in teaching students with special education needs. There were no statistically significant differences in perceptions based on teachers' language of instruction in all the four perceptions of inclusive education.

Gender: Neither teachers' ATT students with disabilities nor their perceived COI was significantly affected by their gender, $F s>$. 1. However, teachers' genders significantly affected their BOI for students $(p=.014$, partial eta squared $=.017)$ and their perceived ICM $(p=.038$, partial eta squared $=.012)$.

In the case of BOI, the $\prod^{2}=.017$ indicates that approximately $1.7 \%$ of the variance of the dependent variable is associated with the gender factor while the $\prod^{2}=$ .012 for ICM also indicates that roughly $1.2 \%$ of the variance of the dependent variable is related to the gender factor. In an earlier study, Jobe and Rust (1996) reached the conclusion that male teachers had a more favorable attitude toward inclusion (mean score 79.44) than female teachers (mean score 73.73). Avramidis and Norwich (2002) explain in their study that while the results of some studies reveal that male teachers have more positive attitudes than female teachers, results of other studies indicate that female teachers have more positive attitudes toward inclusion. The findings of the study by Jobe 
and Rust (1996) concur with the results of this dissertation but do not concur with the study by Leyser and Tappendorf (2001) and Boyle, Topping, and Jindal-Snape (2013) who found that female teachers had more positive attitudes toward inclusion than male teachers. On the other hand, Avramidis et al. (2000) found that gender was not significantly related to teachers' attitudes toward inclusion.

Age: There were significant relationships between participants' ages and their BOI, $F(5,34)=5.19, p<.05 ; \mathrm{ICM}, F(5,34)=2.41, p<.05 ;$ and COI, $F(5,34)=5.35, p<$ .05 . Teachers' perceived ATT did not correlate with age, $F(5,34)=1.05, p>.05$.

Teachers 'age has a stronger or large effect size in comparison to gender considering that the effect size of the three variables is large BOI (7.1\%), ICM (3.4\%), and $\mathrm{COI}(7.3 \%)$. In the case of BOI, the $\Pi^{2}=.071$ indicates that approximately $7.1 \%$ of the variance of the dependent variable is associated with the age factor, the $\prod^{2}=.034$ for ICM also indicates that approximately $3.4 \%$ of the variance of the dependent variable was associated with the age factor while the $\eta^{2}=.073$ for COI also indicates that approximately $7.3 \%$ of the variance of the dependent variable is associated with the age factor. Teachers' age had a small significant effect when it came to their perceived ability to teach students with SEN in their classrooms; the $\prod^{2}=0.15$ indicated a small effect size depicting that approximately $1.5 \%$ of the variance of the dependent variable was associated with the age factor. BOI and COI had a large effect size, ICM a medium effect size and ATT a small effect size on age.

Overall attitudes toward inclusion indicated that older teachers tended to be accepting of inclusive education than younger ones. Older teachers showed more favorable attitudes toward inclusive education than younger teachers - the older a 
teacher, the more likely he or she was going to be supportive of inclusive education. Teachers 40 years old and above were more supportive of inclusive education than their younger colleagues, $F(5,340)=4.62, p=.00, \prod^{2}($ effect size $)=.064$. According to the study conducted by Burge et al. (2008), younger teachers showed more positive attitudes toward including students with disabilities in the general education classrooms. Nevertheless, some studies have revealed that age does not influence teachers' attitudes toward including students with special education needs in their classrooms (Avramidis et al., 2000).

Level of Education: There were significant differences in teachers' perceptions of BOI, $F(2,34)=3.96, p<.05 ;$ ATT $F(2,34)=4.52, p=.05 ;$ and COI $F(2,34)=6.18, p<$ .05.Teacher's perceptions related to ICM were not significantly different by their level of education or highest degree, $F(2,34)=2.07, p>.05$.

The level of education of teachers had a significant medium effect on three dependent variables, BOI (2.3\%), ATT (2.6\%), and COI (3.5\%) but showed a small significant effect on $\operatorname{ICM}(1.2 \%)$. In the case of BOI, the $\Pi^{2}=.023$ indicates that approximately $2.3 \%$ of the variance of the dependent variables associated with the teachers' level of education, ATT, the $\prod^{2}=.026$ shows that approximately $2.6 \%$ of the variance of the dependent variable is related to the teachers' level of education while the $\eta^{2}=.035$ for COI also indicated that $3.5 \%$ of the variance of the dependent variable was associated with the level of education factor. The teachers' level of education was stronger when it came to the concept of inclusion. Teacher's perceptions related to ICM were not significantly different on the basis of their level of education. The $\prod^{2}=.012$ 
indicated that approximately $1.2 \%$ of the variance of the dependent variable was associated with the teachers' level of education.

Overall attitudes toward inclusion on the basis of the level of education indicate that the more educated teachers tended to be more supportive of inclusive education than lesser educated ones. The higher the level of education, the more likely teachers were going to be supportive of inclusive education, $F(2,340)=7.95, p=.00, \eta^{2}($ effect size $)=$ .044. These results are conversant with those of Dupoux, Hammond, Ingalls, and Wolman (2006), and Moberg and Savolainen (2003) who concluded that teachers with higher qualifications had positive perceptions than those with lower qualifications.

Teaching Experience: There were significant differences in teachers perceptions on the basis of teaching experience in the following variables: $\mathrm{BOI}, F(6,34)=3.90, p<$ $.05 ;$ ATT, $F(6,84)=2.56, p<.05 ;$ and COI, $F(6,34)=3.94, p<.01$. Teachers' perceptions of ICM were not impacted by their years of teaching experience, $F(6,34)=$ $1.08, p>.05$.

In the case of ICM, the partial eta square $=.019$ indicate that approximately $1.9 \%$ of the variance of the dependent variable was associated with the teaching experience factor while the partial eta square $=.065$ for BOI and COI indicate that approximately $6.5 \%$ of the variance of the dependent variable was associated with the teaching experience factor. The partial eta square for teachers' perceived ATT $=.043$, indicates that approximately $4.7 \%$ of the variance of the dependent variable was associated with the teaching experience factor. The results indicate that the three dependent variables were significantly affected by teaching experience because the effect size for these variables is considered to be large. 
Overall attitudes toward inclusive education on the basis of teaching experience indicated that teachers' support grew in the early years of their career (6 years to about 25 years), but the support steadily falls after 30 years of teaching $F(6,340)=4.08, p=.001$, $\eta^{2}($ effect size $)=.067$

Experience Teaching in the Inclusive Classroom: Teachers' teaching experience in special education classrooms have significantly affected their perceived ability to teach children with disabilities: ATT, $F(1,34)=5.27, p<.05$ and COI, $F(1,34)=10.99, p<.05$. Neither teachers' perceived BOI nor their ICM were statistically significant: BOI, $F(1,34)=2.14, p>.05$ and $\mathrm{ICM}, F(1,34)=2.26, p>.05$.

As for teachers' perception concerning their experience teaching in inclusive classrooms, the results show that the eta square for $\mathrm{BOI}=.031$ indicates that approximately $3.1 \%$ of the variance of the dependent variable was associated with teachers' experience teaching in the inclusive classroom. The results also show that the three dependent variables BOI (0.6\%)' ICM (0.7\%), and ATT (1.5\%) were not significantly affected by teachers' experience teaching in inclusive classrooms. The effect size for the three variables was considered to be small.

On the whole, teachers who said they had some experience teaching special needs students in an inclusive classroom $(M=3.49, S D=0.54)$ tended to be more supportive of inclusive education than those who said they had no experience $(M=3.29, S D=0.53), F$ $(1,34)=11.99, p=.003, \prod^{2}($ effect size $)=.025$. Results of studies carried out by Avramidis and Norwich (2002), and Taylor, Smiley, and Ramasamy (2003) are contrary to those of this study in that that teachers with more years of teaching experience were less supportive of inclusive education than those with fewer years. 
Training in Special Education: Teachers' attitudes toward inclusive education were affected by their training or lack of training in special education only in the variable about their perceived concept of inclusion $(\mathrm{COI}), F(1,34)=5.33, p<.05$. Teachers' training or lack thereof did not influence their perceptions of inclusive education in the following areas: BOI, $F(1,34)=2.01, p>.05 ; \mathrm{ICM}, F(1,34)=1.04, p>.05 ; F(1,34)=$ $2.50, p>.05$.

In the case of BOI, the $\eta^{2}=.006$ indicated that approximately $0.6 \%$ of the variance of the dependent variable is associated with the training factor while the $\Pi^{2}=$ .003 for ICM also shows that roughly $0.3 \%$ of the variance of the dependent variable was associated with the training factor. The $\Pi^{2}=.007$ for perceived ATT indicated that approximately $0.7 \%$ of the variance of the dependent variable was associated with the training factor and $\prod^{2}=.015$ for perceived COI indicated that approximately $1.5 \%$ of the variance of the dependent variable was related to the training in special education. The effect size for the four dependent variables, BOI (0.6\%), ICM (0.3\%), ATT (0.7\%), and COI (1.5\%), was not significantly affected by teachers' training in special education because the effect sizes are considered to be small.

The overall mean score for teachers who said they had never received any training in special education, $M=3.68, \mathrm{SD}=.46$, was significantly lower than the mean score for those who stated that they had received some form of training in special education, $M=$ $3.79, \mathrm{SD}=.52$. This means that teachers were more likely to be supportive of inclusive education if they had training in special education as opposed to those who did not have any training. O'Toole and Burke (2013) in their study of pre-service teacher attitudes 
towards inclusive education reveal that teachers were positive about inclusion accounted for by their higher level of personal efficacy and lower levels of concern.

Language of Instruction: In all the research variables, no significant differences in perceptions were found between teachers who used French, English or both as languages of instruction: BOI, $F(2,34)=.34, p>.05$; ICM, $F(2,34)=.34, p>.05$; ATT, $F(2,34)=$ $2.85, p>.05 ;$ COI, $F(2,34)=.31, p>.05$.

The results concerning the language of education show that the four dependent variables were not not significantly affected by the language of instruction because the effect sizes for these variables are considered to be small. As for BOI and COI, the $\prod^{2}=$ .002 indicated that approximately $0.2 \%$ of the variance of the dependent variable was associated with the language of instruction factor while the $\prod^{2}=.000$ for ICM also indicates that approximately $0 \%$ of the variance of the dependent variable was associated with the language of instruction factor. The $\eta^{2}=.008$ for perceived ATT indicated that approximately $0.8 \%$ of the variance of the dependent variable was associated with the language of instruction factor.

\section{Interpretations and Discussions}

This study, unlike previous related studies on inclusive education in Cameroon, focuses on attitudes of general education teachers actively experimenting with inclusive education in the SEEPD pilot program. The attitudes shown by teachers in this context have the potential to be more revealing because these teachers have firsthand information about their budding inclusive classroom experiences. Similar studies have been done with teachers in general education institutions that were not all actively engaged in inclusive education (Amah \& Swain; 2014; Stubbs, 2002). The risk with sampling the opinions of 
teachers who are actively involved in inclusive education is that their perceptions can be very subjective as a result of personal biases, fears, and beliefs.

The study investigated the attitudes of general education teachers in some selected schools engaged in a pilot inclusive education program in a country that is still lagging behind in the practice of special education in general and inclusive education in particular (Ambei, 2016; Arrah \& Swain, 2014; Mbibeh, 2013; Shey, 2003; Tanyi, 2016; Tukov, 2008). The findings suggest that even though teachers were very supportive of the benefits of inclusion, $M=4.28, S D=0.68$, they would still prefer to have separate schools or classrooms for students with disabilities, or special education needs as shown by their perceptions of the concept of inclusion, $M=3.07, S D=0.91$. Previous studies have also indicated general education teachers' discomfort with the concept of inclusion (Bailey, Nomanbhoy, \& Tubpun, 2015; Chhabra, Srivastava R, \& Srivastava I, 2010; Thaver \& Lim, 2014). On the other hand, Tindall et al. (2015) reported a positive change in attitude and perception toward both the idea of inclusion and working with persons with disabilities in Ireland. This finding indicates the possibility of change in attitudes with time, especially when there is a more concerted effort to promote inclusion through education investment, education training, and sensitization.

Their preference of separate classrooms by teachers for children with disabilities is also congruent with the low self-evaluation of their ability to teach students with disabilities. Only $29.3 \%$ of teachers thought they had the ability to teach students with disabilities, $M=2.55, S D=.91$. These findings are congruent with Arrah and Swain (2014) who found that general education teachers in Buea, the Southwest Region of Cameroon, needed the training to work with special need students. Other studies have 
also confirmed that teachers become significantly more accepting of inclusion in schools when they participate in teacher preparation programs and in-service training that combine general and special education curricula (Boyle et al., 2013; Engelbrecht et al., 201; Ji-Ryun, 2011).

Even though teachers were not supportive of the concept of inclusion and thought that they did not have skills and strategies to teach students with disabilities, they still felt that inclusive education is beneficial to all students. About $74 \%$ of teachers believed that inclusive classrooms would help both the student with special needs and the regular student, $M=4.45, S D=.66$. A more than an average number of teachers were also positive about their abilities to ICM, $M=3.68, S D=.59$. This finding seemed contradictory to teachers' claim that they did not have the ability to teach students with disabilities. However, considering that the participants in the study were teachers in the SEEPD pilot inclusive education program, it is understandable that most of them might have taken part in some of the training workshops on integrated classroom management offered in schools participating in the pilot program (Mbibeh, 2013; SEEPD, 2011; Tohnain \& Tamanjong, 2014). This consideration leads to the conclusion that even though teachers recognized that short training workshops gave them a substantial head start in inclusive education, they still need to receive formal training in inclusive education and special education to cope with the demands of the classroom (Ji-Ryun, 2011; Mbibeh, 2013).

In the 1983 law number 83/013, the government of Cameroon legislated support for the education of children with disabilities and their integration in public general education schools. The law also contained provisions for various grants to help special 
education schools, special pedagogical assistance, training of specialized staff, and the development of adapted curricula. The findings of this study and previous studies concur that there have been serious issues with the application of 1983, 1990, 2010 law, and other recent government executive orders such as the joint circular letter No. 34/06/LC. The executive order (joint circular letter No. 34/06/LC) was signed on 2 August 2006 by the Ministers of Secondary Education and Social Affairs. Its aim was to facilitate the enrolment of children with disabilities or born to poor persons with disabilities, in public secondary schools (Arrah \& Swain, 2014; Mbibeh, 2013). This study reveals that the training of teachers in special education remains a huge hindrance to the implementation of special education laws. Only 64 out of 346 teachers said they were trained in special education. The support for inclusive education was significantly stronger among teachers who had trained in special education, $M=3.76, S D=.52$, as opposed to those who said they had no training, $M=3.68, S D=.46$. The results depict that teachers were more likely to be supportive of inclusive education if they had training in special education as opposed to those who did not have any training.

As supported by the findings, one of the biggest challenges of inclusive education remains the shortage of trained teachers. The local Higher Teachers' Training College located in the SEEPD pilot inclusive education program constituency at Bambili recently initiated a course in inclusive education for guidance counselors and intends to move further to extend this training to classroom teachers (Mbibeh, 2013). These are timid moves that lead to no significant difference in teacher readiness for inclusive classrooms. However, it is a vital initiative that must become more elaborate and consistent. The local 
training schools and universities should prioritize teacher education programs that have a strong special education component (Boyle et al., 2013; Ji-Ryun, 2011).

The finding from this study that about $70.63 \%$ of teachers believed they did not have the ability to teach students with disabilities is not only indicative of teachers' need for training but also an indication that there is still an acute lack of resources to support special education and the teaching of students with disabilities. The shortages of trained teachers and resources, unfortunately, remain serious, 32 years after the country of Cameroon introduced legislation containing provisions for various grants to support special education schools, special pedagogical assistance, training of specialized staff, and the development of adapted curricula (Biya, 1984). According to the Disability and Rehabilitation Team (2002), the acute shortage of resources for special education in Cameroon have not provided a strong springboard for the development of inclusive schools. The policy of inclusion can be effective if regular schools are equipped with facilities, such as self-contained classrooms, resource rooms, trained teachers, and paraprofessionals, needed to provide vital support to students grappling with learning (Cook, 2001; Friend \& Bursick, 2006). Indeed, many experts suggest that the success of inclusion depends on the knowledge, instructional skills, and in particular on the attitudes and beliefs of general education teachers toward the integration of students with disabilities (Cook, 2001; Friend \& Bursick, 2006). This study affirms that teachers' ATT students with disabilities, $M=2.55, S D=0.95$, is still highly negatively impacted by the lack of knowledge and instructional skills in practices such as differentiated instruction and response to intervention, which in turn influence their beliefs and attitudes. 
Even though evidence regarding gender as a factor affecting teachers' attitudes toward inclusion is inconsistent, the findings of this study indicate that teachers' gender significantly affected their perceived BOI for students $\left(p=.014, \eta^{2}=.017\right)$. Any suggestions about why males were more positive about the benefits of inclusion than females would be based on speculation. Findings from many studies (Boyle et al., 2013; Jobe \& Rust 1996; Leyser \& Tappendorf 2001; Stubbs 2008) confirm these inconsistencies, but it is hard to explain why males and females may see things differently on this subject. A historical and sociocultural analysis of the context may give clues that explain why female teachers were less positive about the benefits of inclusion than their male colleagues. This finding may also be accounted for by the fact that out of 346 teachers who participated in this study, 53\% were males and $47 \%$ females. While the results of some studies reveal that male teachers had more positive attitudes than female teachers, results of other studies indicate that female teachers had more positive attitudes toward inclusion (Avramidis et al., 2000; Carroll et al., 2003; Ellins \& Porter, 2005, Jobe \& Rust, 1996).

Regarding age, older teachers tended to be more supportive of inclusive education than younger ones. This finding revealed that older teachers in general education schools engaged in the practice of inclusive education are not resistant to change nor do they have the tendency to want to preserve the status-quo, as suggested by Clark (1997). The more positive attitudes shown by older teachers could be indicative of continuous exposure to the practice of special education, ongoing professional learning opportunities, workshops, and seminars have given them more ability to accommodate students with disabilities in the general education classrooms (Hwang \& Evans, 2011). This positive attitude is also 
an indication of the importance of continual in-service training for teachers on the management of inclusive classrooms. These findings do not concur with the conclusions of researchers who say that age does not influence teachers' attitudes toward inclusion (Avramidis et al., 2000). Similarly, they do not match with earlier findings that younger persons show more positive views toward the inclusion of students with a disability in the general education classrooms (Burge et al., 2008).

The finding that the higher the level of education, the more likely teachers were going to be supportive of inclusive education is congruent with most literature on teachers' attitudes toward inclusive education. The study found that teachers with masters or doctoral degrees had significantly more positive attitudes than those with bachelor's degrees when teachers' perceived ability to teach children with disabilities and their perceived concept of inclusion were examined. The results of this study tie in with the results of Dupoux et al., (2006) on the attitudes of elementary and secondary school teachers. They found that teachers with a Master's degree had a more positive attitude toward inclusive education $(\mathrm{M}=3.45, \mathrm{SD}=0.61)$ than those who had less than a Masters Degree $(M=3.10, S D=0.49)$.

Similar to the findings of this study, Moberg, and Savolainen (2003) conclude that teachers with higher qualifications have positive attitudes toward inclusion than teachers with lower qualifications. These conclusions indicate the need for educational authorities in Cameroon to provide incentives for teachers to pursue graduate specializations in teacher education. The inference here is clearly that the more teachers are educated, the more likely they will be exposed to training related to the teaching of students with special needs. 
In a context like the one studied, where teachers agree that they need more training to have the ability to teach students with disabilities, it means that giving teachers the opportunity to get more training, do graduate programs, or take graduate level courses related to inclusive education would likely be beneficial.

Also, the conclusion that teachers with training in special education were more supportive of the concept of inclusion than their counterparts with no training is additional evidence that the training of more teachers in special education can make a difference in the practice of inclusive education. It is the duty of inclusive schools such as the SEEPD program schools and educational authorities to recognize and respond to the diverse needs of students, ensure the accommodation of both different styles and rates of learning, and provide quality education to all through appropriate curricula, organizational arrangements, teaching strategies, resource use, and partnerships with their communities. This endeavor can be accomplished by making sure that teachers receive quality training and are provided with the resources needed to work in inclusive classrooms (U.S. Department of Health and Human Services and U.S. Department of Education, 2015).

Teachers should not find themselves in a situation which demands that they look for information and resources needed for routine classroom activities (Gersten \& Woodward, 1990; Lauchlan \& Greig, 2015). Rather, teachers should be provided all the support required for them to embrace new inclusive education initiatives such as the SEEPD pilot program and other similar nascent initiatives in Cameroon. A review of teachers' needs is always very crucial since teachers' complaints about resources need "clarity about the nature of the resources required, and indeed why they are needed at all" 
(Lauchlan \& Greig, 2015, p. 71). Boyle (2012) had also argued that putting the wrong resources into the inclusive education environment without a clear and accurate action plan could worsen teachers' output instead of improving it. In the context of Cameroon, it is necessary to be certain about what the exact needs of teachers are as well as the expectations regarding outcomes.

Several findings from studies investigating teachers' attitudes toward inclusive education practices have concluded that teachers with more years of experience have a more negative attitude toward inclusion than teachers with fewer years of teaching experience (Avramidis \& Norwich, 2002; Leyser \& Tappendorf, 2001; Moberg \& Savolainen, 2003; Taylor et al., 2003). The findings from this study do not completely concur with these studies. Overall teachers' attitudes toward inclusive education by teaching experience indicated that teachers' support grew in the early years of their career ( 6 years to about 25 years) but steadily fell after 30 years of teaching, $F(6,340)=4.08, p$ $=.001, \eta^{2}=.067$. Teachers with 31 years or more of teaching experience certainly need more professional support and incentives, if these results are an indication that teachers' motivation to teach inclusive classrooms is on the decline after 30 years of teaching. Studies on special education and inclusive education in Cameroon have consistently indicated inadequate technical and material support for teachers (Ebontane, 2010; Mbibeh, 2013; Shey, 2003; Tukov, 2008). The persistence of this lack of resources can lead to frustration among teachers, which might explain why these findings indicate that the more experienced teachers became, the more likely they were going to be unsupportive of inclusive classrooms. 
Research has frequently demonstrated that teachers tend to be uncomfortable with new practices due to the fear of the unknown and additional workloads (Kazlow \& Giacquinta, 1977; McInnis, 2000; Mngo, 2011). However, the more they get conversant with new practices, fear gradually disappears. The finding confirmed this trend of attitudes that teachers who had experience teaching students with disabilities were more comfortable with their ATT and the COI than teachers who had no experience. On the whole, teachers with some experience teaching special needs students in an inclusive classroom $(M=3.76, S D=0.47)$ tended to be more supportive of inclusive education than those who said they had no experience $(M=3.60, S D=0.48)$. These findings are congruent with the literature which indicated that Cameroonian teachers are ill-equipped to teach students with special education needs in inclusive classrooms (Ambei, 2016; Ebontane, 2010; Mbibeh, 2013; Shey, 2003; Tanyi, 2016; Tukov, 2008).

\section{Limitation}

The study was limited to teachers with a bachelor's, masters or doctorate who volunteered and were present in the schools at the time the instrument was administered. A total of 400 surveys were administered to willing participants, and 348 were returned, indicating a response rate of $87 \%$. Of the 348 returned surveys two were incomplete or computed incorrectly. Some participants used pencils that were not the number $2 \mathrm{HB}$ pencils provided by the researcher. Using pencils that were not the $2 \mathrm{HB}$ pencils on the instrument meant that the machine could not scan the responses accurately.

Limitations were also noticeable with the scope of the study. The population for the investigation was limited to general education teachers (Grades 6-12). Thus, there is a limitation to the generalization of the findings, which should not extend to all general 
education teachers. The schools were limited to those participating in the SEEPD inclusive education program. These were all bilingual public schools meaning that private schools were not included.

Also, participants in the study came from one of the ten regions of the country. Even though this choice was motivated by the region's strong history of accommodation of persons with disabilities and recent advances in the inclusion of students with disabilities in the general education schools, it is a concern that teachers' attitudes toward inclusion in other regions might have significant culturally-influenced variations.

Another limitation of the study is that it only focuses on secondary school teachers - teachers covering grades 6-12. The study does not investigate the attitudes of the primary level teachers even though the attitudes of teachers in primary schools could differ in some ways from those of their counterparts in secondary schools. In the elementary schools, there are more female teachers than male teachers. Consequently, there would be a big imbalance in gender representation resulting possibly in new attitudinal findings if elementary school teachers were included in the study.

\section{Implications and General Recommendations for Practice}

The findings of this study support a trend characterized by the inability of Cameroonian schools to implement the 1984 legislation stipulating government aid to special education and the development of inclusive education. The slow pace of the development of inclusive education schools in the country was not unexpected because the same 1984 law stated that the financing of inclusive classrooms would depend on the means available to the authorities (Biya, 1984). These results indicate that for special education and inclusive education to work properly in Cameroonian schools, authorities 
have to prioritize its funding, including the unconditional provision of funds for teacher education, the creation of special education programs in colleges and universities, the development of self-contained classrooms and instructional tools and resources.

Based on the findings of the study as reflected by teachers' perspectives on the practice of inclusive education in the seven selected schools engaged in the SEEPD pilot inclusive education program, recommendations are grouped into seven main areas of concern. The areas include (a) introduction of special education courses in teacher training colleges, (b) ongoing professional development in inclusive education, (c) creation of special education programs in public and private universities, (d) adaptive curriculum development and dissemination, (e) training and recruitment of professionals and paraprofessionals, (f) breaking cultural barriers to inclusive education, and (g) prioritizing new funding sources for inclusive education.

\section{Introduction of Special Education Courses in Teacher Training Colleges}

The study reveals that most of the participants who are graduates from the government funded teacher training colleges were more supportive of inclusive education if they had training in special education $(M=3.76, S D=.52)$ as opposed to those who did not have any training $(M=3.68, S D=.46)$. Out of a total of 346 teachers who participated in this study, $18.5 \%$ of teachers said they had received some form of training in special education, while $81.5 \%$ stated that they had never been trained in special education.

As a result, we recommend that the government should ensure the introduction of special education courses in the three higher teacher training colleges in the country. When more than $80 \%$ of teachers involved in a pilot inclusive education program say 
they have no training in special education, it is clear that something needs to be done. These conclusions fall in line with the findings of Tohnain and Tamajong (2014) who identify the absence of courses and programs for the education of people with disabilities in teacher training colleges in Cameroon as a major drawback to the implementation of inclusive practices in regular schools.

\section{Ongoing Professional Development}

The study found that teachers who said they had some experience teaching students with disabilities in an inclusive classroom $(M=3,49 S D=0.54)$ tended to be more supportive of inclusive education than those who said they had no experience $(M=$ 3.29.20, $S D=0.53), F(1,340)=11.99, p=.001, \prod^{2}($ effect size $)=.025$.

There is a strong need to institute and strengthen the special education component in professional development programs in schools. Even when teachers do not receive formal training in schools on how to manage inclusive classrooms, they can still become productive if given a chance to improve their knowledge and skills through short inservice training programs such as seminars and training workshops. The SEEPD program leaders seem to understand the need for professional development, which explains why they have come up with a plan to construct the first resource center in the Government Bilingual High School in Bamenda. This center will serve as a location for seminars and workshops, and provide a library, ICT, Braille services, books, and equipment related to the education of students with disabilities (Muffih, 2011a). Also, National and Regional Boards of Education could also implement required courses in Special Education as part of a teacher's pre-service educational requirements. These measures will ensure the initial exposure to handling students with special education needs and educate the experienced 
teachers on contemporary issues regarding inclusive settings. Evidence provided in this study shows that there are still many questions that need answers and that further studies on general education teachers' attitudes toward inclusion and effective inclusive practices are necessary.

\section{Creation of Special Education Programs in Colleges and Universities}

The findings demonstrate that teachers' perceived COI was influenced by training in special education or lack thereof. They tended to be more supportive of the concept of inclusion as opposed to separate schools for students with disabilities when they had received some form of training in special education $(M=3.30, S D=0.88)$. Teachers with no training at all were significantly less supportive of the COI $(M=3.0, S D=0.91)$.

As a result, it is necessary to create programs for the training of teachers in special education because they are likely to be accepting of the whole concept of inclusion if they receive adequate training. The lack of special education specialists in schools in Cameroon has led to the perception that it is an imported practice and has made teachers less receptive because of the fear of the unknown. It is therefore of great importance to create special education training programs in Cameroonian colleges and universities if the authorities want educators and education stakeholders to embrace the concept of inclusion. The trained special education specialists can lead the effort of inclusion by providing coaching and counsel to their general education colleagues managing inclusive classrooms. Friend and Bursuck (1999) conclude that the ability of general education teachers to accommodate students with special education needs is contingent on guidance from resource teachers or special education teachers who coordinate student services and IEPs for each student with special education needs. 


\section{Adaptive Curriculum Development and Dissemination}

For successful inclusive education to take place, teachers need to tailor the curriculum to suit the needs of all students. To achieve effective inclusion, it begins with proper diagnosis and categorization of students with special education need. Without clear categorization, the development and dissemination of curricula adapted to the needs of the students with special needs become an uphill task. Findings of this study indicate an acute shortage of trained professionals who can ensure proper identification of disabilities as well as the development of curricula that can accommodate the students with various disabilities in general education classrooms.

Literature indicates that curriculum accommodation can be done through the Universal Design for Learning strategy. It is a theoretical framework that guides the development of curricula that are flexible and supportive of students with special education needs (Dolan \& Hall, 2001; Rose, 2001; Rose et al., 2000). The concept calls for the design of structures that anticipate the needs of individuals with disabilities and the accommodation of these needs from the onset (Smith, 2007). The curriculum should be innately flexible, enriched with multiple media, so that the alternatives can be assessed whenever necessary. In order to ensure a successful design for structures that take adequate care of students with special needs of different categories, it is important to begin by creating a special workforce to analyze the current curriculum, in addition to one that determines how to test and evaluate students with specific needs. 


\section{Training and Recruitment of Professionals and Paraprofessionals}

The successful implementation of any inclusive education initiative requires the efforts of trained special education teachers and paraprofessionals (UNESCO, 2009b). A real diagnosis, categorization, and accommodation of students with special needs will only be possible when the Cameroonian education system has a reasonable number of trained special education professionals, including teachers, paraprofessionals, and related service providers. The study results indicate the shortage of special education professionals and by implication the absence of paraprofessionals. In a context where more than $80 \%$ of teachers have either had no experience in teaching students with disabilities or received any form of training on inclusive education, it is evident that there is a huge need to train not only special education professionals but also paraprofessionals.

\section{Breaking Cultural Barriers to Inclusive Education}

Even though several factors may contribute to the finding that teachers' attitudes toward the concept of inclusive education (separate versus integrated classrooms) were negative $(M=3.00, S D=0.91)$, literature affirms that the cultures, norms, and traditions of Cameroon constitute an important factor. The Cameroonian cultures, for the most part, see the bringing up and education of children with disabilities as the responsibility of the parent. This belief explains why the local cultures in Cameroon are both helpful and harmful to the condition of persons with disabilities. The strong family support system within the communities compensates, to some extent, for the acute shortage of special education facilities. Tukov (2008) admits that children with hearing impairments, visual impairments, autism, mental retardation and physical or health disabilities receive invaluable support from parents and family members. There is always someone home to 
provide for their basic needs. Notwithstanding, it is important to help teachers move away from this mindset by providing the right training and accepting their role in the education of students with special education needs, especially in inclusive environments

There might be no clear relationship between the overall negative teachers' attitudes toward the inclusion of students with disabilities in the general education classroom and the Cameroonian government's handling of special education as a subcategory of education. Nonetheless, it is not a stretch to recommend that the government should consider the education of children with disabilities as part and parcel of national education and not a subcategory, by placing the education of children with disabilities under the Ministries of Basic and the Ministry of Secondary Education. The current arrangement that places the management of special education under three ministries - Ministry of Social Affairs, Ministry of Basic Education, and Ministry of Secondary Education — renders the administration of special education ineffective. The subcategorization of special education is likely influenced by the culturally prejudiced perception of the education of children with disabilities as a social and benevolent service instead of responsibility or duty. These perceptions, advertently or inadvertently, tend to influence the quality of education services rendered to students with disabilities. The education of children with mild to severe disabilities should not be largely limited to vocational training because every student has the potential to succeed. The society is better served when all students, including those with disabilities, are given equal opportunities and rights to learn in non-restrictive environments. 


\section{Prioritizing New Funding Sources for Inclusive Education}

Training of special education and inclusive education professionals in Cameroon require much investment by government and other education stakeholders such as churches and local organizations. A major reason for the shortage of trained professionals `could be the lack of funding for teacher training programs, resources, and pilot inclusive education programs such as the SEEPD. Mbibeh (2013) points out that parents, teachers, and administrators are of the opinion that "low budgetary allocations are impediments to the implementation of IE" (p. 65).

\section{Specific Recommendations to the SEEPD Program Managers}

The SEEPD program is not a sufficiently funded program. As a result, the program goals and capacity are limited by its means. This limitation explains why the program covers only selected schools in one of the ten regions of Cameroon. Based on the findings of this study the SEEPD program leaders can do the following things to improve its implementation and scope:

1. Develop an intensive in-service training program for teachers in special education, in general, and inclusive education, in particular. Such programs should be continuous, and professionals should be invited to provide much-needed expertise in inclusive classroom teaching strategies for effective instruction such as Differentiated Instruction, Universal Design for Learning, and Responses to Intervention.

2. Seek to fund from diverse sources to ensure that essential resources such as assistive technologies are made available to students. Considering the financial limitations faced by the program, it will only be able to acquire useful assistive resources 
through partnerships. Physically challenged students need mobility aids, such as wheelchairs, scooters, walkers, canes, crutches, prosthetic devices, and orthotic devices, to enhance their mobility. Other assistive devices that could make a difference for the program participants are audio players, timers, reading guides, Frequency Modulation (FM) listening systems, calculators, writing supports, and graphic organizers.

3. Partner with international schools for teachers and students to have access to basic didactic resources such as textbooks, student workbooks, worksheets, large print texts, Braille texts, videos, software, and internet resources.

\section{Recommendations for Future Research}

The findings of the study show the need for further research in several inclusive education related areas, including:

1. Studies that follow up on the results of this study. This study investigated the attitudes of secondary school teachers in a pilot inclusive education program. This pilot program covers both primary (k1-5) and secondary (grades 6-12) schools. It will be logical to suggest for two follow-up studies. The first of the two studies would investigate primary school teachers' attitudes, in the same pilot inclusive education program.

2. A second study could be done to compare primary school teachers' attitudes toward inclusive education with those of the secondary school teachers. Such a study will not only determine if the ages of students with disabilities influence how teachers perceive their ability to learn in an inclusive environment, but also if teachers' levels of education influence their perceptions since primary school teachers in the country are less educated - most of them are not college graduates. 
3. The impact of the availability of resources. Teachers' abilities to teach students with special needs is largely affected by the availability of resources. Further research can be done to find out teachers' beliefs about the availability of resources and the usefulness of such remedies. Their opinions about the types of support needed and from whom they expect the support would constitute important, informative data that could be used by educational stakeholders.

4. The influence of customs, traditions, and beliefs on attitudes teachers have toward students with disabilities, and their inclusion in general education classrooms is still strong among Cameroonian K-12 teachers. An indication of this influence of this finding could be seen in the current study where $82.95 \%$ of teachers think that most students with disabilities will not be able to make an adequate attempt to complete their assignments. The perception certainly influences this mindset that persons with disabilities are "handicapped" individuals. A socio-cultural investigation of the impact of culture on Cameroonian teachers' attitudes toward inclusive education in the $21^{\text {st }}$ century can reveal salient barriers to inclusion that would otherwise be neglected.

5. A follow-up study that investigates whether or not teachers' levels of consent for inclusive education vary by the type of disabilities. This variation is likely an area of interest because the challenges of integration of students with physical disabilities would differ from those of students with emotional and behavioral disorders.

\section{Summary}

The findings of this study show that most teachers in Cameroon still prefer separate special education institutions to inclusive ones. Their perceptions of the concept of inclusion (or special versus integrated general education) clearly indicate an overall 
negative attitude toward inclusive education as a whole. With $71 \%$ of teachers thinking that integration will likely have an adverse effect on the emotional development of the student with a disability in an inclusive classroom, it is clear that for inclusive education to be embraced, a concerted effort will be needed from all education stakeholders in Cameroon. It is even more of a concern when $82.95 \%$ of teachers think that most students with disabilities will not make an adequate attempt to complete their assignments in an inclusive learning environment. Considering that this study was conducted among teachers in general education institutions currently experimenting with inclusive education, it is likely that the attitudes would be poorer if the study was carried out in most of the schools that were not involved in inclusive education practices. This thought is testimony that the acceptance and growth in the practice of inclusive education in Cameroon, as a whole, remains a walking progress. The pace of this walk and the time it eventually takes to reach the end goal, which is the total acceptance of inclusive education, will depend to a significant extent on the contribution of national educational stakeholders, including government, churches, private individuals, educational leaders, and teachers. 
APPENDIX A

SURVEY 


\section{Opinions Relative to the Integration of Students with Disabilities}

General Directions: Educators have long realized that one of the most important influences on a child's educational progress is the classroom teacher. The purpose of this questionnaire is to obtain information that will aid school systems in increasing the classroom teacher's effectiveness with students with disabilities placed in his or her classroom. Your participation in this survey is voluntary, and your responses are completely anonymous and confidential. Please give your response to each item by checking the box that best expresses your opinion.

\begin{tabular}{lccccccc}
\hline Statement & $\begin{array}{c}\text { Strongly } \\
\text { disagree }\end{array}$ & Disagree & $\begin{array}{c}\text { Not sure } \\
\text { but tend } \\
\text { to } \\
\text { disagree }\end{array}$ & $\begin{array}{c}\text { Not sure } \\
\text { but tend } \\
\text { to agree }\end{array}$ & $\begin{array}{c}\text { Agree } \\
\text { Strong } \\
\text { ly } \\
\text { agree }\end{array}$ \\
& 1 & 2 & 3 & 4 & 5 & 6 \\
\hline
\end{tabular}

1. Most students with disabilities will make an adequate attempt to complete their assignments.

2. Integration of students with disabilities will necessitate extensive retraining of general classroom teachers.

3. Integration offers mixed group interaction that will foster understanding and acceptance of differences among students.

4. It is likely that a student with disability will exhibit behavior problems in a general classroom

5. Students with disabilities can best be served in the general education classroom.

6 . The extra attention students with disabilities require will be to the detriment of the other students. 


\begin{tabular}{lcccccc}
\hline Statement & $\begin{array}{c}\text { Strongly } \\
\text { disagree }\end{array}$ & Disagree & $\begin{array}{c}\text { Not sure } \\
\text { but tend } \\
\text { to } \\
\text { disagree }\end{array}$ & $\begin{array}{c}\text { Not sure } \\
\text { but tend } \\
\text { to agree }\end{array}$ & $\begin{array}{c}\text { Agree } \\
\text { Strongly } \\
\text { agree }\end{array}$ \\
& 1 & 2 & 3 & 4 & 5 & 6 \\
\hline
\end{tabular}

7. The challenge of being in a general classroom will promote the academic growth of the student with a disability.

8. Integration of students with disabilities will require significant changes in general classroom procedures.

9. Increased freedom in the general classroom creates too much confusion for the student with a disability.

10. General classroom teachers have sufficient training to teach students with disabilities.

11. The presence of students with disabilities will not promote acceptance of difference on the part of students without disabilities.

12. The behavior of students with disabilities will set a bad example for students without disabilities.

13. The student with a disability will probably develop academic skills more rapidly in a general education classroom than in a special classroom.

14. Integration of the student with a disability will not promote his or her social independence.

15. It is not more difficult to maintain order in a general classroom that contains a student with a disability than in one that does not contain a student with a disability. 


\begin{tabular}{lcccccc}
\hline Statement & $\begin{array}{c}\text { Strongly } \\
\text { disagree }\end{array}$ & Disagree & $\begin{array}{c}\text { Not sure } \\
\text { but tend } \\
\text { to } \\
\text { disagree }\end{array}$ & $\begin{array}{c}\text { Not sure } \\
\text { but tend } \\
\text { to agree }\end{array}$ & $\begin{array}{c}\text { Agree } \\
\text { Strongly } \\
\text { agree }\end{array}$ \\
& 1 & 2 & 3 & 4 & 5 & 6 \\
\hline
\end{tabular}

16 Students with disabilities will not monopolize the general classroom teacher's time.

17 The integration of students with disabilities can be beneficial for students without disabilities.

18. Students with disabilities are likely to create confusion in the general classroom.

19. General education teachers have the ability necessary to work with students with disabilities.

20. Integration will likely have a negative effect on the emotional development of the student with a disability.

21. Students with disabilities should be given every opportunity to function in the general classroom where possible.

22. The classroom behavior of the student with a disability generally does not require more patience from the teacher than does the classroom behavior of a student without a disability

23. Teaching students with disabilities is better done by special than by general education teachers. 


\begin{tabular}{|c|c|c|c|c|c|c|}
\hline Statement & $\begin{array}{l}\text { Strongly } \\
\text { disagree }\end{array}$ & Disagree & $\begin{array}{l}\text { Not sure } \\
\text { but tend } \\
\text { to } \\
\text { disagree }\end{array}$ & $\begin{array}{l}\text { Not sure } \\
\text { but tend } \\
\text { to agree }\end{array}$ & Agree & $\begin{array}{c}\text { Strongly } \\
\text { agree }\end{array}$ \\
\hline & 1 & 2 & 3 & 4 & 5 & 6 \\
\hline $\begin{array}{l}\text { 24.Isolation in a special } \\
\text { classroom has a beneficial effect } \\
\text { on the social and emotional } \\
\text { development of the student with } \\
\text { a disability }\end{array}$ & $\square$ & $\square$ & $\square$ & \begin{tabular}{|l} 
\\
\end{tabular} & $\square$ & $\square$ \\
\hline $\begin{array}{l}\text { 25. The student with a disability } \\
\text { will not be socially isolated in } \\
\text { the general classroom. }\end{array}$ & $\square$ & $\square$ & $\square$ & $\square$ & $\square$ & $\square$ \\
\hline
\end{tabular}

\section{Demographic Questionnaire}

In this section, provide information to items 1 to 7 . Be sure to check or fill in the box containing the response corresponding to your situation.

Indicate your gender:

26. (a). $\square$ Male, (b). $\square$ Female.

Indicate your age range:
a). $\square$ Less than 20 yrs, b). $\square$ 20-24 yrs, c). $\square$ 25-29 yrs, d). $\square$ 30-34 yrs,
e). $\square$ 35-39 yrs old, f). $\square$ 40-44 yrs, g). $\square 45$ yrs and above.

Indicate your highest degree:

a). $\square$ Bachelor or DIPES I, b). $\square$ Masters or DIPES II, c). $\square$ Master or DEA. 
Indicate your teaching experience:
a). $\square$ Less than 5 yrs, b). $\square$ 6-10 yrs, c). $\square$ 11-15 yrs, d). $\square$ 16-20 yrs,
e). $\square$ 21-25 yrs, f). $\square$ 26-30 yrs, g). $\square 31$ yrs and above.

Do you have any experience teaching students with special needs in your classroom?
a). $\square$ Yes, b). $\square$ No.

Have you had the training to teach students with special needs?

a). $\square$ Yes, b). $\square$ No.

Indicate your language of instruction:
a). $\square$ French, b). $\square$ English, c). $\square$ Both.

\section{Thank you for completing this questionnaire.}




\section{Opinions Relative l'Intégration des élèves handicapés}

Directives générales : Les éducateurs ont longtemps constaté que l'enseignant exerce l'une des influences les plus fortes sur la manière dont un enfant évolue dans son apprentissage. Ce questionnaire vise l'obtention des informations pouvant aider les systèmes scolaires à améliorer l'efficacité des enseignants face aux apprenants handicapés présents dans leurs salles de classe. Votre participation à cette enquête est volontaire et vos réponses purement anonymes et strictement confidentielles. Veuillez répondre en marquant une croix dans la case portant la mention qui exprime mieux votre opinion sur l'idée évoquée dans chacun des cas ci-après :

Déclaration

1. La plupart des élèves handicaps feront des efforts adéquats pour finir leurs devoirs dans une salle régulière.

2 L'intégration des élèves handicapées demande que les enseignants des classes régulières reçoivent une formation additive et adaptée.

\section{L'intégration}

offre la possibilité d'organiser des groupes de travail mixe d'interaction qui facilite la compréhension et renforce l'acceptation des différences entre les élèves

4. Il est probable qu'un élève avec un handicap apprenne
1

$\begin{array}{cccccc}\begin{array}{c}\text { Désaccord } \\ \text { total }\end{array} & \text { Désaccord } & \begin{array}{c}\text { Pas sûr } \\ \text { mais tend } \\ \text { vers le } \\ \text { désaccord }\end{array} & \begin{array}{c}\text { Pas sûr } \\ \text { mais tend } \\ \text { vers } \\ \text { l'accord }\end{array} & \begin{array}{c}\text { Accord } \\ \text { Accord } \\ \text { total }\end{array} & \begin{array}{c}\text { accord } \\ 1\end{array} \\ 2 & 3 & 4 & 5 & 6\end{array}$
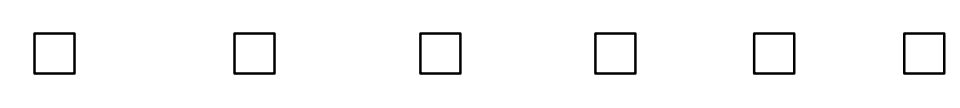
plus rapidement

dans une classe

intégrée que dans

une classe régulière

5. Les élèves

handicapés reçoivent

le meilleur

encadrement dans la

salle de classe

régulière (intégrée).

\begin{tabular}{|c|c|c|c|c|c|c|}
\hline Déclaration & $\begin{array}{c}\text { Désaccord } \\
\text { total }\end{array}$ & Désaccord & $\begin{array}{l}\text { Pas sûr } \\
\text { mais tend } \\
\text { vers le } \\
\text { désaccord }\end{array}$ & $\begin{array}{c}\text { Pas sûr } \\
\text { mais tend } \\
\text { vers } \\
\text { l'accord }\end{array}$ & Accord & $\begin{array}{c}\text { Accord } \\
\text { total }\end{array}$ \\
\hline
\end{tabular}

1

6. L'attention particulière que les élèves handicapés réclament sera au détriment des élèves non-handicapés

7. Faire parti d'une salle de classe régulière est un défi qui renforce la croissance académique d'un élève handicapé.

8. L'intégration des élèves handicapées demande un grand changement dans les procédures d'une salle de classe régulière.

9. La liberté grandissante dans la salle de classe régulière crée trop de confusion pour les élèves handicapés.

10. L'attention particulière que les élèves handicapés réclament sera au détriment des élèves non-handicapés.

\section{2}

3

4

5

6 ( 
11. La présence des élèves handicapés dans une salle de classe n'encouragera pas les élèves nonhandicapés à accepter les différences.

12. Le comportement des élèves handicapés sera un mauvais exemple aux

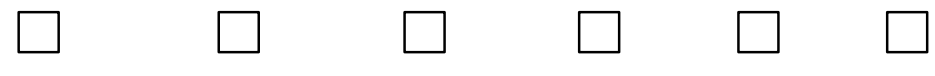
élèves non-handicapés. 


\begin{tabular}{|c|c|c|c|c|c|c|}
\hline Déclaration & $\begin{array}{c}\text { Désaccord } \\
\text { total }\end{array}$ & Désaccord & $\begin{array}{l}\text { Pas sûr } \\
\text { mais tend } \\
\text { vers le } \\
\text { désaccord } \\
3\end{array}$ & $\begin{array}{l}\text { Pas sûr } \\
\text { mais tend } \\
\text { vers } \\
\text { l'accord } \\
4\end{array}$ & Accord & $\begin{array}{c}\text { Accord } \\
\text { total }\end{array}$ \\
\hline
\end{tabular}

13. Il est probable qu'un élève handicapé affiche les problèmes de comportement dans une salle de classe régulière.

14. L'intégration d'un élève handicapé ne contribuera pas à son indépendance sociale.

15. Il n'est pas plus difficile de mettre de l'ordre dans une classe régulière contenant un élève handicapé que dans celle qui ne contient pas d'élève handicapé.

16. Les élèves handicapés ne monopoliseront pas le temps de l'enseignant d'une classe régulière.

17. L'intégration des élèves handicapés peut être bénéfique aux élèves nonhandicapés.

18. Les élèves handicapés sont susceptibles de créer la confusion dans une salle de classe régulière

19. Les enseignants des classes régulières sont assez outillés et capable d'encadrer les élèves handicapés. 


\begin{tabular}{lcccccc}
\hline Déclaration & $\begin{array}{c}\text { Désaccord } \\
\text { total }\end{array}$ & Désaccord & $\begin{array}{c}\text { Pas sûr } \\
\text { mais tend } \\
\text { vers le } \\
\text { désaccord }\end{array}$ & $\begin{array}{c}\text { Pas sûr } \\
\text { mais tend } \\
\text { vers } \\
\text { l'accord }\end{array}$ & $\begin{array}{c}\text { Accord } \\
\text { Accord } \\
\text { total }\end{array}$ \\
\hline
\end{tabular}

20. L'intégration aura un impact négatif sur le développement émotionnel d'un élève ayant un handicap.

21. Dans la mesure du possible, l'on devrait donner chaque occasion aux les élèves handicapés de fonctionner dans une salle de classe générale

22. Généralement le comportement d'un élève handicapé ne demande pas plus de patience de la part de l'enseignant général que celui d'un élève nonhandicapé.

23 Les élèves handicapés sont mieux encadrés par les enseignants spéciaux que par ceux des classes régulières.

24. L'isolation dans une salle de classe spéciale a un effet positif sur le développement social et émotionnel de l'élève ayant un handicap.

25. L'élève handicapé ne sera pas socialement isolé dans une salle de classe régulière 


\section{Questionnaire Démographique}

Veuillez répondre aux questions ci-dessous en marquant une croire dans

la case qui porte la mention qui s'applique à vous.

Votre sexe:

(a). $\square$ Masculin, (b). $\square$ Féminin.

Votre âge:
a). $\square$ Moins de 20 ans, b)
). $\square$ 20-24 ans,
c). $\square$ 25-29 ans, d)
d). $\square$ 30-34 ans,
e. $\square$ 35-39 ans, f). $\square$ 40-44 ans, g). $\square$ 45ans et plus.

Votre diplôme le plus élevé:

a). $\square$ Licence ou DIPES I, b). $\square$ Maitrise ou DIPES II, c). $\square$ Maîtrise ou DEA.

Experiences' professionnelles:
a). $\square$ Moins de 5 ans, b). $\square$
6-10 ans, c).
11-15 ans, d).
16-20 ans,
e). $\square$ 21-25 ans, f). $\square$ 26-30 ans, g). $\square 31$ ans et plus

Avez-vous déjà enseigné des apprenants ayant des besoins spéciaux?

a). $\square$ Oui, b). $\square \quad$ Non.

Avez-vous été formé(e) pour enseigner les apprenants ayant des besoins spéciaux?

a). $\square$ Oui, b). $\square$ Non.

Votre langue d'instruction:
a). $\square$ Le Français,
b). $\square$ L'Anglais,
c). $\square$ Le Français et L'Anglais.

Je vous remercie d'avoir remplis questionnaire. 
APPENDIX B

TABLE OF DEFINITION OF VARIABLES 
Table of Definition of Variables

\begin{tabular}{|c|c|c|c|}
\hline $\begin{array}{l}\text { Variable: (The } \\
\text { name that you } \\
\text { utilize to } \\
\text { identify the } \\
\text { variable } \\
\text { through all the } \\
\text { study) } \\
\text { What? }\end{array}$ & $\begin{array}{l}\text { Conceptual } \\
\text { Definition: (The } \\
\text { specific definition } \\
\text { that you utilize, } \\
\text { according to the } \\
\text { literature, as a } \\
\text { definition of the } \\
\text { variable in your } \\
\text { study) } \\
\text { What it means? }\end{array}$ & $\begin{array}{l}\text { Instrumental } \\
\text { definition: (The items, } \\
\text { stimulus or indicators } \\
\text { in your survey that you } \\
\text { utilize in order to } \\
\text { observe the variable) } \\
\text { How to be observed? }\end{array}$ & $\begin{array}{l}\text { Operational } \\
\text { definition: ( The } \\
\text { procedure to get one } \\
\text { score or value of the } \\
\text { variable) }\end{array}$ \\
\hline $\begin{array}{l}\text { Perceived } \\
\text { concept of } \\
\text { inclusion } \\
\text { (separate } \\
\text { special } \\
\text { education v. } \\
\text { inclusive } \\
\text { education) } \\
\text { (PCI) }\end{array}$ & $\begin{array}{l}\text { Teachers' } \\
\text { preferences } \\
\text { between } \\
\text { including students } \\
\text { in the general } \\
\text { education } \\
\text { classroom } \\
\text { (inclusive } \\
\text { classrooms) or } \\
\text { leave them in } \\
\text { separate special } \\
\text { schools (non- } \\
\text { inclusive } \\
\text { classrooms) }\end{array}$ & $\begin{array}{l}\text { 6-point Likert scale: } \\
\text { (strongly disagree to } \\
\text { strongly agree). } \\
\text { Items Used: } 5,8,13 \& 23 \\
\text { Negatively phrased } \\
\text { items scored by } \\
\text { reversing item } 1=+3 \text {, } \\
2=+2,3=+1,4=-1,5= \\
\text {-2, and } 6=-3 \text {. } \\
\text { 5)Students with } \\
\text { disabilities can best be } \\
\text { served in the general } \\
\text { education classroom } \\
\text { PCI01 } \\
8 \text { )Integration of } \\
\text { students with } \\
\text { disabilities will require } \\
\text { significant changes in } \\
\text { general classroom } \\
\text { procedures PCI08 } \\
\text { 13)The student with a } \\
\text { disability will probably } \\
\text { develop academic skills } \\
\text { more rapidly in a } \\
\text { general education } \\
\text { classroom than in a } \\
\text { special classroom } \\
\text { PCI13 } \\
23 \text { ) Teaching students } \\
\text { with disabilities is } \\
\text { better done by special } \\
\text { than by general } \\
\text { education teachers. } \\
\text { PCI23 }\end{array}$ & $\begin{array}{l}\text { The subject response } \\
\text { to each item using a } 6 \\
\text { point Likert- scale, as } \\
\text { follows: } \\
\text { 1=strongly disagree } \\
\text { 2=Disagree } \\
3=\text { Not sure but tend to } \\
\text { disagree } \\
\text { 4=Not sure but tend to } \\
\text { agree } \\
5=\text { agree } \\
6=\text { Strongly agree } \\
\text { Likert scale } 1=-3(1),- \\
2(2),-1(3),+1(4), \\
+2(5),+3(6) \text {. } \\
\text { Score=Sum of } \\
\text { positively scored } \\
\text { items. } \\
\text { The responses will be } \\
\text { tabulated on a ratio } \\
\text { scale, determined by } \\
\text { adding scores } \\
\text { obtained from } \\
\text { answers to the } \\
\text { interpersonal items, } \\
\text { on a range from } 4- \\
6=24\end{array}$ \\
\hline
\end{tabular}




\begin{tabular}{|c|c|c|c|}
\hline Variable & $\begin{array}{l}\text { Conceptual } \\
\text { Definition }\end{array}$ & Instrumental definition & $\begin{array}{l}\text { Operational } \\
\text { definition }\end{array}$ \\
\hline $\begin{array}{l}\text { Perceived } \\
\text { ability to } \\
\text { teach } \\
\text { children } \\
\text { with } \\
\text { disabilities } \\
\text { (PAT) }\end{array}$ & $\begin{array}{l}\text { Perception of } \\
\text { teachers' } \\
\text { competence to } \\
\text { teach students with } \\
\text { disabilities- } \\
\text { appropriate skills } \\
\text { and strategies }\end{array}$ & $\begin{array}{l}\text { 6-point Likert scale: } \\
\text { (strongly disagree to } \\
\text { strongly agree). } \\
\text { Items Used } 2,10 \& 19 \\
\text { Negatively phrased items } \\
\text { scored by reversing item. } \\
1=1=+3,2=+2,3=+1,4= \\
-1,5=-2, \text { and } 6=-3 \\
\text { 2)Integration of students } \\
\text { with disabilities will } \\
\text { necessitate extensive } \\
\text { retraining of general } \\
\text { classroom teachers. PTA02 } \\
\text { 10) General education } \\
\text { teachers have the ability } \\
\text { necessary to work with } \\
\text { students with disabilities. } \\
\text { PTA10 } \\
\text { 19)General classroom } \\
\text { teachers have sufficient } \\
\text { training to teach students } \\
\text { with disabilities. PTA19 }\end{array}$ & $\begin{array}{l}\text { Likert scale } 1=-3(1),- \\
2(2),-1(3),+1(4), \\
+2(5),+3(6) \text {. } \\
\text { Score=Sum of } \\
\text { positively scored } \\
\text { items. } \\
\text { The responses will be } \\
\text { tabulated on a ratio } \\
\text { scale, determined by } \\
\text { adding scores } \\
\text { obtained from answers } \\
\text { to the interpersonal } \\
\text { items, on a range from } \\
3-6=18\end{array}$ \\
\hline
\end{tabular}




\begin{tabular}{|c|c|c|c|}
\hline Variable & $\begin{array}{l}\text { Conceptual } \\
\text { Definition }\end{array}$ & Instrumental definition & $\begin{array}{l}\text { Operational } \\
\text { definition }\end{array}$ \\
\hline $\begin{array}{l}\text { Perceived } \\
\text { classroom } \\
\text { management } \\
(\mathrm{PCM})\end{array}$ & $\begin{array}{l}\text { It is the teachers' } \\
\text { capability or ability } \\
\text { to use time } \\
\text { effectively and to } \\
\text { keep order in the } \\
\text { general education } \\
\text { classroom. }\end{array}$ & $\begin{array}{l}\text { 6-point Likert scale: (strongly } \\
\text { disagree to strongly agree). } \\
\text { Items Used } 1,4,6,9,12,15,16,18 \text {, } \\
22,25 \\
\text { Negatively phrased items scored by } \\
\text { reversing item. } \\
\text { 1=1= }+3,2=+2,3=+1,4=-1,5=-2 \text {, } \\
\text { and } 6=-3 \\
\text { 1) Most students with disabilities } \\
\text { will make an adequate attempt to } \\
\text { complete their assignments. PCM01 } \\
\text { 4) It is likely that a student with } \\
\text { disability will exhibit behavior } \\
\text { problems in a general classroom. } \\
\text { PCM04 } \\
\text { 6) The extra attention students with } \\
\text { disabilities require will be to the } \\
\text { detriment of the other students. } \\
\text { PCM06 } \\
\text { 9) Increased freedom in the general } \\
\text { classroom creates too much } \\
\text { confusion for the student with a } \\
\text { disability. PCM09 } \\
\text { 12) The behavior of students with } \\
\text { disabilities will set a bad example } \\
\text { for students without disabilities. } \\
\text { PCM12 } \\
\text { 15) It is not more difficult to } \\
\text { maintain order in a general } \\
\text { classroom that contains a student } \\
\text { with a disability than in one that } \\
\text { does not contain a student with a } \\
\text { disability. PCM15 } \\
\text { 16) Students with disabilities will } \\
\text { not monopolize the general } \\
\text { classroom teacher's time. PCM16 } \\
\text { 18) Students with disabilities are } \\
\text { likely to create confusion in the } \\
\text { general classroom. PCM18 } \\
\text { 22)The classroom behavior of the } \\
\text { student with a disability generally } \\
\text { does not require more patience from } \\
\text { the teacher than does the classroom }\end{array}$ & $\begin{array}{l}\text { The subject } \\
\text { response to each } \\
\text { item using a } 6 \\
\text { point Likert- } \\
\text { scale, as follows: } \\
\text { 1=strongly } \\
\text { disagree } \\
\text { 2=Disagree } \\
\text { 3=Not sure but } \\
\text { tend to disagree } \\
4=\text { Not sure but } \\
\text { tend to agree } \\
5=\text { agree } \\
6=\text { Strongly agree } \\
\text { Likert scale1=- } \\
3(1),-2(2),-1(3), \\
+1(4),+2(5), \\
+3(6) \text {. } \\
\text { Score=Sum of } \\
\text { positively scored } \\
\text { items. } \\
\text { The responses } \\
\text { will be tabulated } \\
\text { on a ratio scale, } \\
\text { determined by } \\
\text { adding scores } \\
\text { obtained from } \\
\text { answers to the } \\
\text { interpersonal } \\
\text { items, on a range } \\
\text { from } 10-6=60\end{array}$ \\
\hline
\end{tabular}


behavior of a student without a

disability. PCM22

25)The student with a disability will

not be socially isolated in the

general classroom. PCM25 


\begin{tabular}{|c|c|c|c|}
\hline Variable & $\begin{array}{l}\text { Conceptual } \\
\text { Definition }\end{array}$ & Instrumental definition & $\begin{array}{l}\text { Operational } \\
\text { definition }\end{array}$ \\
\hline $\begin{array}{l}\text { Perceived } \\
\text { outcome } \\
\text { for students } \\
\text { with } \\
\text { disabilities } \\
\text { (POS) }\end{array}$ & $\begin{array}{l}\text { Teachers' } \\
\text { perception of the } \\
\text { benefits or lack } \\
\text { thereof of inclusive } \\
\text { classrooms and } \\
\text { schools to both } \\
\text { students with } \\
\text { disabilities and } \\
\text { regular students } \\
\text { taught in the } \\
\text { integrated } \\
\text { classroom. }\end{array}$ & $\begin{array}{l}\text { 6-point Likert scale: (strongly } \\
\text { disagree to strongly agree). } \\
\text { Items Used } 3,7,11,14,17,20,21,24 \\
\text { Negatively phrased items scored by } \\
\text { reversing item. } \\
1=1=+3,2=+2,3=+1,4=-1,5=-2 \text {, } \\
\text { and } 6=-3 \\
\text { 3) Integration offers mixed group } \\
\text { interaction that will foster } \\
\text { understanding and acceptance of } \\
\text { differences among students. POS03 } \\
\text { 7) The challenge of being in a general } \\
\text { classroom will promote the academic } \\
\text { growth of the student with a disability. } \\
\text { POS07 } \\
\text { 11)The presence of students with } \\
\text { disabilities will not promote } \\
\text { acceptance of difference on the part of } \\
\text { students without disabilities.POS11 } \\
\text { 14) Integration of the student with a } \\
\text { disability will not promote his or her } \\
\text { social independence.POS14 } \\
\text { 17) The integration of students with } \\
\text { disabilities can be beneficial for } \\
\text { students without disabilities. POS17 } \\
\text { 20) Integration will likely have a } \\
\text { negative effect on the emotional. } \\
\text { POS20 development of the student } \\
\text { with a disability } \\
\text { 21) Students with disabilities should } \\
\text { be given every opportunity to function } \\
\text { in the general classroom where } \\
\text { possible. POS } 21 \\
\text { 24) Isolation in a special classroom } \\
\text { has a beneficial effect on the social } \\
\text { and emotional development of the } \\
\text { student with a disability. POS } 24\end{array}$ & $\begin{array}{l}\text { The subject } \\
\text { response to each } \\
\text { item using a } 6 \\
\text { point Likert- } \\
\text { scale, as follows: } \\
\text { 1=strongly } \\
\text { disagree } \\
\text { 2=Disagree } \\
3=\text { Not sure but } \\
\text { tend to disagree } \\
4=\text { Not sure but } \\
\text { tend to agree } \\
5=\text { agree } \\
6=\text { Strongly agree } \\
\text { Likert scale1=- } \\
3(1),-2(2),-1(3), \\
+1(4),+2(5), \\
+3(6) \text {. } \\
\text { Score=Sum of } \\
\text { positively scored } \\
\text { items. } \\
\text { The responses } \\
\text { will be tabulated } \\
\text { on a ratio scale, } \\
\text { determined by } \\
\text { adding scores } \\
\text { obtained from } \\
\text { answers to the } \\
\text { interpersonal } \\
\text { items, on a range } \\
\text { from } 8-6=48\end{array}$ \\
\hline
\end{tabular}


Table of Definition of Demographic Variables

\begin{tabular}{|c|c|c|c|}
\hline $\begin{array}{l}\text { Variable: (The } \\
\text { name that you } \\
\text { utilize to } \\
\text { identify the } \\
\text { variable } \\
\text { through all the } \\
\text { study) } \\
\text { What? }\end{array}$ & $\begin{array}{l}\text { Conceptual Definition: } \\
\text { (The specific definition } \\
\text { that you utilize, } \\
\text { according to the } \\
\text { literature, as a } \\
\text { definition of the } \\
\text { variable in your study) } \\
\text { What it means? }\end{array}$ & $\begin{array}{l}\text { Instrumental definition: } \\
\text { (The items, stimulus or } \\
\text { indicators in your } \\
\text { survey that you utilize } \\
\text { in order to observe the } \\
\text { variable) } \\
\text { How to be observed? }\end{array}$ & $\begin{array}{l}\text { Operational definition: } \\
\text { ( The procedure to get } \\
\text { one score or value of } \\
\text { the variable) }\end{array}$ \\
\hline Gender & $\begin{array}{l}\text { This is an item on the } \\
\text { demographic survey in } \\
\text { which the subject is } \\
\text { asked to identify their } \\
\text { gender }\end{array}$ & $\begin{array}{l}1=\text { Male } \\
2=\text { Female }\end{array}$ & $\begin{array}{l}\text { This is assumed to be a } \\
\text { metric scale }\end{array}$ \\
\hline Age & $\begin{array}{l}\text { This is an item on the } \\
\text { demographic survey in } \\
\text { which the subject is } \\
\text { asked to identify their } \\
\text { age range }\end{array}$ & $\begin{array}{l}\text { Age ranges are } \\
\text { categorized as follows: } \\
1=\text { Less than } 20 ; \\
2=20-26 ; 3=26-31 \\
4=31-36 ; 5=36-41 \\
6=41-46 ; \\
7=46 \text { and above. }\end{array}$ & $\begin{array}{l}\text { Ratio scale was used. } \\
\text { Ages fall into six } \\
\text { groups. This is } \\
\text { assumed to be metric } \\
\text { scale. }\end{array}$ \\
\hline $\begin{array}{l}\text { Level of } \\
\text { education }\end{array}$ & $\begin{array}{l}\text { This is an item on the } \\
\text { demographic survey in } \\
\text { which the subject is } \\
\text { asked to identify their } \\
\text { level of education }\end{array}$ & $\begin{array}{l}1=\mathrm{BA} \\
2=\text { Masters } \\
3=\mathrm{DEA}\end{array}$ & $\begin{array}{l}\text { This is assumed to be a } \\
\text { metric scale }\end{array}$ \\
\hline $\begin{array}{l}\text { Years of } \\
\text { teaching } \\
\text { experience }\end{array}$ & $\begin{array}{l}\text { This is an item on the } \\
\text { demographic survey in } \\
\text { which the subject is } \\
\text { asked to identify their } \\
\text { age range }\end{array}$ & $\begin{array}{l}1=\text { Less than five years; } \\
2=6-10 ; 3=11-15, \\
4=16-20 ; 5=21-25, \\
6=26 \text { and above }\end{array}$ & $\begin{array}{l}\text { Ratio scale was used } \\
\text { Experience fall into six } \\
\text { groups }\end{array}$ \\
\hline $\begin{array}{l}\text { Experience } \\
\text { teaching in } \\
\text { inclusive } \\
\text { classrooms }\end{array}$ & $\begin{array}{l}\text { This is an item on the } \\
\text { demographic survey in } \\
\text { which the subject is } \\
\text { asked to indicate if he } \\
\text { or she has experience } \\
\text { teaching in inclusive } \\
\text { classrooms }\end{array}$ & $\begin{array}{l}1=\text { Yes } \\
2=\text { No }\end{array}$ & $\begin{array}{l}\text { This is assumed to be a } \\
\text { metric scale }\end{array}$ \\
\hline $\begin{array}{l}\text { Training in } \\
\text { teaching } \\
\text { students with } \\
\text { SEN in the } \\
\text { general } \\
\text { education } \\
\text { classroom }\end{array}$ & $\begin{array}{l}\text { This is an item on the } \\
\text { demographic survey in } \\
\text { which the subject is } \\
\text { asked to indicate if he } \\
\text { or she has been trained }\end{array}$ & $\begin{array}{l}1=\text { Yes } \\
2=\mathrm{No}\end{array}$ & $\begin{array}{l}\text { This is assumed to be a } \\
\text { metric scale }\end{array}$ \\
\hline
\end{tabular}




\begin{tabular}{|c|c|c|c|}
\hline $\begin{array}{l}\text { Language of } \\
\text { instruction }\end{array}$ & $\begin{array}{l}\text { This is an item on the } \\
\text { demographic survey in } \\
\text { which the subject is } \\
\text { asked to identify the } \\
\text { language he or she } \\
\text { used in class (English } \\
\text { or English) }\end{array}$ & $\begin{array}{l}1=\text { English } \\
2=\text { French } \\
3=\text { Both }\end{array}$ & $\begin{array}{l}\text { The ordinal scale was } \\
\text { used. 1=English } \\
2=\text { French } \\
3=\text { Both }\end{array}$ \\
\hline
\end{tabular}


APPENDIX C

LETTER OF APPROVAL FROM THE INSTITUTIONAL REVIEW BOARD OF ANDREWS UNIVERSITY 
July 19, 2013

\section{Andrews $\mathbf{Q}$ University}

Agnes Mngo

Tel: $269-815-5185$

Email: yensi@andrews.edu

RE: APPLICATION FOR APPROVAL OF RESEARCH INVOLVING HUMAN SUBJECTS

IRB Protocol \#: 13-087 Application Type: Original Dept.: Teaching, Learning \& Curriculum Review Category: Expedited Action Taken: Approved Advisor: Faith-Ann McGarrell Title: An investigation of the attitudes held by teachers towards the inclusion of students with

disabilities in some selected secondary schools in Cameroon.

This letter is to advise you that the Institutional Review Board (IRB) has reviewed and approved your IRB application of research involving human subjects entitled: "An investigation of the attitudes held by teachers towards the inclusion of students with disabilities in some selected secondary schools in Cameroon" IRB protocol number 13087 under Expedited category. This approval is valid until July 19, 2014. If your research is not completed by the end of this period you must apply for an extension at least four weeks prior to the expiration date. We ask that you inform IRB whenever you complete your research. Please reference the protocol number in future correspon ience regarding this study.

Any future changes made to the study design and/or consent form require prior approval from the IRB before such changes can be implemented. Please use the attached report form to request for modifications, extension and completion of your study.

While there appears to be no more than minimum risk with your study, should an incidence occur that results in a research-related adverse reaction and/or physical injury, this must be reported immediately in writing to the IRB. Any project-related physical injury must also be reported immediately to the University physician, Dr. Reichert, by calling (269) 473-2222. Please feel free to contact our office if you have questions.

Best wishes in your research.

Sincerely

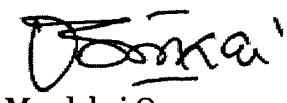

Mordekai Ongo

Research Integrity \& Compliance Officer 


\section{APPENDIX D}

LETTERS OF APPROVAL FROM THE REGIONAL DELEGATE OF SECONDARY EDUCATION FOR THE NORTH WEST REGION OF CAMEROON 


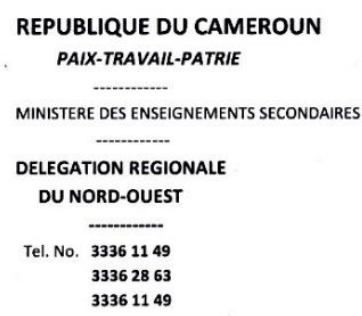

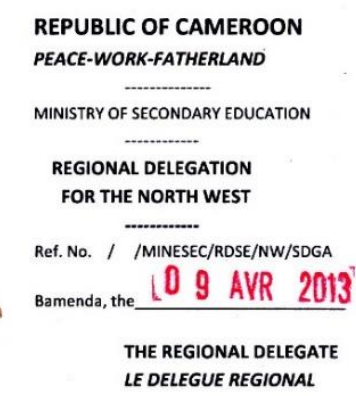

\section{Object: AUTHORISATION TO CARRY OUT RESEARCH ON INCLUSIVE EDUCATION}

To: The Principal
1. GBHS Ndop
2. GBHS Kumbo
3. GBHS Fundong
4. GBHS Ndu
5. GBHS Mbengwi
6. GBHS Wum
7. GBHS Bamenda

Dear sir,

Authorisation is hereby granted for Agnes Yensi Mngo, student at the Andrews University of the state of Michigan, to carry out research on the topic 'An Investigation of the Attitudes Held by Teachers towards Students with Disabilities in Selected Schools in Cameroon'. Additional approval is granted for her to disseminate the instrument and collect all necessary data from the General Education teachers of the SEEPD program schools in the North West Region. The following schools listed below are to be visited.
1. GBHS Ndop
2. GBHS Kumbo
3. GBHS Fundong
4. GBHS Ndu
5. GBHS Mbengwi
6. GBHS Wum
7. GBHS Bamenda

You are called upon to give the necessary assistance needed, making sure that the classes are not interrupted.

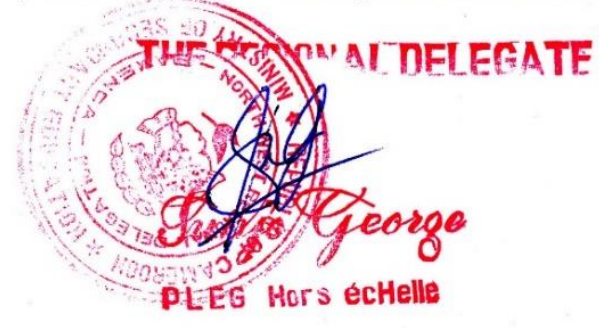


REPUBLIQUE DU CAMEROUN

PAIX-TRAVAIL-PATRIE

MINISTERE DES ENSEIGNEMENTS SECONDAIRES

DELEGATION REGIONALE

DU NORD-OUEST

Tel. No. 33361149

33362863

33361149
REPUBLIC OF CAMEROON

PEACE-WORK-FATHERLAND

\author{
MINISTRY OF SECONDARY EDUCATION \\ REGIONAL DELEGATION \\ FOR THE NORTH WEST \\ Ref. No. / /MINESEC/RDSE/NW/SDGA
}

Bamenda, the O 9 AVR 2013.

THE REGIONAL DELEGATE

LE DELEGUE REGIONAL

\section{Object: AUTHORISATION TO CARRY OUT RESEARCH ON INCLUSIVE EDUCATION}

TO

Institutional Review Board

Andrews University

4150 Administrative Drive, Room 210

Berrien Springs MI 49104-0355

Dear sir,

Authorisation is hereby granted for Agnes Yensi Mngo, student at the Andrews University of the state of Michigan, to carry out research on the topic 'An Investigation of the Attitudes Held by Teachers towards Students with Disabilities in Selected Schools in Cameroon'. Additional approval is granted for her to disseminate the instrument and collect all necessary data from the General Education teachers of the SEEPD program schools in the North West Region. The following schools listed below are to be visited.

1. GBHS Ndop

2. GBHS Kumbo

3. GBHS Fundong

4. GBHS Ndu

5. GBHS Mbengwi

6. GBHS Wum

7. GBHS Bamenda

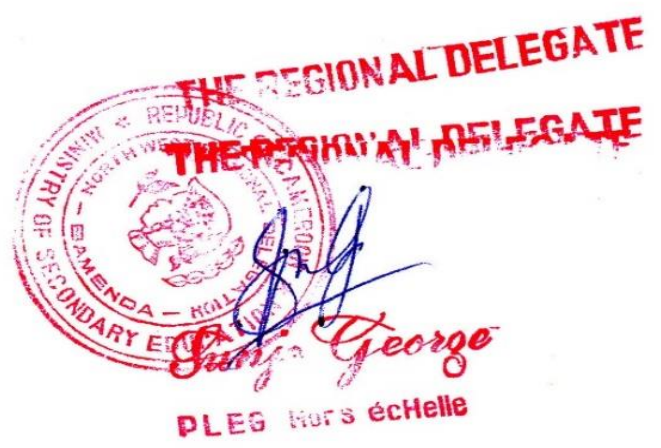


APPENDIX E

INFORMED CONSENT 


\section{Andrews University \\ Berrien Springs, Michigan 49104 \\ Informed Consent to Participate in a Research Study}

\section{A. PURPOSE}

Under the supervision of Dr. Faith-Ann McGarrell, Professor of Curriculum and Instruction at Andrews University, Agnes Y. Mngo, a graduate student in Curriculum and Instruction, is conducting research on an investigation of the attitudes held by general education teachers toward students with disabilities in a pilot inclusive education program in Cameroon The purpose of the survey that will be administered to about 700 teachers in seven Cameroonian bilingual secondary education schools is to investigate teachers 'attitudes toward inclusive education.

\section{B. PROCEDURES}

By accepting to participate in this study, I agree to complete a questionnaire that will seek to know my positions on issues related to the level of satisfaction and dissatisfaction I have with inclusive education.

1. Objectives 2. Implementation.

This will be done by responding to a six- point Likert scale questionnaire which requires that for each question, you choose from the following responses: strongly disagree, disagree, not sure but tend to disagree, not sure but tend to agree, agree, strongly agree.

\section{RISKS}

I understand that there are no risks involved in this study and that my responses are entirely anonymous.

I also understand that no individual identities are required on the questionnaires or will be used in any reports or publications resulting from the study.

\section{BENEFITS}

There will be no direct benefit to me from participating in this research study. However, the results and recommendations of this study would help Cameroonian secondary education authorities understand exactly what the views of teachers are, regarding inclusive education objectives and its implementation. The results will also address and determine the needs and extent of investment by educational leaders in teacher preparation, professional development for the management of inclusive classrooms. This would, in turn, enable government and other secondary education providers to make improvements where needed and consolidate achievements of the new system of education

\section{E. ALTERNATIVES}

I am free to choose not to participate in this research study.

\section{F. COSTS}

There will be no costs to me as a result of taking part in this research study.

\section{G. COMPENSATION}

I will be provided a snack ( $\$ 3.00)$ during the time spent (30 minutes) to complete the questionnaire.

\section{H. QUESTIONS}

I have spoken with Agnes Mngo about this study and have had my concerns taken care of. If I have any further questions about the study, I can contact Agnes Mngo by calling 
269-815-5185 or write to the Department of Teaching Learning and Curriculum, Andrews University, 100 Old US 31, Berrien Springs, MI 49103

\section{CONSENT}

I have been given a copy of this consent form to keep.

PARTICIPATION IN RESEARCH STUDY IS VOLUNTARY. I am free to decline to participate in this research study, or I may withdraw my participation at any point without penalty. My decision whether or not to participate in this research study will have no influence on my present or future status in my institution.

Signature

Date

Research Participant

Signature

Interviewer

Date 
REFERENCE LIST 


\section{REFERENCE LIST}

Adera, B. A. \& Asimeng-Boahene, L. (2011). The perils and promises of inclusive education in Ghana. Journal of the International Association of Special Education, 12(1), 28-32.

Ajuwon, P. M. (2008). Inclusive education for students with disabilities in Nigeria: Benefits, challenges and policy implications. International Journal of Special Education, 23(3), 11-16.

Ajzen, I. (1991). The theory of planned behavior. Organizational Behavior and Human Decision Processes, 50(2), 179-211.

Ambei, F. R. (2016). The effect of pedagogical knowledge training on the development of inclusive practices for primary school teachers: The case of Buea Sub Division, South-West Region of Cameroon. International Journal of Humanities Social Sciences and Education 3(7) 68-86

Ammah, J. O. A \& Hodge, S. R. (2005). Secondary physical education teacher's beliefs and practices in teaching students with severe disabilities: A descriptive analysis. The High School Journal, 89(2), 40-54.

Antonak, R. F., \& Larrivee, B. (1995). Psychometric analysis and revision of the opinions relative to mainstreaming scale. Exceptional Children, 62, 139-147.

Armstrong, A. C., Armstrong, D., Lynch, C., \& Severin, S. (2005). Special and inclusive education in the Eastern Caribbean: Policy, practice, and provision. International Journal of Inclusive Education, 9, 71 - 87.

Armstrong, D., Armstrong, A, C., \& Spandagou, I. (2011). Inclusion: By Choice or by chance. International Journal of Inclusive Education, 15(1), 29-39.

Arrah, R. O. \& Swain, K. D. (2014). Teachers' perceptions of students with special education needs in Cameroonian secondary schools. International Journal of Special Education, 29(3), 101-110.

Avramidis, E. (2006). Promoting inclusive education: From 'expertism' to sustainable, inclusive practices. In R. Webb (Ed) Changing teaching and learning in the primary school. (pp. 132-146) Buckingham, Open University Press. 
Avramidis, E., Bayliss, P., \& Burden, R. (2000). A survey into mainstream teachers' attitudes towards the inclusion of children with special educational needs in the ordinary school in one local educational authority. Educational Psychology, 20(2), 193-213.

Avramidis, E., \& Kalyva, E. (2007). The influence of teaching experience and professional development on Greek teachers' attitudes towards inclusion. European Journal of Special Needs Education, 22(4), 367-389.

Avramidis, E. \& Norwich, B. (2002) Mainstream teachers' attitudes towards inclusion/integration: a review of the literature. European Journal of Special Needs Education, 17(2), 129-147.

Bahn, K. E. (2009). Classroom teacher attitudes toward inclusion. (Doctoral dissertation). Available from ProQuest Dissertations and Theses database. (UMI No.3368746)

Bailey, L., Nomanbhoy, A., \& Tubpun, T. (2015). Inclusive education: Teacher perspectives from Malaysia. International Journal of Inclusive Education, 19(5), $547-559$.

Barnes, A. \& Harlacher, J. (2008). Clearing the confusion: Response-to-intervention as a set of principles. Education \& Treatment of Children, 31, 417-431.

Barnes, M. (October 2009). Parent/School Partnership. Texas School Improvement Conference. Retrieved from http://tsiconference.wikifoundry.com/page/Parent\% 2FSchool+Partnership

Berninger, V. W. (2006). Research-supported ideas for implementing reauthorized IDEA with intelligent professional psychological services. Psychology in the Schools 43(7), 781-796.

Berry, R. A. W. (2006). Inclusion, power, and community: Teachers and students interpret the language of community in an inclusion classroom. American Educational Research Journal, 43(3), 489-529.

Bigham, T. (2010). Do teachers have a negative attitude toward the inclusion of students with special needs? (Master's Thesis). Retrieved from https://www.ohio.edu/ education/academic-programs/teacher-preparation/department-of-teachereducation/masters-programs/loader.cfm?csModule=security/getfile \&amp; PageID=2185293

Bishop, A. \& Jones, P. (2002). Promoting inclusive practice in primary initial teacher training: Influencing hearts as well as minds. Support for Learning, 17(2), 58-63.

Biya, P. (1984). Cameroun : Loi n 83-013 du Juillet 1983 relative à la protection des personnes handicapées. Yaounde, Cameroon. Retrieved from http://www.afubuafa.org/ sites/default/files/Cameroon\%20Report.pdf 
Biya, P. (1990). Decree No 90/15/0 of 26/11/1990, Presidency of the Republic of Cameroon, Yaounde. Retrieved from http://www.afub-uafa.org/sites/default/files/ Cameroon\%20Report.pdf

Boling, E. (2007). "Yeah, but I don't want to deal with it:" Changes in a teacher candidate's conceptions of inclusion. Teaching Education, 18(3), 217-231.

Bones, R. \& Lambe, J. (2006). Student teachers' attitudes to inclusion: Implications for initial teacher education in Northern Ireland, International Journal of Inclusive Education, 10(6), 511-527.

Bosnjak, M., Tuten, T. L., \& Wittmann, W. W. (2005). Unit (non) response in web-based access panel surveys: An extended planned-behavior approach. Psychology \& Marketing, 22(6), 489-505.

Boyle, C., Topping, K., \& Jindal-Snape, D. (2013). Teachers' attitudes towards inclusion in high schools. Teachers and Teaching, 19(5), 527-542.

Bradley, E. L. (2009) General education teachers' attitude toward the inclusion of students with disabilities (Master's Thesis). Available from ProQuest Dissertations \& Theses database. (UMI No. 1465935)

Bryant, D. P., Smith, D. D., \& Bryant, B. R. (2008). Teaching students with special needs in inclusive classrooms. Boston, MA: Pearson Education.

Burge, P., Ouellette- Kuntz, H., \& Hutchinson, N. (2008). A quarter century of inclusive education for children with intellectual disabilities in Ontario: Public perceptions. Canadian Journal of Educational Administration and Policy, 87, 1-22.

Burstein, N., Sears, S., Wilcoxen, A., Cabello, B., \& Spagna, M. (2004). Moving toward inclusive practices. Remedial and Special Education, 25(2), 104-116.

Cagney, T.L. (2009) Attitudes of general education teachers toward including students with special needs. (Master's Thesis) Available from ProQuest Dissertations database (UMI No. 1468068).

Callender, C. \& Hansen, A. (2004). Family-school partnerships: Information and approaches for educators. Bethesda, MD: National Association of School Psychologists (NASP). Retrieved from http://www.nasponline.org/educators/ HCHSIIFamily-SchoolPartnerships.pdf.

Carroll, A., Forlin, C., \& Jobling, A. (2003). The impact of teacher training in special education on the attitudes of Australian pre-service general educators towards people with disabilities. Teacher Education Quarterly, 30, 65-79. 
Casey-Hayford, L. \& Lynch, P. (2003). A review of good practice in ICT and special education needs for Africa. DFIED's Imfundo: Partnership for IT in Education http://www.comp.dit.ie/dgordon/Publications/Contributor/Ghana/ SENPHASE1FINAL.pdf

Centre for Research in Child and Family Development in Education. (2008). UNESCO Chair in Special Needs Education. Buea, Cameroon: University of Buea.

Chhabra, S., Srivastava, R., \& Srivastava, I. (2010). Inclusive education in Botswana: The perceptions of school teachers. Journal of Disability Policy Studies, 20(4), 219-228.

Clarke, J. S. (1997). Personal and organizational structure correlates of receptivity and resistance to change and effectiveness in institutions of higher education. Baton Rouge, LA: Louisiana State University.

Coalition des ONG Camerounaises pour les Droits des Enfants. (2000). Rapport général des travaux de l'atelier technique de production du rapport complémentaire sur la mise en ouvre de la convention relative aux droits de l'enfant camerounais. Kribi, Cameroon : COCADE.

COCADE. (2010). Shadow Report of NGOs on the implementation of the African charter on the rights and welfare of the child in Cameroon. Cameroon National Coalition of NGOs for Child Rights Plan International. Retrieved from www.crin.org

Comité des Droits de L'Enfant. (2010). Examen du deuxième rapport du Cameroun sur la mise en cuvre de la convention relative aux droits de l'enfant (CDE) : Réponse du gouvernement au comité des droits de l'enfant. Geneva, Suisse: Gouvernement Du Cameroun.

Constantino, S. M. (2008). 101 Ways to create real family engagement. ENGAGE! Press. Retrieved from http://www.esc16.net/users/0020/Link_Files/101\%20Ways\% 20to\%20Create\%20Real\%20Family\%20Engagement.pdf

Cook, B. G. (2001). A comparison of teachers' attitudes toward their included students with mild and severe disabilities. Journal of Special Education, 34(4) 203-213.-

Cook, B. G. \& Schirmer, B. R. (2003) 'What is special about special education? Overview and analysis', Journal of Special Education, 37 (3), 200-204.

Cook, B. G., Cameron, D. L., \& Tankersley, M. (2007). Inclusive teachers' attitudinal ratings of their students with disabilities. The Journal of Special Education, 4, 230-238.

Cramer, A. C. (2014). Preservice teachers' attitudes and efficacy beliefs toward inclusion of students with autism spectrum disorders in the Midwestern Region of the United States. (Doctoral dissertation). Available from ProQuest Dissertations and Theses database. (UMI3628751). 
D’Alonzo, B. J., Giordano, G., \& Cross, T. L. (1996). Improving teachers' attitudes through teacher education toward the inclusion of students with disabilities into their classrooms. The Teacher Educator, 31, 304-312.

D’Alonzo, B. J., Giordano, G., \& VanLeeuwen, D. M. (1997). Perceptions by teachers about the benefits and liabilities of inclusion. Preventing School Failure, 42, 411.

Daane, C. J., Beirne-Smith, M., Latham, D. (2000). Administrators and teachers' perceptions of the collaborative efforts of inclusion in the elementary grades. Education, 121, 331-338.

Daniel, P. (December 1997). Educating students with disabilities in the least restrictive environment: A slippery slope for Educators. Journal of Education Administration. 35(5), 397-410.

Davis, P. \& Florian, L. (2004) Teaching strategies and approaches for pupils with special educational needs: A scoping study (Research Report 516). Retrieved from http://www.dfes.gov.uk/research.

Day, T. \& Prunty, A. (2015). Responding to the challenges of inclusion in Irish schools. European Journal of Special Needs Education, 30 (2), 237-252.

Dedrick, R. F., Marfo, K., \& Harris, D. M. (2007). Experimental analysis of question wording in an instrument measuring teachers' attitudes toward inclusive education. Educational and Psychological Measurement, 67, 116-131.

Disability and Rehabilitation Team. (2002). The UN standard rules on the equalization of opportunities for persons with disabilities. Regional Report AFRO. Geneva, Switzerland: World Health Organization:

Disability and Rehabilitation Team. (2004). Review of disability issues and rehabilitation services in 29 African Countries. Disability and Rehabilitation Team. Geneva, World Health Organization.

Dixon, S. (2005). Inclusion - Not segregation or integration is where a student with special needs belong. Journal of Educational Thought, 39(1), 33-53.

Doh, P. S. (2007) Harmonization challenges in higher education. Case of the French and British bicultural system in Cameroon. (Doctoral dissertation). Retrieved from http:www.uta.fi/laitokset/jola/heg/opetus/heem_theses_en.php

Dolan, R. P. \& Hall, T. E. (2001). Universal design for learning: Implications for large scale assessment. IDA perspectives, 27(4), 22-25.

Dupoux, E., Hammond, H., Ingalls, L., \& Wolman, C. (2006). Teachers' attitudes toward students with disabilities in Haiti. International Journal of Special Education, 2l(134), 1-14. 
Dykeman, B. F. (2006). Alternative strategies in assessing special education needs. Education and Treatment of Children, 127(2), 265-273.

Ebontane, N. P. (2010). Handicapism: The case of the hearing impaired in inclusive education in Cameroon: Implications for planning and policy. The Nigerian Journal of Guidance and Counseling, 15(1), 1-10.

Ellins, J. \& Porter, J. (2005). Departmental differences in attitudes to special educational needs in the secondary school. British Journal of Special Education, 32(4), 188195.

Engelbrecht, P., Nel, M., Norma, N., \& Dan, T. (2015). Enacting understanding of inclusion in complex contexts: Classroom practices of South African teachers. South African Journal of Education, 35(3), 1-10.

Ernest, P. (1989). The knowledge, beliefs and attitudes of the mathematics teacher: A model. Journal of Education for Teaching, 15(1), 13-33.

Faculty of Education University of Buea. (2010). Annual Report. Buea: Cameroon. Retrieved from www.weac.org/resouce/june97/speech.htm

Fakolade, O. A., Adeniyi, S. O., \& Tella, A. (2009). Attitude of teachers towards the inclusion of special needs children in general education classroom: The case of teachers in some selected schools in Nigeria. International Electronic Journal of Elementary Education, 1(3), 155-169.

Fazio, R. (1986). How do attitudes guide behavior? In R. M., Sorrentino, \& E. T., Higgins, (Eds), Handbook of motivation and cognition. Foundations of social behavior, (pp. 204-243). New York: The Guilford Press.

Fazio, R. H., Powell, M. C., \& Williams, C. J. (1989). The role of attitude accessibility in the attitude-to-behavior process. Journal of Consumer Research, 16, 280

Feifer, S.G. (2008). Integrating response to intervention (RTI) with neuropsychology: A scientific approach to reading. Psychology in the Schools, 45, 812-825.

Ferguson, R. V. (1997). Environment design and quality of life. In R. I. Brown (Ed.), Quality of life for people with disabilities: Models, research and practice. (pp.251-269). Cheltenham, UK: Stanley Thornes.

Fishbein, M. A. (1967). Readings in attitude theory and measurement. New York, NY: Wiley.

Fishbein, M. A. \& Ajzen, I. (1975). Belief, attitude, intention and behavior: An introduction to theory and research. Reading, MA: Addison-Wesley.

Fonkeng, G. E. (2007). The history of education in Cameroon, 1884-2004. Lewiston, NY: Edwin Mellen Press. 
Forlin, C. (2000). Inclusion: Identifying potential stressors for regular class teachers, Educational Research, 43(3), 235-245.

Forlin, C. (2007a). Inclusive educational practices: A way forward for Hong Kong. Chinese Education \& Society, 40(4), 64-77.

Forlin, C. (2007b). Classroom diversity: Towards a whole school approach. In S. N. Phillipson (Ed.), Learning diversity in the Chinese classroom: Contexts and practice for students with special needs (pp. 95-123). Hong Kong: Hong Kong University Press.

Forlin, C. (2008). Education reform for inclusion in Asia: What about teacher education? In C. Forlin, \& M. G. J. Lian (Eds.), Reform, inclusion \& teacher education: Towards a new era of special education in the Asia-Pacific Region (pp. 74-82). London \& New York, NY: Routledge.

Forlin, C., \& Lian, M. G. J. (Eds.) (2008). Reform, inclusion and teacher education: Towards a new era of special education in the Asia-Pacific Region. London \& New York, NY: Routledge.

Forlin, C. \& Sin, K. (2010). Developing support for inclusion: A professional learning approach for teachers in Hong Kong. International Journal of Whole Schooling, 6(1), 7-26.

Friend, M. \& Bursuck, W. D. (1999). Including students with special needs. (2nd ed.). Boston: Allyn \& Bacon.

Friend, M., \& Bursuck, W. D. (2006). Including students with special needs: A Practical Guide for Classroom Teachers. New Jersey: Prentice Hall.

Friend, M., \& Bursuck, W. D. (2012). Including students with special needs: A practical guide for classroom teachers (6th ed.). Boston, MA: Pearson.

Fuchs, D., Fuchs L., \& Vaughn S. (2008). Response to intervention: A framework for reading educators. Newark, NJ: International Reading Association.

Fuchs, L. S., \& Fuchs, D. (2006). A framework for building capacity for responsiveness to intervention. School Psychology Review, 35(4), 621-626.

Fullan, M. (2007). The new meaning of educational change ( $4^{\text {th }}$ ed.) New York, NY: Teachers College Press.

Galović, D., Brojčin, B., \& Glumbić, N. (2014). The attitudes of teachers towards inclusive education in Vojvodina. International Journal of Inclusive Education, 18(12), 1262-1282.

Garuba, A. (2003). Inclusive education in the 21st century: Challenges and opportunities for Nigeria. Asia Pacific Disability Rehabilitation Journal, 12(2), 191-200. 
Gersten, R., \& Woodward, J. (1990). Rethinking the regular education initiative: Focus on the classroom teacher. Remedial and Special Education, 11(3), 7-16.

Greene, J. P. (2007). Fixing special education. Peabody Journal of Education, 82(4), 703-723.

Guner, N. (2012). The effect of preventive classroom management training program on approval and disapproval behaviors of teachers. International Journal of Instruction, 5(1), 153-166.

Handler B. R. (2003). Special education: An evaluation of educational environmental placement trends since the regular education initiative. Retrieved from http://eric.ed.gov/?id=ED480184.

Hegarty, S. (1995). Review of the present situation in special needs education. UNESCO. Retrieved from http://unesdoc.unesco.org/images/0010/001026/102688Eb.pdf

Heiman, T. (2004). Teachers coping with changes: Including students with disabilities in mainstream classes: An International View. International Journal of Special Education, 19(2), 99-102.

Hinkle, D. E., Wiersma, W., \& Jurs, S. G., (2003). Applied statistics for the behavioral sciences. (5th Edition). Boston, MA: Houghton Mifflin.

Hittie, M. (2000). Building community in the classroom. International Education Summit, Detroit, MI. Retrieved from http://www.wholeschooling.net/WS/WSPress/ CommBldgMH.pdf

Holdnack, J. A., \& Weiss, L. G. (2006). IDEA 2004: Anticipated implications for clinical practice-integrating assessment and intervention. Psychology in the Schools, 43(8), 871-882.

Hsu, T. (2010). A comparison of Taiwan educators' attitudes, knowledge, and perceived barriers toward the inclusion of students with disabilities. (Doctoral dissertation). Available from ProQuest Dissertations and Theses database. (UMI No. 3414267)

Hwang, Y. \& Evans, D. (2011). Attitudes towards inclusion: Gaps between belief and practice. International Journal of Special Education, 26(1), 136-146.

Idol, L. (2006). Toward inclusion of special education students in general education. Remedial and Special Education, 27(2), 77-94.

International Disability Alliance. (December 2011). Cameroon: Observations of the committee on economic, social and cultural rights. 47th Session State Report and List of Issues of the Committee on Economic, Social and Cultural Rights. Retrieved from http://www2.ohchr.org/english/bodies/cescr/cescrwg47.htm. 
Ji-Ryun, K. (2011). Influence of teacher preparation programmes on preservice teachers' attitudes toward inclusion. International Journal of Inclusive Education 15(3), 355-377.

Jobe, D., Rust, J. O., \& Brissie, J. (1996). Teachers' attitudes toward inclusion of students with disabilities into regular classrooms. Education, 117(1), 148-153.

Jones, V. \& Jones, L. (2009). Comprehensive classroom management: Creating communities of support and solving problems (9th ed.). Upper Saddle River, NJ: Prentice Hall.

Karugo, G. K. (1998). The Future of Special Education Teachers in Eastern Africa. The Future of Education in Eastern Africa: Proceedings of the Second Pwpa Eastern Africa Regional Conference: Kampala, Uganda, July 22-25, 1987. (Ed. S. A. H. Abidi). Kampala, Uganda: The Professors World Peace Academy.

Kauffman, J. M. \& Hallahan, D. P. (2005). Special education: What it is and why we need it. Boston, MA: Pearson Education.

Kavale, K. A. \& Forness, S. R. (2000). History, rhetoric, and reality: Analysis of the inclusion debate. Remedial and Special Education, 21(5), 280-296.

Kavale, K. A. \& Spaulding, L. S. (2008). Is response to intervention good policy for specific learning disability? Learning Disabilities Research \& Practice, 23(4), 169-179.

Kazlow, C. \& Giacquinta, J. (1977). Faculty receptivity to organization change: A test of two explanations of resistance to innovation in higher education. Journal of Research and Development in Education, 10(2), 87-98.

Kirby, A., Davies R., \& Bryant, A. (2005) Do teachers know more about specific learning difficulties than general practitioners? British Journal of Special Education, 32(3) 122-126.

Knight, B. (1999). Toward inclusion of students with special education needs in the regular classroom. Support for Learning, 14(1), 3-5.

Knight, K. (1997). Automating knowledge acquisition for machine translation. Al Magazine, 18(4), 81-95.

Koutrouba, K., Vamvakan, M., \& Steliou, M. (2006). Factors correlated with teachers' attitudes towards the inclusion of students with special educational needs in Cyprus. European Journal of Special Needs Education, 21(4), 381-394.

Kuester, V. M. (2000). 10 Years on: Have teacher attitudes toward the inclusion of students with disabilities changed? Paper presented at the ISEC 2000, London. England. Retrieved from https://books.google.com/books?isbn=1627345582. 
Laurin-Bowie, C. (2009). A global report on education for all, disability and inclusion. Inclusion International, 106-107.

Leatherman, J. M. \& Niemeyer, J. A. (2005). Teachers' attitudes toward inclusion: Factors influencing classroom practice. Journal of Early Childhood Teacher Education, 26(1), 23-36.

Leyser, Y. \& Kirk, R. (2004). Evaluating inclusion: An examination of parent views and factors influencing their perspectives. International Journal of Disability Development and Education, 51(3), 271-285.

Lindsay, G. (2003). Inclusive education: A critical perspective. British Journal of Special Education, 30(1), 3-12.

Markova, M., Krolak-Schwerdt, S. \& Glock, S. (2016). Preservice teachers' attitudes toward inclusion and toward students with special educational needs from different ethnic backgrounds. The Journal of Experimental Education, 84(3), 554578.

Mastropieri, M. A. \& Scruggs, T. E. (2007). The inclusive classroom: Strategies for effective instruction (3rd ed). Upper Saddle River, NJ: Pearson.

Mathews, D. (1996). Is there a public for public schools? Dayton, OH: Kettering Foundation Press.

Mbibeh, L. (2013). Implementing inclusive education in Cameroon: Evidence from the Cameroon Baptist Convention Health Board. International Journal of Education, 5(1), 52-68.

McInnis, C. (2000). Changing academic work roles: The everyday realities challenging quality in teaching. Quality in Higher Education, 6(2), 143-152.

McNally, R. D., Cole, P. G., \& Waugh, R. F. (2001). Regular teachers' attitudes to the need for additional classroom support for the inclusion of students with intellectual disability. Journal of Intellectual \& Developmental Disability, 26(3), 257-273.

Menlove, R., Hudson, P. \& Suter, D. (2001). A field of IEP dreams: Increasing general education teacher participation in the IEP development process. TEACHING Exceptional Children, 33(5), 28-33.

Ministry of Social Affairs. (1990). La decennie des Nation Unites pour les Personnes Handicappees au Cameroon 1983-1992. Yaounde, Cameroon: MINAS.

Mitchell, D. R. \& Brown R. I. (1991). Early intervention studies for young children with special needs. London, England: Chapman and Hall. 
Mngo, Y. Z. (2007). Report on the assistive technology for hearing impaired workshop. Report presented in partial fulfillment of requirement for the class EDPC/SPED525: Psychology and Education of Exceptional Children: Andrews University.

Moberg, S. \& Savolainen, H. (2003). Struggling for inclusive education in the north and the south: Educators' perceptions on inclusive education in Finland and Zambia. International Journal of Rehabilitation Research, 26, 21-31.

Monahan, R. G., Marino, S. B., Miller, R., \& Cronic, D. T. (1997). Rural teachers', administrators', and counselors' attitudes about inclusion (Report No. 021000) Greenwood, SC (ERIC Document Reproduction Service No. ED 406 099)

Muffih, T. P. (2010). SEEPD launches feasibility test on inclusive education. The $C B C$ Health Board Chronicle, 3(17), 3.

Muffih, T. P. (2011a). SEEPD commended for spearheading inclusive education in NW Region. The CBC Health Board Chronicle, 3(27), 2.

Muffih, T. P. (2011b). SEEPD commended for spearheading inclusive education in NW Region. The CBC Health Bard Chronicle, 3(27), 2-3.

Muffih, T. P. (2011c). Annual activity report of the CBC: Cameroon Baptist Convention Health Board. Bamenda.

Ngoh, O. E. T. (2007). Cameroon: Disabled children gain free college admission. Retrieved from http://allafrica.com/stories/200709210671.html

Ngoh, V. J. (1987). Cameroon 1884-1985: A hundred years of history. Yaounde, Cameroon: Navy Group.

Ngole, R. N. (2011). Inadequate literacy support for children with special needs in Cameroon: A social injustice. Retrieved from http://www.worldpulse.com/ pulsewire/solutions/41310.

Ngwang, E. (2008). From integration to inclusion. Bamenda conference on disability and rehabilitation, 9-11. Retrieved from http://icdr.utoronto.ca/wp-content/uploads/ 2015/05/Bamenda-Conference-Proceedings-2008-Final.pdf

Obeng, C. (2007). Teachers' views on the teaching of children with disabilities in Ghanaian classrooms. International Journal of Special Education, 22(1), 96-102.

Ocloo, M. A. \& Subbeya, M. (2008). Perception of basic education school teachers towards inclusive education in the Hohoe District of Ghana. International Journal of Inclusive Education, 12(5-6), 639- 650. 
Ofiesh, N. (2006). Response to intervention and the identification of specific learning disabilities: Why we need comprehensive evaluations as part of the process. Psychology in the Schools, 43(8), 883-898.

Oliver, M. (1990). The politics of disablement. Basingstoke: Macmillan.St. Martins Press Retrieved from http://www.independentliving.org/docs3/oliver99.pdf

Omprakash Foundation. (June 2011). ITCIG-SENTTI needs the services of a speech and language development therapist volunteer - to work in Cameroon. Retrieved from http://omprakash.org.

Osgood, R. (2005). The History of Inclusion in the United States. Washington, DC: Gallaudet University Press.

O’Toole, C. \& Burke, N. (2013). Ready, willing, and able? Attitudes and concerns in relation to inclusion amongst a cohort of Irish pre-service teachers. European Journal of Special Needs, 26(3), 239-253.

Pajares, M. F. (1992). Teachers beliefs and educational research: Cleaning up a messy contract. Review of Educational Research, 62(3), 307-332.

Peck, C. A., Donaldson, J., \& Pezzoli, M. (1990). Some benefits no handicapped adolescents perceive for themselves from their social relationships with peers who have severe handicaps. Journal of the Association for Persons with Severe Handicaps, 15, 241-249.

Peetsma, T. (2001). Inclusion in education: Comparing pupil's development in special and regular education. Educational Review, 53, 125-136.

Perry, E. A. (1997). Is equity always best? Educational stakeholders lash out. Inclusion and School Leadership, 35(5), 451-465.

Powell, J. (2006). Barriers to Inclusion: Special Education in the United States and Germany. St. Paul, MN: Paradigm.

Punch, K. F. (2003). Survey research: The basics. Thousand Oaks, CA: Sage.

Rapp, W. H. \& Arndt, K. L. (2012). Teaching everyone: An introduction to inclusive education. Baltimore, MA: Paul H. Brookes.

Razer, M., Mittelberg, D., Motola, M., \& Bar-Gosen, N. (2015). Israeli high school teachers' perceptions and attitudes towards a pedagogy of inclusion. International Journal of Inclusive Education, 19(9), 944-964.

Rivera, D. P. \& Smith, D. D. (1997). Teaching students with learning and behavior disabilities $\left(3^{\text {rd }} \mathrm{ed}\right)$. Boston, MA: Allyn and Bacon. 
Romer, V. A. (2004) Attitudes of junior high teachers towards teaching students with Learning disabilities in inclusive classes in public schools in New, Providence, Bahamas (Doctoral Dissertation). Available from ProQuest Dissertations and Theses database. (UMI No. 3153196).

Rose, D. \& Meyer, A. (2002). Teaching every student in the digital age: Universal design for learning. Alexandria, VA: ASCD.

Rose, D., Sethuraman, S., \& Meo, G. (2000) Universal design for learning. Journal of Special Education Technology, 15(2), 26-60.

Rudd, F. (2002). Grasping the promise o/inclusion. Palm Springs, CA. (ERIC Document Reproduction Service No. ED471855).

Salend, S. J. (2001). Creating inclusive classrooms: Effective and reflective practices $\left(4^{\text {th }}\right.$ ed). NJ: Merrill.

Salend, S. J. (2005). Creating inclusive classrooms: Effective and reflective practices (5th ed.). Upper Saddler River, NJ: Merrill Prentice Hall.

Saucier. (2000). Isms and the structure of social attitudes. Journal of Personality and Social Psychology, 78(2), 366-385.

Savolainen, H., Engelbrecht, P., \& Malinen, O. P. (2012). Understanding teachers' attitudes and self-efficacy in inclusive educations: Implications for pre-service and in-service teacher education. European Journal of Special Needs Education, 27(1), 51-68.

Schultz, J. (1998). Inclusion questions and answers: A parent's guide. Retrieved from http://www.ldonline.org/article/5901

Schwarz, N. \& Bohner, G. (2001). Intrapersonal processes. Oxford, UK: Backwell.

Scruggs, T. E. \& Mastropieri, M. A. (1996). Teacher perceptions of mainstreaming/inclusion, 1958-1995: A research synthesis. Exceptional Children, 63(1), $59-74$.

Secer, Z. (2010). An analysis of the effects of in-service teacher training on Turkish preschool teachers' attitudes towards inclusion. International Journal of Early Years Education, 18(1), 43-53.

SEEPD. (2011). Local and international instruments backing inclusive education practice in Cameroon: Bamenda, Cameroon. Wiley

Segall, M. J. \& Campbell, J. M. (2012). Factors relating to education professionals' classroom practices for the inclusion of students with autism spectrum disorders. Research in Autism Spectrum Disorders, 6(3), 1156-1167. 
Shey, P. F. (2003). Parents' perspective on the education of children with disabilities in regular schools in Cameroon, Oslo. (Unpublished Master's Thesis). Retrieved from http://www.rocare.org/grants/2008/Children\%20living\%20with\%20disabilities\%2 0and $\% 20$ education $\% 20$ in $\% 20$ Cameroon.pdf

Simmons, B. \& Bayliss, P. (2007). The role of special schools for children with profound and multiple learning difficulties: Is segregation always best? British Journal of Special Education, 34(1), 19-24.

Sindelar, P., Shearer, D., Yendol-Hoppey, D., \& Liebert, T. (2006). The sustainability of inclusive school reform. Exceptional Children, 72(3), 317-331.

Sisk, J. (2006). Assistive Technology Services. Retrieved from http://www.fcps.edu/ss/its/ index.htm

Smietana, M. (2001). Inclusion and science evaluation. Critical issues for science teachers. Retrieved from http: www.cedu.niu.edu/scied/courses/tedu532/ inclusion_and_science_education.htm.

Smith, D. D. (2007). Introduction to special education: Making a difference ( $6^{\text {th }}$ ed.), Boston, MA: Allyn and Bacon.

Snyder, L., Garriott, P., \& Williams Aylor, M. (2001). Inclusion confusion: Putting the 138 pieces together. Teacher Education and Special Education, 24, 198-207.

Stainback, S. \& Stainback, W. (1991). Promoting inclusive education: What happened in one school. Quality Outcomes-Driven Education, 1(3), 15-25.

Stainback, S. \& Stainback, W. (1996). Inclusion a guide for educators. Baltimore MA: Paul H. Brookes.

Stanovich, P. J. (1999). Conversations about inclusion. Teaching Exceptional Children, $31,54-58$.

Stubbs, S. (2009). Attitudes of general education teachers in grades one through six toward inclusion in new providence, Bahamas. (Doctoral dissertation). Available from ProQuest Dissertations and Theses database. (UMI No. 3339234)

Subban, P. \& Sharma, U. (2006). Primary school teachers' perceptions of inclusive education in Victoria, Australia. International Journal of Inclusive Education, 21, $42-52$.

Tabot, T. \& Ojong, M. (2008). Philosophical and historical foundations of education in Cameroon, 1844-1960. Limbe, Cameroon: Design House. 
Talmor, R., Reiter, S., \& Freigin, N. (2005) Factors relating to regular education teacher burnout in inclusive education. European Journal of Special Needs Education, 20(2), 215-229.

Tani, E. L. \& Nformi, D. J. (2016) Inclusive education in Cameroon; dictates of learning environment on the Academic participation of students with physical disabilities in the South West Region of Cameroon. International Journal of History and Cultural Studies, 2(3), 48-61.

Tanyi, M. E. (2016). Pedagogic barriers in Cameroon inclusive classrooms: The impact of curriculum, teachers' attitudes and classroom infrastructure. Journal of Education and Practice, 7(18), 210-221.

Taylor, R. L., Smiley, L.R., \& Ramasamy, R. (2003). Effects of educational background and experience on teacher views of inclusion. Educational Research Quarterly, 26, 3-10.

Tchombe, T. M. (2001). Structural reforms in education in Cameroon. Unpublished Policy Paper. Retrieved from http://www.unifr.ch/ipg/ecodoc/conferences/ DocuPDF Conf Inter/Tchombe.pdf

Thaver, T. \& Lim, L. (2014). Attitudes of preservice mainstream teachers in Singapore towards people with disabilities and inclusive education. International Journal of Inclusive Education, 18(10), 1038-1052.

Thomas, G. \& Loxley, A. (2007). Deconstructing special education and constructing inclusion ( $2^{\text {nd }}$ ed). New York, NY: Open University Press.

Tindall, D., MacDonald, W., Carroll, E., \& Moody, B. (2015). Pre-service teachers' attitudes toward children with disabilities: An Irish perspective. European Physical Education Review, 21(2), 206-221.

Titanji, P. (2008). Education for all in Cameroon: What principals need to know and do. African Journal of Special Education, 1(1), 105-115.

Tohnain L. N., Fonkeng, G. E., \& Ngueffo, N. (2008) Educational Research Network for West and Central Africa (ERNWACA) Report on Children living with disabilities and education in Cameroon: Challenges and Perspectives. Retrieved from http://www.rocare.org/grants/2008/Children\%20living\%20with\%20disabilities\%2 0and\%20education\%20in\%20Cameroon.pdf

Tohnain, N. \& Tamajong, E. (2014). Educational obstacles for children living with disabilities in Cameroon: The way forward. ROCARE/EDUCI African Education Development Issues, 5, 216-242.

Tomlinson, C. A. (1999). The differentiated classroom: Responding to the needs of all learners. Alexandria, VA: ASCD. 
Tomlinson, C. A. (2000). Differentiation of instruction in the elementary grades. Champaign, IL: University of Illinois.

Tukov, M. F. (2008). The education of children with special needs in Cameroon: The role of teachers and parents towards inclusive education. Norway: University of Oslo.

UN Convention on the Rights of the Child. (2008). List of issues: Cameroon. Report presented during the $28^{\text {th }}$ session of the Committee on the Rights of the Child. Pre-sessional Working group. .Retrieved from http://www2.ohchr.org/english/ bodies/crc/docs/AdvanceVersions/CRC.C.GBR.CO.4.pdf

UNESCO. (1990). World declaration on education for all: Meeting basic learning needs. Jomtien, Thailand. Retrieved from http://unesdoc.unesco.org/images/ 0012/001275/127583e.pdf

UNESCO. (1994a). Final report world conference on special needs education: Adopted by the World Conference on Special Needs Education: Access and Quality. Salamanca, Spain. Retrieved from http://unesdoc.unesco.org/images/ 0011/001107/110753eo.pdf

UNESCO. (1994b). The Salamanca statement and framework for action on special needs education: access and quality. United Nations Ministry of Educational, Scientific and Education and Science. Cultural Organization, Spain. Retrieved from http://www.unesco.org/education/pdf/SALAMA_E.PDF

UNESCO. (1995). Review of the present situation in special needs education. Report prepared by Dr. Seamus Hegarty Director of the National Foundation for Educational Research (NFER) The United Kingdom. Retrieved from https://books.google.com/ books?id=kYs4OgAACAAJ\&dq

UNESCO. (2001). Inclusive schools \& community support programs. Phase two. Paris: France. Retrieved from http://unesdoc.unesco.org/images/0012/001252/ 125235Eo.pdf

UNESCO. (2003) Overcoming exclusion through inclusive approaches in education: a challenge and a vision, Conceptual paper, Paris: France, Place de Fontenoy Retrieved from. http://unesdoc.unesco.org/images/0013/001347/134785e.pdf

UNESCO. (2005). Guidelines for inclusion: ensuring access to education for all. Paris: France, Place de Fontenoy Retrieved from http://unesdoc.unesco.org/images/ 0014/001402/140224e.pdf

UNESCO. (2008). Policy brief (No 3). Inclusion: Halfway to Dakar - where are we? Editorial by Nicholas Burnett. Author. Retrieved from http://unesdoc.unesco.org/ images/0016/001613/161315e.pdf 
UNESCO (2009a). Defining an inclusive agenda: Reflections around the 48th session of the international Conference on Education. Geneva, Switzerland. Retrieved from http://unesdoc.unesco.org/images/0018/001868/186807e.pdf

UNESCO (2009b). Teaching children with disabilities in inclusive settings. Bangkok, UNESCO. Retrieved from http://unesdoc.unesco.org/images/0018/001829/182975e.pdf

UNESCO. (2013). Inclusive education: Barriers to inclusive education. Bangkok: UNESCO. Retrieved from http://www.unescobkk.org/education/inclusiveeducation/what-is-inclusive-education/barriers-to-inclusive-education/

United Nations (1991). Convention on the rights of the child. New York, NY. Retrieved from https://treaties.un.org/doc/publication/mtdsg/volume\%20i/chapter\%20iv/iv11.en.pdf

United Nations. (1948). Universal declaration of human rights. New York and United Nations. Retrieved from http://www.un.org/en/universal-declaration-human-rights

United Nations. (1994) The standard rules on equalisation of opportunities for persons with disabilities. New York, NY. Retrieved from http://www.refworld.org/docid/ 3b00f2e80.html

United Nations. (2006). Convention on the rights of persons with disabilities. NY and United Nations. Retrieved from http://www.un.org/disabilities/default.asp?navid= $12 \&$ pid $=150$

United Nations. (2008). Reports submitted by states parties under article 44 of the Convention. Committee on the rights of the child. Retrieved from http://www2.ohchr.org/english/bodies/crc/docs/AdvanceVersions/ CRC.C.GBR.CO.4.pdf

U.S Department of Education (1999). The Individuals with Disabilities Education Act of Amendments of 1997. Final Regulations. Washington DC. Author. Retrieved from https://www2.ed.gov/pubs/AnnualPlan2001/index.html

Vakil, S., Welton, E., O’Connor, B., \& Kline, L. S. (2008). Inclusion means everyone! The role of the early childhood educator when including young children with autism in the classroom. Early Childhood Education Journal, 36, 321-326.

Voltz, D. L., Brazil, N., \& Ford, A. (2001). What matters most in inclusive education: A practical guide for moving forward. Intervention in School and Clinic, 37(1), 2330 .

Wagner, R. \& Muller, G. (2011). The power of two: You are built for collaborating, but chances are, you aren't forming enough good partnerships in your workplace. New York, NY: Gallup Press. 
Waldron, N. L., McLeskey, J., \& Pacchiano, D. (1999). Giving teachers a voice: Teachers' perspectives regarding elementary inclusive school programs (ISP). Teacher Education and Special Education, 22, 14-153.

WEAC. (2012). Special education inclusion. Wisconsin Education Association Council. Retrieved from http://www.weac.org/

Wiener, J. (2009). Fostering social acceptance in inclusive classrooms. Education Canada, 49(4), 16-20.

Wilson, C. H., Ellerbee, K. L., \& Christian, S. H. (2011). Best practices of inclusion at the elementary level. Eric Digest, ED522452.

Wilson, T., Lindsey, S. \& Schooler, T. Y. (2000). A model of dual attitudes. Psychological Review, 107, 101-126.

Yuh, E. \& Shey, P. (2008). The education of persons with special needs in Cameroon: A history. African Journal of Special Education, 1(1), 27-31. 
VITA 


\section{DEGREE INFORMATION}

$\begin{array}{lll}\text { EdS } & \text { December 2010 } & \begin{array}{l}\text { Andrews University } \\ \text { Area of Specialization: Curriculum and Instruction }\end{array} \\ \text { MA } & \text { October 1996 } & \begin{array}{l}\text { University of Yaoundé I } \\ \text { Linguistics }\end{array} \\ \text { B.A. } & \text { June 1993 } & \text { University of Yaoundé I: English Studies }\end{array}$

\section{TEACHING EXPERIENCE}

$1993-2005$

Adventist High School Yaoundé Teacher of English as Second \& Foreign Language P. O. Box 401 Yaoundé, Cameroon

$2000-2005$

Lycée de Nkolndongo (Nkolndongo High School) Teacher of English as Second \& Foreign Language P.O. Box 401 Yaoundé, Cameroon

$2001-2002$

Lycée de Nanga-Eboko (Nanga-Eboko High School) Teacher of English as Second \& Foreign Language Nanga-Eboko, Cameroon

\section{EDUCATIONAL LEADERSHIP EXPERIENCE}

$2001-2005$

$1998-2001$
Lycée de Nkolndongo (Nkolndongo High School) Head of the Department of English

Adventist High School, Yaoundé Head of the Department of English 